\title{
Learning in urology : the influence of simulators and human factors
}

Citation for published version (APA):

Persoon, M. C. (2012). Learning in urology : the influence of simulators and human factors. [Doctoral Thesis, Maastricht University]. Maastricht University. https://doi.org/10.26481/dis.20120119mp

Document status and date:

Published: 01/01/2012

DOI:

10.26481/dis.20120119mp

Document Version:

Publisher's PDF, also known as Version of record

\section{Please check the document version of this publication:}

- A submitted manuscript is the version of the article upon submission and before peer-review. There can be important differences between the submitted version and the official published version of record.

People interested in the research are advised to contact the author for the final version of the publication, or visit the DOI to the publisher's website.

- The final author version and the galley proof are versions of the publication after peer review.

- The final published version features the final layout of the paper including the volume, issue and page numbers.

Link to publication

\footnotetext{
General rights rights.

- You may freely distribute the URL identifying the publication in the public portal. please follow below link for the End User Agreement:

www.umlib.nl/taverne-license

Take down policy

If you believe that this document breaches copyright please contact us at:

repository@maastrichtuniversity.nl

providing details and we will investigate your claim.
}

Copyright and moral rights for the publications made accessible in the public portal are retained by the authors and/or other copyright owners and it is a condition of accessing publications that users recognise and abide by the legal requirements associated with these

- Users may download and print one copy of any publication from the public portal for the purpose of private study or research.

- You may not further distribute the material or use it for any profit-making activity or commercial gain

If the publication is distributed under the terms of Article $25 \mathrm{fa}$ of the Dutch Copyright Act, indicated by the "Taverne" license above, 


\title{
LEARN ING IN UROLOGY
}

\section{The influence of simulators and human factors}

\author{
Marjolein Persoon
}


The research reported here was carried out at Mastricht University in Learning!

In the School of Health Professions Education

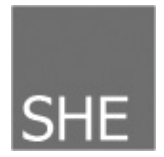

In collaboration with Catharina Hospital Eindhoven and UMC St. Radboud Nijmegen.

Financial support for this thesis was provided by:

- Astellas Pharma

- AstraZeneca

- Covidien

- Ferring Pharmaceuticals

- Hoogland Medical

- Ipsen

- Karl Storz

- Olympus Nederland

- Pfizer

- Skillslab Catharina Ziekenhuis Eindhoven

- Stöpler

ISBN: 978-94-6169-182-8

Copyright (c) M.C. Persoon, 2011.

All rights reserved. None of the contents may be reproduced or transmitted in any form without the prior permission of the holder of the copyright.

Layout and printing: Optima Grafische Communicatie, Rotterdam, The Netherlands 


\title{
Learning in Urology
}

\section{The influence of simulators and human factors}

\author{
PROEFSCHRIFT
}

ter verkrijging van de graad Doctor aan de universiteit van Maastricht, op gezag van de Rector Magnificus, Prof. mr. G.P.M.F. Mols volgens het besluit van het College van Decanen,

in het openbaar te verdedigen op donderdag 19 januari 2012 om 16.00 uur

door

Marjolein Christine Persoon 


\section{Promotores:}

Prof. dr. A.J.J.A. Scherpbier

Prof. dr. J.A. Witjes (UMC St. Radboud Nijmegen)

\section{Copromotores:}

Dr. A.J.M. Hendrikx (Catharina Ziekenhuis Eindhoven)

Dr. B.M.A. Schout (Vrije Universiteit Amsterdam)

\section{Beoordelingscommissie:}

Prof. dr. J.J.G. van Merriënboer (voorzitter)

Dr. A. de Bruin

Prof. dr. T. Dornan (University of Manchester, Verenigd Koninkrijk)

Prof. dr. Nijman (Universitair Medisch Centrum Groningen)

Dr. P. Teunissen 


\section{TABLE OF CONTENTS}

1 Introduction 7

2 A simulator for teaching transrectal ultrasound procedures: how useful 23 and realistic is it?

Published in Simulation in Healthcare; 2010 Oct;5(5): 311-14

3 Virtual reality laparoscopic nephrectomy simulator is lacking in construct validity

Published in Journal of Endourology; 2010 Jan; 24(1):117-22

4 The effect of a low fidelity model on cystoscopic skill training: a randomized controlled trial

Published in Simulation in Healthcare; 2010 Aug;5(4): 213-18

5 The effect of distractions in the operating room during endourological procedures

Published in Surgical Endoscopy; 2011 Feb;25(2): 437-43

6 The effect of distraction on the performance of endourological tasks:

a randomized controlled trial

Published in the British Journal of Urology International; 2011

May;107(10):1653-57

7 Learning curves in laparoscopic radical prostatectomy: When is proficiency reached?

Submitted

8 Conclusions and general discussion

Summary

Samenvatting

Dankwoord

Curriculum Vitae

List of publications

SHE Dissertation Series 

CHAPTER 1

\section{Introduction}




\section{INTRODUCTION}

\section{Urological procedures}

Over the years conventional open surgical procedures have increasingly been replaced by minimally invasive procedures, requiring fewer and smaller incisions to gain access to the organs to be operated upon. In endourological procedures, like transurethral resection of bladder tumours (TURBT), transurethral resection of the prostate (TURP) and ureterorenoscopy (URS), the endoscope and operating instruments are introduced through the natural orifice of the urethra into the bladder and, if indicated, further into the ureters. In cases of benign prostate hyperplasia (BPH) where lower urinary tract symptoms (LUTS) can occur due to enlargement of the prostate, volumetry can be performed by transrectal ultrasound (TRUS), which can also be used for transrectal prostate biopsies in diagnosing prostate cancer. ${ }^{1,2}$ Indications for TURBT are bladder tumours noticed during inspection of the bladder with a cystoscope (cystoscopy).

Another commonly used minimally invasive technique, is laparoscopy in which incisions of approximately $1 \mathrm{~cm}$ are made to introduce laparoscopic operating instruments into the abdomen or pelvis to reach the target organ(s). Since the first performance of laparoscopic nephrectomy in the early nineties of the $20^{\text {th }}$ century, the use of laparoscopic and robot assisted techniques has increased rapidly, and today radical prostatectomy, pyeloplasty and pelvic lymph node dissection are performed laparoscopically in many clinics. ${ }^{3-13}$ Reported benefits of the laparoscopic approach include improved postoperative course with less pain, fewer complications, less blood loss and fewer hospital days compared to open surgery, but, since laparoscopic surgery is technically more complex involving altered tactile feedback, different eye-hand coordination and translation of a two dimensional video image into a three-dimensional working area the learning curve for laparoscopic techniques is longer than that for open surgery. ${ }^{14-17}$

Robot assisted surgery, another minimally invasive technique, in which the surgeon is positioned behind a console, controlling the instruments in the patient, differs from laparoscopy in that it provides a binocular view offering a three dimensional working area, where instruments have more degrees of freedom, making tissue handling easier. Urological procedures performed by robot, such as radical prostatectomy, cystectomy, nephrectomy and pyeloplasty, generally have a shorter learning curve for inexperienced surgeons compared to laparoscopy. ${ }^{18-20}$

\section{Traditional training methods}

The majority of urological training programmes is based on the traditional Halstedian master-apprentice type of training, in which skills are learned in clinical settings where 
the trainee performs procedures in real patients supervised by a clinical teacher. ${ }^{21}$ However, today's high demands of patient safety and the increasing unacceptability, both ethically and legally, of errors and serious complications due to inexperience have resulted in objections being raised to the Halstedian approach, especially for technically challenging techniques like endoscopy and laparoscopy. ${ }^{22,23}$

Nevertheless, there are obvious advantages to training in clinical settings, such as opportunities for trainees to learn multiple skills, like decision making, empathy, professionalism and psychomotor skills, in an integrated manner, while active participation in patient care can clarify the relevance of the skills to be learnt and enhance learners' motivation to learn. On the other hand, it is not always possible to combine teaching and treatment without prolonging procedure time, while inadequate supervision may impair learning and lead to errors with adverse consequences for patients. Also, since learning in clinical practice depends on exposure to pathology and procedures, which is difficult to plan in real time health care, learning opportunities in the clinical setting are largely determined by chance, with the risk that trainees may not be able to gain enough practice to achieve adequate competence, a situation that has been exacerbated by the restriction of working hours for residents. ${ }^{24,25}$ As a consequence educators have been forced to explore other training formats, such as simulators made from different types of material on which trainees can practise skills at a level that is appropriate for their level of training and without putting patients at risk. ${ }^{26-29}$ Simulation-based education can complement training in clinical settings, because it allows learners to practise and acquire skills in a controlled and safe environment thereby enhancing their self-confidence. ${ }^{26,30}$ Although skills training on models can obviously not replace real clinical experience, it can make a valuable contribution to training by enabling trainees to master basic skills before performing them on real patients, thereby ensuring patient safety and increasing the effectiveness of learning in clinical practice for trainers and trainees. $^{31}$

\section{Simulators and training programmes}

In urology, as in various other surgical specialties, endourological and laparoscopic skills can be learnt by practising on animate models, inanimate models or computerized simulators. ${ }^{32-34}$ Practising on live animals or animate models has limitations, since it requires strict hygiene and can only be done in specialized skills laboratories, and animate models can be re-used less frequently than inanimate ones, leading to increased financial costs. Moreover, ethical considerations increasingly restrict the use of animal models.

An example of inanimate simulators for basic laparoscopic skills are box trainers, made from plastic or cardboard with a non-transparent upper side through which 
laparoscopic instruments can be inserted, while a camera connected to a display screen visualizes the working field. A box trainer is used in Fundamentals of Laparoscopic Surgery (FLS), a training programme, comprising five theoretical modules on basic principles and physiological aspects of laparoscopic surgery and a box trainer for hands on training that was developed by the Society of American Gastrointestinal and Endoscopic Surgeons (SAGES) and the American College of Surgeons (ACS) in response to the increasing demand for training of laparoscopic skills outside the operating theatre. ${ }^{35,36}$ The programme uses a box trainer based on the McGill Inanimate Systems for Training and Evaluation of Laparoscopic Skills (MISTELS), a validated training model for basic laparoscopic skills, offering five basic tasks for practising manual skills: transferring pegs, precision cutting of a gauze, placement and securing of a ligating loop, simple suture with extracorporeal knot and simple suture with intracorporeal knot. ${ }^{35,37-41}$

The term virtual reality (VR) refers to computer-simulated environments simulating physical presence in places in the real world as well as in imaginary worlds. In a virtual reality training simulator a computer is connected to trocars and a display screen, simulating the operating environment and providing tasks for trainees to improve their dexterity. As several parameters of trainee performance, such as movements with instruments, errors and completion time, can be recorded by the computer, performance can be measured objectively and results are reproducible. Although these simulators often do not provide the type of immediate feedback that can be given by experts, a positive relationship has been reported between training on virtual reality models and enhanced performance of in vivo procedures. ${ }^{42-47}$

Since all types of simulators have been shown to improve trainees' performance, it can be assumed that animate, inanimate and virtual reality simulators, separately or in combination, are all suitable for training purposes. ${ }^{46,48-51}$ Based on the closeness of their resemblance to real life situations, simulators can be classified on a scale from low to high fidelity models. According to Issenberg, high fidelity simulators can be further categorized as a) realistic three-dimensional procedural simulators, b) interactive simulators and c) virtual reality simulators. ${ }^{30}$ Box trainers are low fidelity models, because they do not resemble reality and do not provide feedback. A virtual reality model imitates images of real organs and measuring performance parameters can be qualified as a high fidelity model. Since high fidelity models are not necessarily superior to low fidelity models in all situations, the usefulness of a model may be better defined using the concept of functional fidelity, indicating the extent to which the skills required for the real task are performed during the simulated tasks. That this concept is suitable for defining the usefulness of models is supported by various studies demonstrating the effectiveness of bench-based training models in the acquisition of technical skills in novices, implying that a model does not have to look realistic as long as the steps of 
the procedure can be practised adequately. ${ }^{52-55}$ On the other hand, superior results have been reported for training with a high-fidelity model, and high fidelity simulations have been shown to enhance learning provided they are used under appropriate conditions. ${ }^{51}$ These conditions include feedback to the learner, repetitive practice, integration in the curriculum, different levels of difficulty, the use of multiple learning strategies, variety of clinical conditions, a controlled environment, individualized learning, the presence of clearly stated goals and the use of validated simulators. ${ }^{30}$ However, in learning complex procedures it may be better for trainees to start with low fidelity simulations and continue with medium and high fidelity simulation before moving on to the real clinical setting. ${ }^{56,57}$ Pollock et al. investigated the effects of such an approach in which learners were presented with a simple-to-complex sequence of instruction. Initially, in the first phase, learners were presented with separate elements that could be processed serially and after that, in the second phase, information was presented all at once, including the interactions among the elements. When learners were confronted with the full set of interacting elements during both phases they gained less understanding than was achieved with the from simple-to-complex sequence. ${ }^{58}$ Considering that high fidelity environments tend to be more complex than low fidelity environments a similar from simple to complex effect seems achievable with simulators by gradually increasing the fidelity of the learning environment. ${ }^{59}$

\section{Validation and Assessment}

Before a simulator is implemented in a training programme for surgical skills, its value as an effective training model and predictor of performance should be established by systematic objective validation, involving face, content, construct and criterion validity. In this thesis, we inferred face validity from novices' opinions on the realism of the simulator, while content validity is based on experts' judgements of the realism of the simulator and its appropriateness as a training tool. Objective validity comprises construct and criterion validity, the latter being subdivided into concurrent and predictive validity. Construct validity relates to the ability of the simulator to discriminate between different levels of surgical experience and skill performance. In other words, a simulator has good construct validity if experts systematically outperform novices, and novices' simulator performance improves as their clinical experience increases. Criterion validity is established by determining whether performance on the simulator correlates with performance of the same skills in a different setting. A positive correlation of simulator performance with performance on an old training model or method at the same stage of training indicates concurrent validity, and positive correlation with performance in practice on a real patient in the operating theatre establishes predictive validity. ${ }^{60}$ 
In the literature a variety of urological training models has been described, but, as noted in a review by Schout et al., only few validation studies have been published, implying that the validity of many models remains as yet unproven. ${ }^{32}$ Although establishing construct and criterion validity, in particular, is very time consuming and costly, it is nevertheless of paramount importance that accurate methods be developed for objective assessment of the skills to be performed in real life, in order to be able to properly evaluate the effects of simulator-based training.

\section{Proficiency and learning curves}

Calls for proof of care providers' competence relating to increasing demands with regard to patient safety in the public debate have raised several questions: When is a surgeon's performance of a certain procedure "good enough"? 22 How many procedures should a surgeon have performed before he or she can be considered proficient? Which parameters are used to determine proficiency and how are they to be measured? Insight into the learning curves of procedures may be helpful in answering these questions. Although learning curves come in different shapes, depending on the procedure and the learner, they generally start off with a steep rise immediately following the start of training and mostly end at a plateau level. A simple, reproducible definition that can be used to quantify the surgical learning curve is the time required and/or the number of procedures needed to perform before an average surgeon is competent to perform a procedure independently with a reasonable outcome. ${ }^{61,62}$ However, this definition immediately raises the question as to what is a "reasonable outcome". This question has been subject of much debate, as the outcome of a procedure depends on many factors other than surgical skills, such as variations in patient pathology and different techniques. Inevitably, practical considerations, like limited time and resources, will require a compromise between optimal and acceptable results.

\section{Factors influencing performance}

Multiple factors, in addition to procedural knowledge and psychomotor skills, can influence urological surgeons' and residents' performance in the operating theatre, including personal factors, like motivation, lack of sleep and personal problems, and patient related factors, such as variability and severity of patient pathology. ${ }^{63,64} \mathrm{An}$ environmental factor that can potentially impact on surgeons' performance in theatre is distraction, defined as any event that diverts attention away from the task in hand. Negative effects of distractions on the concentration and safety of pedestrians and drivers have been shown in everyday life. ${ }^{65-67}$ Distractions and interruptions are also a familiar phenomenon in the operating theatre, the most common ones being non-patient 
related conversations, telephone calls, beepers going off, music and people entering the operating theatre. ${ }^{68-70}$

It is widely accepted that surgical procedures require not only manual skills but also considerable cognitive and decision making skills. ${ }^{63,64}$ As Sir Frederick Treves wrote in 1891: "The actual manipulative part of surgery requires no very great skill and many artisan shows infinitely more adeptness in his daily work...It is the mental process involved in an operation that not a few fail".71

Research in cognitive psychology has demonstrated negative effects of what is called multi-task interference, referring to the phenomenon that, when two or more tasks are performed simultaneously, performance is often slower and with more errors than when tasks are carried out separately. ${ }^{72}$ Since surgery requires manual skills in combination with decision making, reasoning and maintenance of high focus and attention, it is safe to assume that surgeons' performance is susceptible to dual-task interference. Fortunately, the effects of task interference, while severe during learning periods, generally diminish considerably with practice, a finding that was validated by Ruthruff et al., who showed that learning can reduce task interference even if it cannot completely eliminate it. ${ }^{73,74}$ Training with simulators and practice environments requiring dual task execution, already shown to be successful in fields like the aviation industry and neurorehabilitation, can therefore be expected to also have beneficial effects in surgical training. ${ }^{75,76}$

\section{General problem definition}

In this thesis we focused on training of endourological and laparoscopic skills within the field of urology. These minimally invasive techniques have rapidly evolved over the past two decades and clearly require other skills than open surgery. New techniques bring new challenges not only in clinical practice but also in medical education. The operating instruments that are used in minimally invasive procedures have limited degrees of motion compared to the human hand and consequently these procedures lend themselves to simulation with the use of computerized and non-animate models.

The relation between simulators, training programmes and environmental factors has not yet been clearly established. Since many factors play a role it is important that simulators, before they are implemented in training programmes and used for assessment, are evaluated to make sure that they teach the right skills and are a valid teaching tool. Validation of new models therefore remains a crucial goal of research in the field of urology training. On the other hand, psychomotor skills and procedural knowledge learnt on a simulator do not guarantee successful performance of procedures in the real world. Environmental and personal factors can enhance or impair the learning process as well as performance in the operating theatre. Gaining more insight into these processes requires: 
- Exploration and validation of new simulators;

- Integration of simulators and educational knowledge in an effective training programme;

- Exploration of environmental factors that impact on performance in the operating theatre;

- Exploration of learning curves for urological procedures.

In order to be able to evaluate simulators, training programmes and performance of individuals, accurate assessment parameters are of paramount importance. Obviously the gold standard is the effect on patient outcome, but this is not easily measured. Patient outcome parameters depend on complex interactions of multiple factors and on subjectivity of the different assessors involved. Clearly defined criteria to determine when proficiency is reached for a certain procedure could aid in setting quality standards that can be used in assessments.

In this thesis we aimed to evaluate several of the above-mentioned aspects of learning in urology by finding answers to the following research questions:

- How useful and realistic is a new simulator for teaching transrectal ultrasound (TRUS) for training purposes? What measures can be taken to improve the simulator in collaboration with the developing engineers?

- Can a virtual reality simulator for laparoscopic nephrectomy distinguish between different levels of expertise? Do trainees' skills improve after training on the simulator?

- How can low and high fidelity simulators be combined? What is the value of training on a low fidelity simulator in addition to training on a high fidelity simulator in a cystoscopy training programme?

- What is the influence of distraction on operation flow and performance of trainees? What kind of distractions occur during endourological procedures and what is the effect of distraction on participants during training of endourological skills?

- How can proficiency be defined for laparoscopic radical prostatectomy (LRP)? Which criteria can be used to define when a LRP procedure is considered technically successful or unsuccessful?

\section{Outline of this thesis}

Chapter 2 describes the technical aspects of a simulator for teaching transrectal ultrasound (TRUS). An existing simulator was adjusted to enable performance of TRUS by the developing engineers (Sonofit, Germany) in collaboration with urologists and urology residents in the Netherlands. Forty-seven participants (urologists and urologists in training) judged the usefulness and realism of the simulator. 
In Chapter 3, the construct validity of a virtual reality simulator for laparoscopic nephrectomy was determined. In many clinics laparoscopic nephrectomy has become the standard procedure. A virtual reality simulator enables effective training of laparoscopic skills but, since it is very expensive, it is important to assess its validity before implementing it in a training programme. The question whether the simulator can distinguish between different levels of expertise is addressed in this chapter.

The question whether in cystoscopy training a low fidelity model can be useful in addition to a validated high fidelity virtual reality model is addressed in Chapter 4. In a randomized controlled trial, one group of medical students trained cystoscopy skills on a low fidelity glass globe model before moving on to training on the validated virtual reality model (URO Mentor) and another group started immediately with the training programme on the URO Mentor. Performance of the students was assessed on the URO Mentor in order to determine whether training on the low fidelity model had a positive or negative effect on performance.

Chapter 5 presents an observational study exploring what kind of distractions are present in the operating theatre during endourological procedures. In other activities in society, like driving a car, there is evidence that distractions impair performance. We hypothesized that for cognitively demanding tasks like endourological procedures distractions could have a negative effect on performance. In addition to exploring the frequency and types of distractions, the impact of the distraction on the flow of the procedure was observed. During interviews with the operating urologists and urologists-in-training their opinions on the effect of distraction were explored. To ensure anonymity among participants, the study was performed in two hospitals. Chapter 6 describes a randomized controlled trial performed among medical students in order to quantify the effect of distraction on participants' performance during a training session in endourological tasks. We used verbal distractions to simulate the situation during real-life surgery in which the urologist can be distracted by questions about other patients. We therefore presented a medical case to all participants before they performed the tasks on the URO Mentor. In the intervention group the participants were distracted by questions about a medical case that were asked at a predetermined moment during training. To ensure objective assessment of performance, number of traumas, number of missed lesions in the bladder and time to completion were measured by the URO mentor. Chapter $\mathbf{7}$ illustrates the difficulty of reaching consensus as to when proficiency is achieved. For laparoscopic radical prostatectomy (LRP) we aimed to determine criteria to define when a LRP procedure is considered technically successful or unsuccessful. Since the first step in analyzing learning curves and defining the number of procedures needed to attain proficiency is to define the conditions that determine proficiency, we explored the opinions of urologists and performed a literature search on learning curves of LRP and definitions of proficiency. 
In Chapter $\mathbf{8}$ the results of the preceding chapters and future perspectives are discussed. 


\section{REFERENCES}

1. Fuchsjager M, Shukla-Dave A, Akin O, Barentsz J, Hricak H. Prostate cancer imaging. Acta Radiol 2008 Feb;49(1):107-20.

2. Shapiro A, Lebensart PD, Pode D, Bloom RA. The clinical utility of transrectal ultrasound and digital rectal examination in the diagnosis of prostate cancer. Br J Radiol 1994 Jul;67(799):668-71.

3. Clayman RV, Kavoussi LR, Soper NJ, Dierks SM, Meretyk S, Darcy MD, et al. Laparoscopic nephrectomy: initial case report. J Urol 1991 Aug;146(2):278-82.

4. Rodriguez A, Pow-Sang JM. Laparoscopic surgery in urologic oncology. Cancer Control 2006 Jul; 13(3):169-78.

5. Argyropoulos AN, Tolley DA. Upper urinary tract transitional cell carcinoma: current treatment overview of minimally invasive approaches. BJU Int 2007 May;99(5):982-7.

6. Cathelineau X, Sanchez-Salas R, Barret E, Rozet F, Galiano M, Benoist N, et al. Radical prostatectomy: evolution of surgical technique from the laparoscopic point of view. Int Braz J Urol 2010 Mar;36(2):129-39.

7. Fuchs GJ, Yurkanin JP. Endoscopic surgery for renal calculi. Curr Opin Urol 2003 May;13(3):243-7.

8. Guillonneau B, Vallancien G. Laparoscopic radical prostatectomy: initial experience and preliminary assessment after 65 operations. Prostate 1999 Apr 1;39(1):71-5.

9. Guillonneau B, Rozet F, Barret E, Cathelineau X, Vallancien G. Laparoscopic radical prostatectomy: assessment after 240 procedures. Urol Clin North Am 2001 Feb;28(1):189-202.

10. Herrmann TR, Rabenalt R, Stolzenburg JU, Liatsikos EN, Imkamp F, Tezval H, et al. Oncological and functional results of open, robot-assisted and laparoscopic radical prostatectomy: does surgical approach and surgical experience matter? World J Urol 2007 Apr;25(2):149-60.

11. Janetschek G, Marberger M. Laparoscopic surgery in urology. Curr Opin Urol 2000 Jul;10(4):351-7.

12. Schuessler WW, Schulam PG, Clayman RV, Kavoussi LR. Laparoscopic radical prostatectomy: initial short-term experience. Urology 1997 Dec;50(6):854-7.

13. Trabulsi EJ, Guillonneau B. Laparoscopic radical prostatectomy. J Urol 2005 Apr;173(4):1072-9.

14. Dunn MD, Portis AJ, Shalhav AL, Elbahnasy AM, Heidorn C, McDougall EM, et al. Laparoscopic versus open radical nephrectomy: a 9-year experience. J Urol 2000 Oct;164(4):1153-9.

15. Kercher KW, Heniford BT, Matthews BD, Smith TI, Lincourt AE, Hayes DH, et al. Laparoscopic versus open nephrectomy in 210 consecutive patients: outcomes, cost, and changes in practice patterns. Surg Endosc 2003 Dec;17(12):1889-95.

16. Figert PL, Park AE, Witzke DB, Schwartz RW. Transfer of training in acquiring laparoscopic skills. J Am Coll Surg 2001 Nov;193(5):533-7.

17. Wentink M. Hand-eye coordination in minimally invasive surgery. Theory, surgical practice and training. Delft University of Technology. Ponsen en Looijen BV, Delft, The Netherlands.; 2003.

18. Babbar P, Hemal AK. Robot-assisted partial nephrectomy: current status, techniques, and future directions. Int Urol Nephrol 2011 Feb 25.

19. Babbar P, Hemal AK. Robot-assisted urologic surgery in 2. Urol Ann 2011 Jan;3(1):1-7.

20. Minnillo BJ, Cruz JA, Sayao RH, Passerotti CC, Houck CS, Meier PM, et al. Long-Term Experience and Outcomes of Robotic Assisted Laparoscopic Pyeloplasty in Children and Young Adults. J Urol 2011 Feb 18.

21. Halsted W. The training of the surgeon. Bull Johns Hopkins Hosp 1904;15:267-76.

22. Inspectie voor de gezondheidszorg. Risico's minimaal invasieve chirurgie onderschat. 2007 Nov 1.

23. Hamdorf JM, Hall JC. Acquiring surgical skills. Br J Surg 2000 Jan;87(1):28-37.

24. Spencer J. Learning and teaching in the clinical environment. BMJ 2003 Mar 15;326:591-4. 
25. DaRosa DA, Skeff K, Friedland JA, Coburn M, Cox S, Pollart S, et al. Barriers to Effective Teaching. Acad Med 2011 Feb 21.

26. Kneebone RL, Scott W, Darzi A, Horrocks M. Simulation and clinical practice: strengthening the relationship. Med Educ 2004 Oct;38(10):1095-102.

27. Sachdeva AK, Bell RH, Jr., Britt LD, Tarpley JL, Blair PG, Tarpley MJ. National efforts to reform residency education in surgery. Acad Med 2007 Dec;82(12):1200-10.

28. Smith AJ, Aggarwal R, Warren OJ, Paraskeva P. Surgical training and certification in the United kingdom. World J Surg 2009 Feb;33(2):174-9.

29. Ziv A, Wolpe PR, Small SD, Glick S. Simulation-based medical education: an ethical imperative. Simul Healthc 2006;1(4):252-6.

30. Issenberg SB, McGaghie WC, Petrusa ER, Lee GD, Scalese RJ. Features and uses of high-fidelity medical simulations that lead to effective learning: a BEME systematic review. Med Teach 2005 Jan;27(1):10-28.

31. Bradley P, Bligh J. Clinical skills centres: where are we going? Med Educ 2005 Jul;39(7):649-50.

32. Schout BM, Hendrikx AJ, Scherpbier AJ, Bemelmans BL. Update on training models in endourology: a qualitative systematic review of the literature between January 1980 and April 2008. Eur Urol 2008 Dec;54(6):1247-61.

33. Torricelli FC, Guglielmetti G, Duarte RJ, Srougi M. Laparoscopic skill laboratory in urological surgery: tools and methods for resident training. Int Braz J Urol 2011 Jan;37(1):108-12.

34. Schreuder HW, Oei G, Maas M, Borleffs JC, Schijven MP. Implementation of simulation in surgical practice: minimally invasive surgery has taken the lead: the Dutch experience. Med Teach 2011; 33(2):105-15.

35. Fundamentals of laparpscopic surgery. 1-1-2009. Ref Type: Internet Communication

36. Persoon MC, Scherpbier AJ, Oei SG, Meijerink WJ, Schijven MP, Schout B, et al. [Learning laparoscopy without patients]. Ned Tijdschr Geneeskd 2009 Jan 17;153(3):60-2.

37. Derossis AM, Fried GM, Abrahamowicz M, Sigman HH, Barkun JS, Meakins JL. Development of a model for training and evaluation of laparoscopic skills. Am J Surg 1998 Jun;175(6):482-7.

38. Fraser SA, Klassen DR, Feldman LS, Ghitulescu GA, Stanbridge D, Fried GM. Evaluating laparoscopic skills: setting the pass/fail score for the MISTELS system. Surg Endosc 2003 Jun;17(6):964-7.

39. Fraser SA, Feldman LS, Stanbridge D, Fried GM. Characterizing the learning curve for a basic laparoscopic drill. Surg Endosc 2005 Dec;19(12):1572-8.

40. Fried GM, Derossis AM, Bothwell J, Sigman HH. Comparison of laparoscopic performance in vivo with performance measured in a laparoscopic simulator. Surg Endosc 1999 Nov;13(11):1077-81.

41. Fried GM, Feldman LS, Vassiliou MC, Fraser SA, Stanbridge D, Ghitulescu G, et al. Proving the value of simulation in laparoscopic surgery. Ann Surg 2004 Sep;240(3):518-25.

42. Matsumoto ED, Pace KT, D'A Honey RJ. Virtual reality ureteroscopy simulator as a valid tool for assessing endourological skills. Int J Urol 2006 Jul;13(7):896-901.

43. Michel MS, Knoll T, Kohrmann KU, Alken P. The URO Mentor: development and evaluation of a new computer-based interactive training system for virtual life-like simulation of diagnostic and therapeutic endourological procedures. BJU Int 2002 Feb;89(3):174-7.

44. Schout BM, Muijtjens AM, Hendrikx AJ, Ananias HJ, Dolmans VE, Scherpbier AJ, et al. Acquiring flexible cystoscopy skills on a virtual reality simulator by experts and novices. BJU Int 2009.

45. Seymour NE, Gallagher AG, Roman SA, O'Brien MK, Bansal VK, Andersen DK, et al. Virtual reality training improves operating room performance: results of a randomized, double-blinded study. Ann Surg 2002 Oct;236(4):458-63. 
46. Seymour NE. VR to OR: a review of the evidence that virtual reality simulation improves operating room performance. World J Surg 2008 Feb;32(2):182-8.

47. Shah J, Darzi A. Virtual reality flexible cystoscopy: a validation study. BJU Int 2002 Dec;90(9): 828-32.

48. Eversbusch A, Grantcharov TP. Learning curves and impact of psychomotor training on performance in simulated colonoscopy: a randomized trial using a virtual reality endoscopy trainer. Surg Endosc 2004 Oct;18(10):1514-8.

49. Grober ED, Hamstra SJ, Wanzel KR, Reznick RK, Matsumoto ED, Sidhu RS, et al. The educational impact of bench model fidelity on the acquisition of technical skill: the use of clinically relevant outcome measures. Ann Surg 2004 Aug;240(2):374-81.

50. Ogan K, Jacomides L, Shulman MJ, Roehrborn CG, Cadeddu JA, Pearle MS. Virtual ureteroscopy predicts ureteroscopic proficiency of medical students on a cadaver. J Urol 2004 Aug;172(2): 667-71.

51. Sidhu RS, Park J, Brydges R, MacRae HM, Dubrowski A. Laboratory-based vascular anastomosis training: a randomized controlled trial evaluating the effects of bench model fidelity and level of training on skill acquisition. J Vasc Surg 2007 Feb;45(2):343-9.

52. Anastakis DJ, Regehr G, Reznick RK, Cusimano M, Murnaghan J, Brown M, et al. Assessment of technical skills transfer from the bench training model to the human model. Am J Surg 1999 Feb; 177(2):167-70.

53. Fried GM, Feldman LS. Objective assessment of technical performance. World J Surg 2008 Feb; 32(2):156-60.

54. Matsumoto ED, Hamstra SJ, Radomski SB, Cusimano MD. The effect of bench model fidelity on endourological skills: a randomized controlled study. J Urol 2002 Mar;167(3):1243-7.

55. Reznick R, Regehr G, MacRae H, Martin J, McCulloch W. Testing technical skill via an innovative "bench station" examination. Am J Surg 1997 Mar;173(3):226-30.

56. Farmer. Handbook of simulator training. Ashgate Publishing Ltd, England; 1999.

57. Maran NJ, Glavin RJ. Low- to high-fidelity simulation - a continuum of medical education? Med Educ 2003 Nov;37 Suppl 1:22-8.

58. Pollock E, Chandler P, Sweller J. Assimilating complex information. Learning and Instruction 2002 Feb 1;12(1):61-86.

59. van Merriënboer JG, Kirschner PA. Ten steps to complex learning: a systematic approach to fourcomponent instructional design. Lawrence Erlbaum Associates, Inc, New Jersey, USA; 2007.

60. McDougall EM. Validation of surgical simulators. J Endourol 2007 Mar;21(3):244-7.

61. Dagash H, Chowdhury M, Pierro A. When can I be proficient in laparoscopic surgery? A systematic review of the evidence. J Pediatr Surg 2003 May;38(5):720-4.

62. Subramonian K, Muir G. The 'learning curve' in surgery: what is it, how do we measure it and can we influence it? BJU Int 2004 Jun;93(9):1173-4.

63. Hall JC, Ellis C, Hamdorf J. Surgeons and cognitive processes. Br J Surg 2003 Jan;90(1):10-6.

64. Kohls-Gatzoulis JA, Regehr G, Hutchison C. Teaching cognitive skills improves learning in surgical skills courses: a blinded, prospective, randomized study. Can J Surg 2004 Aug;47(4):277-83.

65. McCartt AT, Hellinga LA, Bratiman KA. Cell phones and driving: review of research. Traffic Inj Prev 2006 Jun;7(2):89-106.

66. Nasar J, Hecht P, Wener R. Mobile telephones, distracted attention, and pedestrian safety. Accid Anal Prev 2008 Jan;40(1):69-75.

67. Strayer DL, Drews FA, Crouch DJ. A comparison of the cell phone driver and the drunk driver. Hum Factors 2006;48(2):381-91 
68. Healey AN, Primus CP, Koutantji M. Quantifying distraction and interruption in urological surgery. Qual Saf Health Care 2007 Apr;16(2):135-9.

69. Primus CP, Healey AN, Undre S. Distraction in the urology operating theatre. BJU Int 2007 Mar; 99(3):493-4.

70. Ullmann Y, Fodor L, Schwarzberg I, Carmi N, Ullmann A, Ramon Y. The sounds of music in the operating room. Injury 2008 May;39(5):592-7.

71. Treves F. A manual of operative surgery. London: Cassell and Company; 1891.

72. Meyer DE, Kieras DE. A computational theory of executive cognitive processes and multiple-task performance: Part 1. Basic mechanisms. Psychol Rev 1997 Jan;104(1):3-65.

73. Levy J, Pashler H. Is dual-task slowing instruction dependent? J Exp Psychol Hum Percept Perform 2001 Aug;27(4):862-9.

74. Ruthruff E, Pashler HE, Hazeltine E. Dual-task interference with equal task emphasis: graded capacity sharing or central postponement? Percept Psychophys 2003 Jul;65(5):801-16.

75. Lee A. Fligth simulation: virtual environments in aviation. Hampshire, England: Ashgate Publishing; 2005.

76. O'Shea S, Morris ME, lansek R. Dual task interference during gait in people with Parkinson disease: effects of motor versus cognitive secondary tasks. Phys Ther 2002 Sep;82(9):888-97. 



\title{
CHAPTER 2
}

\section{A simulator for training trans rectal ultrasound procedures: how useful and realistic is it?}

\author{
Marjolein C. Persoon \\ Barbara M.A. Schout \\ Elisabeth J. Martens \\ Irene M. Tjiam \\ Alexander V. Tielbeek \\ Albert J.J.A. Scherpbier \\ J.Alfred Witjes \\ Ad J.M. Hendrikx
}




\section{ABSTRACT}

\section{Introduction}

We describe a new simulator for teaching transrectal ultrasound (TRUS) and present the results of a preliminary evaluation of the simulator's realism and usefulness for training.

\section{Methods}

A simulator for abdominal ultrasound was adjusted by the developer to enable simulation of TRUS by providing an opening for inserting a dummy rectal probe. In order to enable TRUS simulation, data from ultrasound prostate imaging of eight real patients obtained with our regular ultrasound machine were transferred to the simulator by connecting the computer of the simulator to the ultrasound machine. These data were used to create images in the TRUS simulator. Residents and urologists used the simulator to perform TRUS in one of the eight patient cases and judged the simulator's realism and usefulness.

\section{Results}

We were able to construct an initial urological module for the TRUS simulator. The images shown on the monitor of the simulator are quite realistic. The simulator can be used without difficulty to collect data to create cases and to perform TRUS. The absence of an option for prostate biopsy and the lack of tissue resistance were mentioned as two important shortcomings. Forty-seven participants rated the simulator's overall realism and usefulness for training purposes as 3.8 (SD 0.7) and 4.0 (SD 0.8), respectively on a five-point Likert scale.

\section{Conclusions}

The simulator we describe can be used as a training tool for TRUS. It enables training with different patient cases and minimizes the burden to patients. Simulation of prostate biopsies should be added to increase the model's usefulness. 


\section{INTRODUCTION}

Transrectal ultrasound (TRUS) is widely used to diagnose benign prostate hyperplasia $(\mathrm{BPH})$, to measure prostate volume and in performing transrectal prostate biopsies to diagnose prostate cancer. ${ }^{1,2}$ Because TRUS can cause discomfort to patients and requires skills in 3D-orientation and interpretation of findings, a realistic TRUS simulator, which does not burden patients, seems desirable to facilitate training. Little research has been done on TRUS simulators. A 1990 paper described a TRUS simulator in which the prostate was simulated by a Foley catheter balloon, but this simulator was not satisfactory. ${ }^{3}$ More recently, Sclaverano et al. described the first version of a simulator for ultrasound-guided prostate biopsy. New simulators are under development but validation studies have not yet been published. ${ }^{4}$ The ultrasound simulators that are currently used in medical training offer no option for TRUS..$^{5-10}$ A simulator for abdominal ultrasound was adapted to simulate ultrasound imaging of the urogenital tract by the developer of the simulator. ${ }^{5,9}$ We describe this new TRUS simulator and evaluate its realism and usefulness for training purposes.

\section{METHODS}

An existing simulator for abdominal ultrasound ${ }^{7,9}$ was adjusted by the developer to enable simulation of TRUS. An opening for insertion of a dummy rectal probe was created in the foam rubber mannequin and a dummy rectal probe was provided. The adapted ultrasound simulator (Sonofit, Germany) is composed of a personal computer (PC) trolley, software, a mannequin and a tracking device (Ascension, Burlington, USA) attached to a dummy probe (Fig. 1). The simulator has a data collection and management mode for use by supervisors and a training mode for students. In the data collection mode, the computer is connected to an ultrasound machine and data are downloaded while ultrasonography is performed in a real patient using a three-dimensional (3D) ultrasound scanner or a freehand 3D technique. In this way real-3D ultrasound data are obtained. The simulator software uses the tracking device to measure the position of the probe as it is moved during examination of the patient. The mannequin is equipped with an electromagnetic localization system and the probe contains an electromagnetic sensor. To simulate 2D ultrasound images, the 3D data that are loaded onto the system during the real-time procedure are virtually placed in the mannequin and retrieved in accordance with the position of the probe. Parameters like depth settings, ultrasound gain and contrast are used to calculate images at a frame rate of approximately 20 images/s to provide real-time feedback during simulated ultrasound. ${ }^{5}$ 
We collected data from TRUS procedures in eight patients by connecting the computer and the tracking device of the simulator to the ultrasound machine used to perform the real TRUS procedures. The reasons to perform TRUS in the real patients were an increase in prostate-specific antigen (PSA), lower urinary tract symptoms and measurement of the prostate in patients eligible for brachytherapy. Five patients were diagnosed with prostate malignancy based on the histology of prostate biopsy. Three patients were diagnosed with benign prostate hyperplasia based on a combination of PSA, digital rectal exam, ultrasound and histology of prostate biopsy. One case was used in a training session of a nationwide ultrasound course for urology residents in the Netherlands. In some countries urological ultrasound procedures are performed by radiologists, but in the Netherlands TRUS is routinely performed by urologists and urology residents. All the participating residents $(n=40)$ and the seven course instructors (practising urologists) received a standardized introduction to the mechanism of the simulator and then used the simulator to perform TRUS in a simulation of a patient with an enlarged benign prostate. The participants had no previous experience with the simulator. After the training session, which lasted 20 to 30 minutes for each participant, the participants were given a questionnaire asking them to rate the realism and usefulness of the simulator on a five-point Likert scale ( $1=$ not realistic, not useful; $5=$ very realistic, very useful). Items on

Figure 1: The transrectal ultrasound simulator set up for training

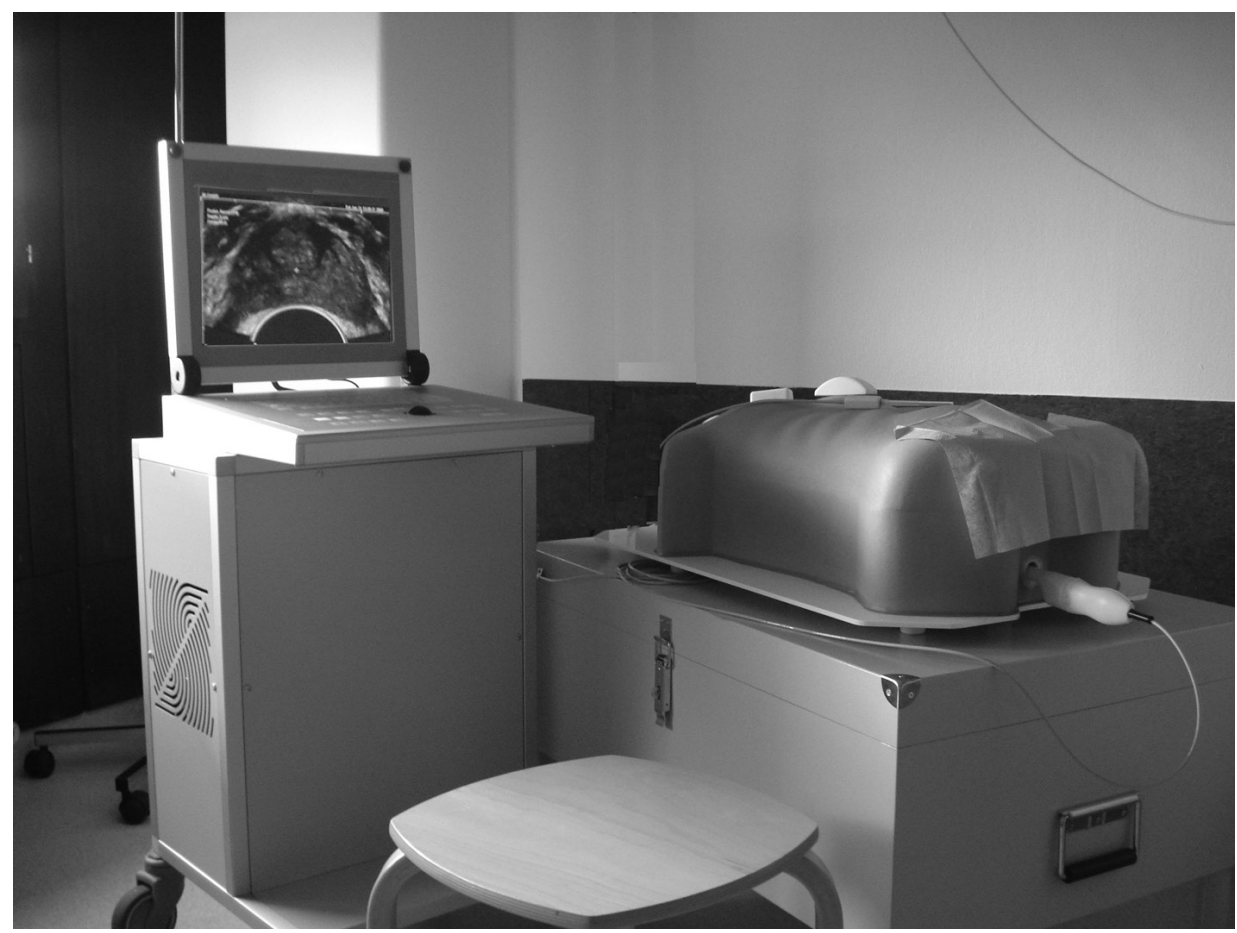


realism related to ergonomics, anatomy, instruments, image and colours, design, tissue resistance and an overall score. The usefulness items related to hand-eye coordination, knowledge and handling of equipment, 3D orientation, recognition of pathology and an overall score. The participants were also asked to write comments about any shortcomings of the simulator.

Approval from our institutional review board and informed consent from the patients and participants were obtained to carry out the evaluative study described. The data were processed anonymously, as is required by the nationwide ethical and legal rules of conduct for medical research. There is no financial benefit for the research group related to selling rates of the simulator in the future. The developing company provided a model for research purposes only and had no other involvement in the study.

\section{RESULTS}

We did not experience major difficulties in collecting patient data. It took no more than approximately five minutes to set-up the simulator, and the same amount of time was sufficient to check the recordings. Hyper- and hypo echoic areas can be recognized and volume can be measured. Images of the prostate, including the seminal vesicles, in the transversal and sagittal planes can be simulated by rotating the probe and moving it from the base to the apex of the prostate. The training mode also offers options to describe the case and ask students questions. Additional information can be provided on screen together with the images.

The ultrasound images on the simulator are nearly identical to real ultrasound images (Fig. 2). All kinds of pathological findings can be collected and stored in the computer of the simulator. Patient cases stored in the computer of the simulator can be used repeatedly for training purposes in a skills lab. The simulator costs approximately $€ 50,000$ and optional devices, such as a puncture needle, patient cases and a transesophageal probe are available at extra cost.

\section{Limitations of the simulator}

The opening in the dummy in which the rectal probe is inserted is surrounded by foam plastic to simulate tissue resistance, but the external and internal anal sphincter are not simulated. This detracts from the realism of the sensation when the dummy probe is inserted. Colour Doppler imaging can be included in the simulator, but arterial pulsations are not shown. Movements of the dummy rectal probe in the transversal and sagittal planes provide images that are comparable with real ultrasonography, but the correspondence is less good with images resulting from tilting the dummy probe. 
Figure 2: Transversal and sagittal images of the prostate on the simulator

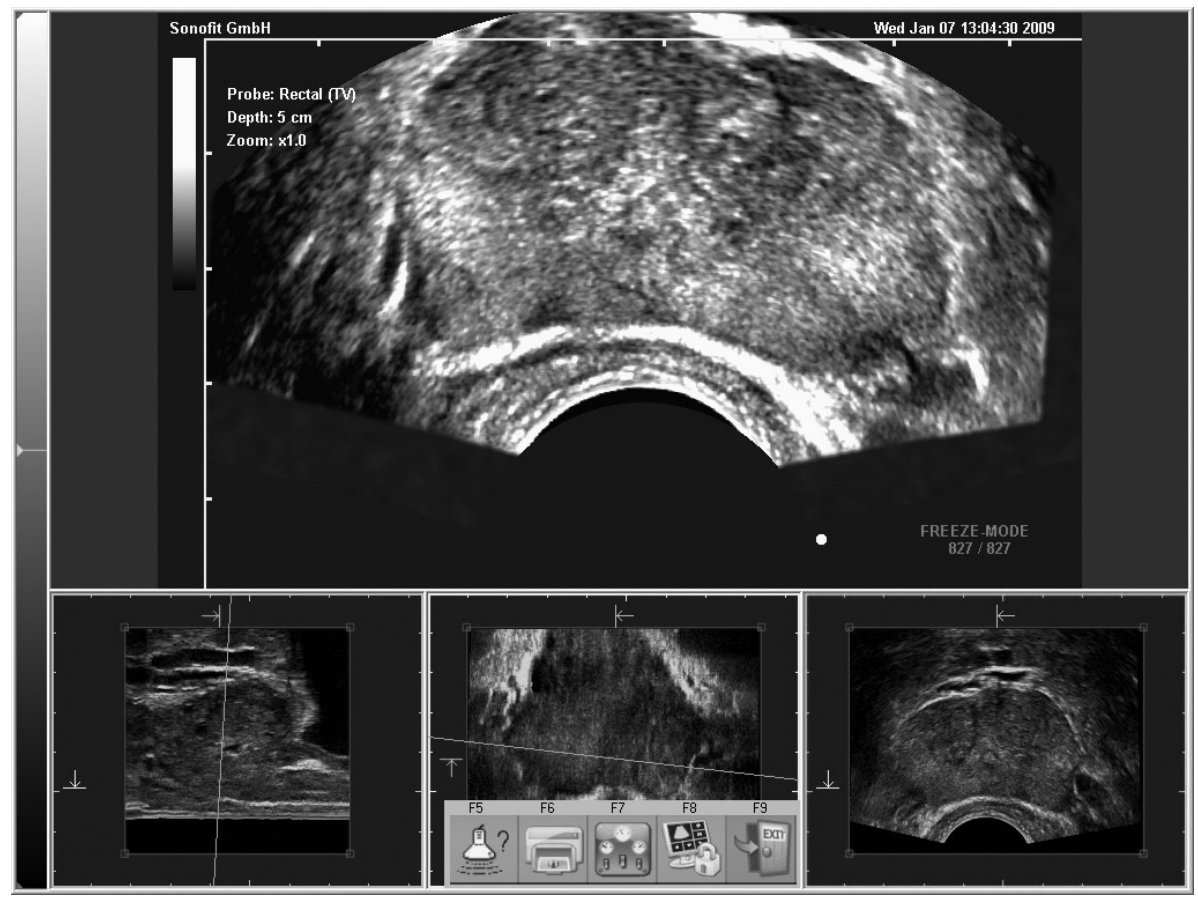

The simulator does not include an option for prostate biopsy, but the gynaecological version of the simulator allows for amniocentesis. To simulate an ultrasound guided prostate biopsy, a second tracking device might be attached to a puncture needle, which could be mounted on the rectal probe.

\section{Evaluation of the simulator}

The 47 participants had a mean number of 4.9 (SD 5.4) years of experience with TRUS. The mean number of TRUS procedures performed was 550 (SD 2250). The mean scores (on a five-point scale) on realism and usefulness were 3.8 (SD 0.7) and 4.0 (SD 0.8), respectively. The highest ratings were for training in 3D orientation (4.0, SD 0.8) and recognition of pathology (4.1, SD 0.9) (table 3). The overall score on the realism of tissue resistance was 2.3 (SD 1.0). Most of the participants' comments related to the inability to simulate prostate biopsy. Other comments concerned the need for greater variety of cases and simulation of tissue resistance. The comments are summarized in table 1. 
Table 1: Most frequent comments with regard to improvement of the simulator.

\begin{tabular}{|c|c|c|}
\hline Comments from 33 of 47 participants & No of remarks & Percentage(\%) \\
\hline The simulator should also allow for prostate biopsies. & 12 & 25 \\
\hline More pathology should be included. & 9 & 19 \\
\hline Tissue resistance is not realistic. & 8 & 17 \\
\hline The simulator does not include the digital rectal exam. & 4 & 8 \\
\hline $\begin{array}{l}\text { The simulator does not offer a simultaneous view of the transversal } \\
\text { and sagittal planes }\end{array}$ & 4 & 8 \\
\hline The range of probe movement is limited & 4 & 8 \\
\hline No 3D images are provided to guide the student & 2 & 4 \\
\hline The mannequin cannot be positioned on its side. & 1 & 2 \\
\hline $\begin{array}{l}\text { The simulator does not include placement of gold markers for } \\
\text { brachytherapy }\end{array}$ & 1 & 2 \\
\hline Other & 3 & 6 \\
\hline Total & 48 & $100 \%$ \\
\hline
\end{tabular}

\section{Discussion}

In the preceding sections we described the use of an existing abdominal ultrasound simulator that was adapted to simulate TRUS and we used a questionnaire to evaluate its realism and usefulness. The adaptation of the simulator involved creating an opening in the mannequin and provision of a dummy rectal probe. Data from TRUS procedures in real patients is downloaded onto the computer of the simulator. The simulator provides lifelike ultrasound images that can be used for repeated practice. Different patient cases can be included and theoretical information can be added by supervisors. Limitations of the model are the restricted range of movement of the rectal probe and the absence of functionality for biopsies. According to the participants, the simulator was particularly useful for training in $3 \mathrm{D}$ orientation and identification of pathology. The scores on overall realism and usefulness were quite high compared with similar scores reported for other simulators. ${ }^{11}$ Ratings were low in relation to the realism of tissue resistance.

Although it may cause discomfort, TRUS is not a hazardous procedure, and the necessary skills can also be learned in real-time procedures with supervision from a surgeon. The software of the simulator that was adapted for TRUS also allows for simulation of liver biopsies and amniocentesis. In the future it may well be feasible to increase the range of training options by adding prostate and kidney biopsies. This study was conducted in an early phase of the development of the simulator. We sought residents' and urologists' judgements of the usefulness of the simulator as an educational tool to inform the developers about the needs of the target group. Further studies will have to be performed when further adjustments and improvements have been made. ${ }^{12}$ 
The role of simulation in the training of medical professionals is increasing. Simulators are not only valuable as training tools, they can also be used as standardized assessment tools. They allow trainees to make errors in a safe environment. ${ }^{13,14}$ It is of paramount importance that a simulator is thoroughly validated before it is used for assessment purposes. The costs involved in training surgical residents is a matter of concern. ${ }^{15}$ Simulators might be favourable from a cost perspective but there is as yet no evidence of the financial benefits of simulator based training for TRUS. Prices of simulators range from 5,000 to 200,000 dollars, depending on the sophistication of the simulator. Factors that need to be taken into account in determining the cost-effectiveness of simulators include the time of trainees and instructors for simulation-based training at the expense of clinical work, and the benefits in terms of patient safety. ${ }^{16}$

In conclusion, the TRUS simulator we investigated enables repeated use of ultrasound images of real patients for training purposes in a skills lab. It appears to be a promising educational tool to build competence in procedures involving TRUS without inconveniencing patients. However, simulation of prostate biopsies should be added to increase the usefulness of the simulator and justify financial costs. Further developments might lead to more widespread use of the simulator, and this would necessitate validation studies to ensure effective training.

\section{Acknowledgements}

The authors would like to thank Mereke Gorsira for her editorial assistance. 


\section{REFERENCES}

1. Fuchsjager M, Shukla-Dave A, Akin O, Barentsz J, and Hricak H: Prostate cancer imaging. Acta Radiol 2008; 49: 107-120.

2. Shapiro A, Lebensart PD, Pode D, and Bloom RA: The clinical utility of transrectal ultrasound and digital rectal examination in the diagnosis of prostate cancer. Br J Radiol 1994; 67: 668-671.

3. Cos LR: Simulator for transrectal ultrasound of prostate. Urology 1990; 35: 450-1.

4. Sclaverano S, Chevreau G, Vadcard L, Mozer P, and Troccaz J: BiopSym: a simulator for enhanced learning of ultrasound-guided prostate biopsy. Stud Health Technol Inform 2009;142:301-306.

5. Terkamp C, Kirchner G, Wedemeyer J, Dettmer A, Kielstein J, Reindell H, et al.: Simulation of abdomen sonography. Evaluation of a new ultrasound simulator. Ultraschall Med 2003; 24: 239-4.

6. d'Aulignac D, Laugier C, Troccaz J, and Vieira S: Towards a realistic echographic simulator. Med Image Anal 2006; 10: 71-81.

7. Ehricke HH. SONOSim3D: a multimedia system for sonography simulation and education with an extensible case database. Eur J Ultrasound 1998 Aug;7(3):225-300.

8. Knudson MM, and Sisley AC: Training residents using simulation technology: experience with ultrasound for trauma. J Trauma 2000; 48: 659-65.

9. Maul H, Scharf A, Baier P, Wustemann M, Gunter HH, Gebauer G, et al.: Ultrasound simulators: experience with the SonoTrainer and comparative review of other training systems. Ultrasound Obstet Gynecol 2004; 24: 581-5.

10. Weidenbach M, Drachsler H, Wild F, Kreutter S, Razek V, Grunst G, et al.: EchoCom. Anaesthesia 2007;62:347-53.

11. Schout BM, Hendrikx AJ, Scherpbier AJ, and Bemelmans BL. Update on training models in endourology: a qualitative systematic review of the literature between January 1980 and April 2008. Eur Urol 2008; 54: 1247-1261.

12. McDougall EM:. Validation of surgical simulators. J Endourol 2007; 21: 244-247.

13. Monsky WL, Levine D, Mehta TS, Kane RA, Ziv A, Kennedy B, et al.: Using a sonographic simulator to assess residents before overnight call. AJR Am J Roentgenol 2002; 178:35-39.

14. Brigden D,and Dangerfield P: The role of simulation in medical education. Clinical teacher 2008; 1: 167-170.

15. Bridges $M$, and Diamond $\mathrm{DL}$ : The financial impact of teaching surgical residents in the operating room. Am J Surg 1999; 177:28-32.

16. Laguna MP, de Reijke TM, and de la Rosette JJ: How far will simulators be involved into training? Curr Urol Rep 2009; 10: 97-105. 



\section{CHAPTER 3}

\section{Virtual reality laparoscopic nephrectomy simulator is lacking in construct validity}

Rob P.W.F. Wijn Marjolein C. Persoon Barbara M.A. Schout Elisabeth J. Martens Albert J.J.A. Scherpbier

Ad J.M. Hendrikx 


\section{ABSTRACT}

\section{Background and purpose}

Several training models have been developed to improve surgeons' operative skills as well as patient outcomes. Before implementing these models in training programs, their usefulness needs to be assessed. In this study we examined the ability of a laparoscopic nephrectomy (LN) virtual reality (VR) simulator to distinguish between different levels of expertise (construct validity).

\section{Methods}

Twenty-two novices (no LN experience), 32 intermediates ( $<10 \mathrm{LN}$ procedures performed) and ten experienced urologists ( $\geq 10 \mathrm{LN}$ procedures performed) performed the same retroperitoneal task on the LN VR simulator (Mentice ${ }^{\circledR}$, Sweden) three times, performing a practice task before and after the second time. Outcome parameters were time, blood loss, path length and total score (combination of 62 different parameters).

\section{Results}

No significant differences were found between intermediate and experienced participants. Task 3 performance showed no significant difference between any of the groups. Both intermediates and experienced participants were significantly faster than novices on the first two tasks and had a better total score. Learning curves of intermediate and experienced participants were flat after task two.

\section{Conclusions}

The LN-VR simulator did not distinguish between intermediate and experienced participants. The analysis of the learning curves suggests that the tasks measured dexterity in using the simulator rather than an actual improvement of operative skills. We conclude that the LN-VR-simulator does not have sufficient construct validity and is therefore, in its present form, not suitable for implementation in a urological training program. 


\section{INTRODUCTION}

In recent decades laparoscopy has become an important routine procedure in surgical disciplines. ${ }^{1}$ In comparison with open surgery, laparoscopy is technically challenging, due to altered tactile feedback, different hand-eye coordination, and translation of a two dimensional video image into a three-dimensional working space. ${ }^{2}$ Since the first laparoscopic nephrectomy was performed by Clayman et al. in 1991, the laparoscopic approach has proven to be an effective alternative for open nephrectomy. ${ }^{4,5}$ Operation time, blood loss, and the number of intraoperative complications have been reported to decrease with surgeons' increasing experience..$^{3-8}$

Virtual reality (VR) simulators have the potential to improve basic surgical skills and shorten learning curves. ${ }^{9}$ Previous studies have shown that VR laparoscopic simulators are useful for skills training and assessment and in helping novices improve their skills. ${ }^{10-21}$ Mentice (Gothenburg, Sweden) developed a VR simulator for laparoscopic nephrectomy which simulates a number of steps of the real time procedure.

Before incorporating this simulator into urological specialist training, it is important to examine the validity of the simulator to ensure that trainees can acquire the required operative skills by training on the simulator. An important component of validity is construct validity, i.e. the ability of an instrument to distinguish between different levels of experience and training. Another important issue is to determine learning curves, reflecting the speed of trainees' progress as they are training on the simulator. ${ }^{19}$

The main objective of this study is to answer the following questions: "Is the LN VR simulator capable of discriminating between different levels of expertise?" (construct validity) and "Are trainees with the same level of expertise able to improve their skills by practicing on the LN VR simulator?" (learning curve).

\section{MATERIAL AND METHODS}

\section{Participants}

Urologists, urology residents, and medical students were recruited and divided into three groups: the experienced group had performed $\geq 10 \mathrm{LN}$ procedures, the intermediate group had assisted in more than one procedure but performed $<10 \mathrm{LN}$, and the novice group had had no experience in $\mathrm{LN}$ at all. The cut-off point between intermediate and experienced was set at $10 \mathrm{LNs}$, based on the literature on learning curve development. ${ }^{6-8}$ All study participants gave informed consent. None of the participants had any previous experience on this LN-VR simulator. 


\section{Simulator}

The LN-VR simulator is designed for learning and practicing LN tasks. It consists of a hardware package developed by Xitact (Morges, Switzerland) and a software package developed by Mentice ${ }^{\circledast}$ (Fig. 1). ${ }^{22}$ The LN software includes a retroperitoneal and transperitoneal approach. Dissecting the renal hilum via the retroperitoneal approach was selected as the subject of the present study (Fig. 2).

Fig.1. Xitact ${ }^{\circledR}$ Instrument Haptic Port (Xitact, Morges, Switzerland)

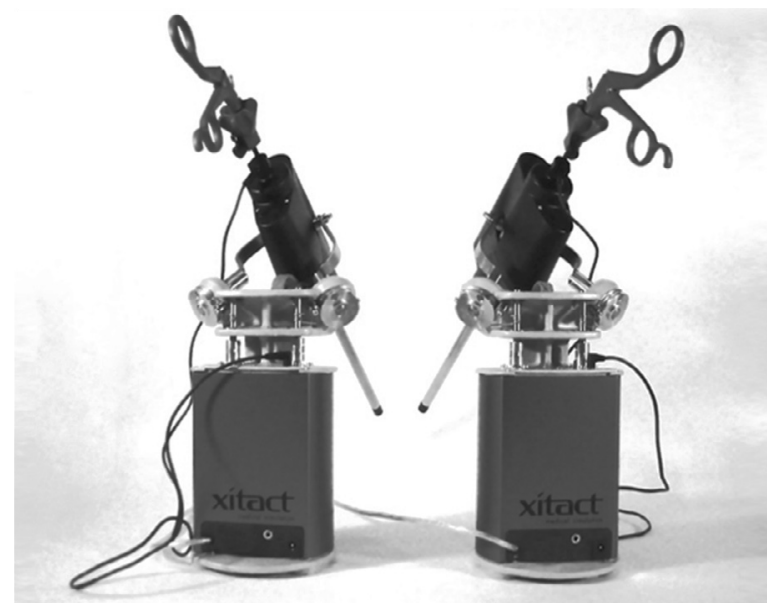

Figure 2. Image display of the clip-and-cut task of the hilum of the Laparoscopic Nephrectomy.

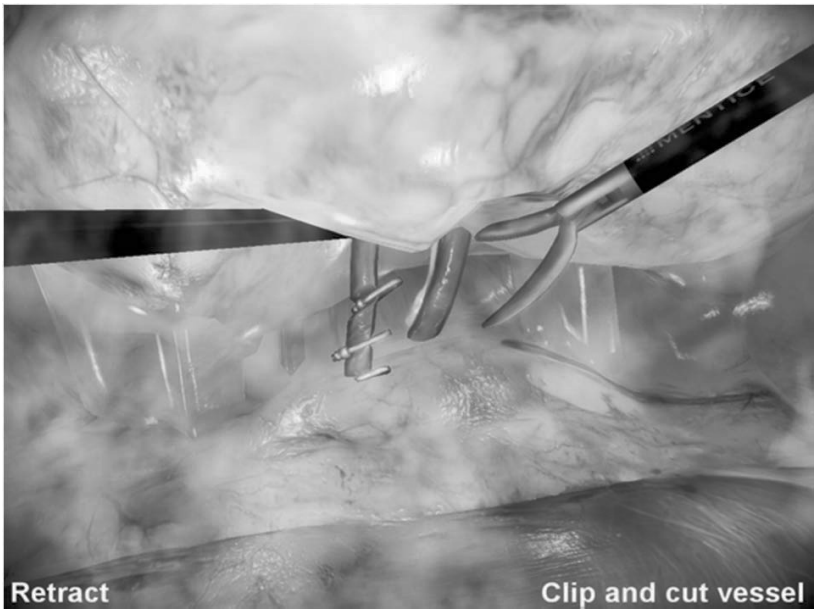




\section{Procedure}

According to the literature two to seven trials on a new simulator should be allowed for the trainee in order to eliminate the learning curve effect of the simulator itself. ${ }^{12}$ In our study protocol (Fig 3.), the study participants performed five tasks after an introduction. The participants performed the real test task three times alternated with two training tasks. The participants completed a questionnaire consisting of questions about demographics (part 1) and questions asking about the realism and usefulness of the simulator, with answer options on a five-point Likert scale from $1=$ not realistic/poor/useless to 5 = realistic/good/useful (part 2).

Figure 3. Overview of the study protocol

\begin{tabular}{|c|}
\hline Introduction \\
\hline Basic introduction simulator \\
First part of questionnaire \\
Introduction video: clip and cut task renal hilum \\
Practice task: mobilizing the kidney from the colon \\
\hline
\end{tabular}

\section{Trainingsprotocol}

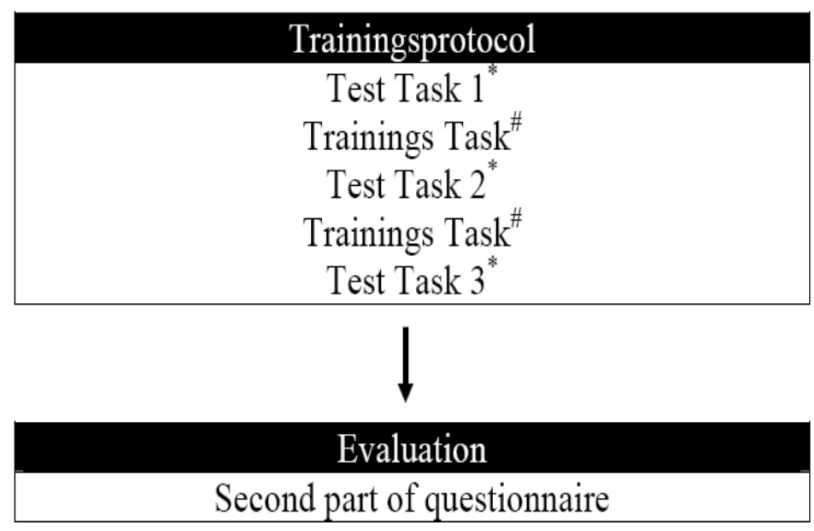

* Test Task = dissecting the renal hilum and clipping and cutting the vessels

\# Trainings Task = dissecting, clipping and cutting the ureter

\section{Parameter assessment}

We were unable to find any consensus in the literature regarding a measure of desired performance outcome for VR tasks. ${ }^{16,23}$ The LN-VR simulator records a total of 62 objective performance parameters per task, ranking them according to a system for parameter evaluation previously used by Van Dongen and colleagues. ${ }^{10}$ All these parameters 
are used to classify individual participants' scores into one of three groups: Top 25\%, intermediate $50 \%$, and bottom $25 \%$. Scores in the first quartile are awarded two points, scores in the second and third quartile one point and scores in the fourth quartile gain no points. The total score is the sum of all 62 scores. We evaluated the following outcome parameters: Time $(\mathrm{sec})$, hemorrhage $(\mathrm{ml})$, path length (distance of displacement of all instruments used in meters) and the total score (sum of 62 parameters).

\section{Statistical analysis}

One-way analysis of variance with post-hoc Bonferroni testing was performed to analyze the parametric data and the Kruskall-Wallis test was used to analyze the nonparametric data. For the analysis of the comparisons between the groups' learning curves paired sample $t$ tests were used. Statistical significance was set at $P<0.05$ for all the tests. All statistical analyses were performed using the Statistical Package for the Social Sciences version 16.0 .

\section{RESULTS}

\section{Demographics}

A total of 64 participants from 11 different hospitals in the Netherlands, grouped according to their experience in performing LN as novices (22), intermediates (32) and

Table 1. Demographic data for novices, intermediates and experienced participants

\begin{tabular}{|c|c|c|c|c|}
\hline Demographics & & $\begin{array}{l}\text { Novices } \\
(\mathrm{n}=22)\end{array}$ & $\begin{array}{l}\text { Intermediates } \\
\qquad(n=32)\end{array}$ & $\begin{array}{l}\text { Experienced } \\
\qquad(n=10)\end{array}$ \\
\hline Female gender, n (\%) & & $16(73 \%)$ & $11(34 \%)$ & $0(0 \%)$ \\
\hline Age in years (mean $\pm s d)$ & & $23.3 \pm 1.3$ & $34.9 \pm 6.4$ & $43.7 \pm 4.6$ \\
\hline \multirow[t]{3}{*}{ Dexterity, n (\%) } & Right & $18(82 \%)$ & $29(91 \%)$ & $8(80 \%)$ \\
\hline & Left & $4(18 \%)$ & $2(6 \%)$ & $1(10 \%)$ \\
\hline & Ambidexterity & $0(0 \%)$ & $1(3 \%)$ & $1(10 \%)$ \\
\hline $\begin{array}{l}\text { Performed LN ( } n \text { ) by } \\
\text { themselves (mean } \pm s d \text { ) }\end{array}$ & & $0(0)$ & $0.9(0.4)$ & $71(12)$ \\
\hline $\begin{array}{l}\text { Previous experience on } \\
\text { VRsimulators, but not on } \\
\text { LN-VR simulator, } \mathrm{n}(\%)\end{array}$ & & $13(59 \%)$ & $20(63 \%)$ & $5(50 \%)$ \\
\hline $\begin{array}{l}\text { Experience with } \\
\text { computer games }>5 \\
\text { years, } \mathrm{n}(\%)\end{array}$ & & $13(59 \%)$ & $15(47 \%)$ & $4(40 \%)$ \\
\hline
\end{tabular}


experienced urologists (10), were included in the study. All novices were medical students in years 4 to 6 of the 6-year curricula of the Faculty of Health, Medicine and Life Sciences, Maastricht University, the Netherlands and the Faculty of Medicine of Nijmegen University, the Netherlands. The intermediates were urology trainees in years 1 to 6 of residency training and urologists with limited experience (mean experience 0.9 LN). All experienced participants were urologists with a mean experience of 71 LNs (Table 1).

\section{Construct validity}

The results of the three groups on time, hemorrhage, path length and total score on three identical, consecutive tasks are shown in Table 2. None of the parameters yielded a significant difference between the intermediate and the experienced group. The intermediate and the experienced participants were faster than the novices on tasks 1 and 2. The intermediates had significantly higher total scores on tasks 1 and 2 compared to the novices. Another significant difference between novices and intermediates was the one for path length in task 2. No significant differences between the groups could be demonstrated for task 3.

Table 2. Results of the four outcome parameters for the three tasks in novices, intermediates and experienced. Result are presented as the mean value \pm standard deviation. N.S. = non significant

\begin{tabular}{|c|c|c|c|c|c|c|}
\hline \multirow{2}{*}{$\begin{array}{l}\text { Outcome } \\
\text { Parameter } \\
\text { Time (sec) }\end{array}$} & \multirow{3}{*}{$\begin{array}{c}\begin{array}{c}\text { Novices } \\
(n=22)\end{array} \\
\text { mean }+ \text { sd } \\
943.8 \pm 239\end{array}$} & \multirow{3}{*}{$\begin{array}{l}\text { Intermediates } \\
\qquad(n=32) \\
\text { mean + sd } \\
714.1 \pm 181\end{array}$} & \multirow{3}{*}{$\begin{array}{l}\text { Experienced } \\
\qquad(n=10) \\
\text { mean + sd } \\
730.7 \pm 201\end{array}$} & \multicolumn{3}{|c|}{$\begin{array}{l}\text { Intergroup differences } \\
\quad(p \text {-values) }\end{array}$} \\
\hline & & & & $\begin{array}{l}\text { Nov vs. } \\
\text { Int }\end{array}$ & $\begin{array}{l}\text { Nov vs. } \\
\text { Exp }\end{array}$ & $\begin{array}{l}\text { Int vs. } \\
\text { Exp }\end{array}$ \\
\hline Task 1 & & & & 0.001 & 0.025 & N.S. \\
\hline Task 2 & $676.6 \pm 174$ & $531.1 \pm 164$ & $439.3 \pm 104$ & 0.005 & 0.001 & N.S. \\
\hline Task 3 & $511.3 \pm 153$ & $448.2 \pm 169$ & $423.7 \pm 132$ & N.S. & N.S. & N.S. \\
\hline \multicolumn{7}{|c|}{ Hemorrhage (ml) } \\
\hline Task 1 & $1038 \pm 758$ & $721 \pm 709$ & $1230 \pm 1123$ & N.S. & N.S. & N.S. \\
\hline Task 2 & $519 \pm 584$ & $485 \pm 590$ & $370 \pm 528$ & N.S. & N.S. & N.S. \\
\hline Task 3 & $281 \pm 291$ & $430 \pm 690$ & $303 \pm 590$ & N.S. & N.S. & N.S. \\
\hline \multicolumn{7}{|c|}{ Path Length (m) } \\
\hline Task 1 & $17.5 \pm 5.6$ & $14.0 \pm 4.6$ & $16.3 \pm 6.8$ & N.S. & N.S. & N.S. \\
\hline Task 2 & $12.9 \pm 4.6$ & $10.0 \pm 3.4$ & $9.4 \pm 3.1$ & 0.022 & N.S. & N.S. \\
\hline Task 3 & $10.1 \pm 4.5$ & $8.9 \pm 3.3$ & $9.7 \pm 4.8$ & N.S. & N.S. & N.S. \\
\hline \multicolumn{7}{|c|}{ Total score (points) } \\
\hline Task 1 & $15.5 \pm 4.4$ & $19.7 \pm 4.1$ & $17.5 \pm 5.3$ & 0.003 & N.S. & N.S. \\
\hline Task 2 & $15.7 \pm 4.4$ & $19.2 \pm 5.0$ & $19.6 \pm 3.8$ & 0.025 & N.S. & N.S. \\
\hline Task 3 & $17.0 \pm 5.1$ & $18.7 \pm 4.9$ & $18.1 \pm 6.4$ & N.S. & N.S. & N.S. \\
\hline
\end{tabular}




\section{Learning curve}

The learning curves for time, hemorrhage, path length and total score are shown in Figure 4. The improvements per group on the outcome parameters between task 1 and 2 and between task 2 and 3 are presented in tables 3 and 4, respectively.

The total score did not improve significantly in any of the three groups. The experienced group showed a significant improvement in time, hemorrhage and path length between task 1 and task 2 but no significant improvement between task 2 and task 3 . The intermediate group improved significantly on time and path length between task 1 and task 2 but improved only on time between task 2 and task 3. The novices improved significantly on time, hemorrhage and path length between task 1 and task 2 and on time and path length between task 2 and task 3 .

Figure 4: Learning curves of the novice, intermediate and experienced groups for four outcome parameters
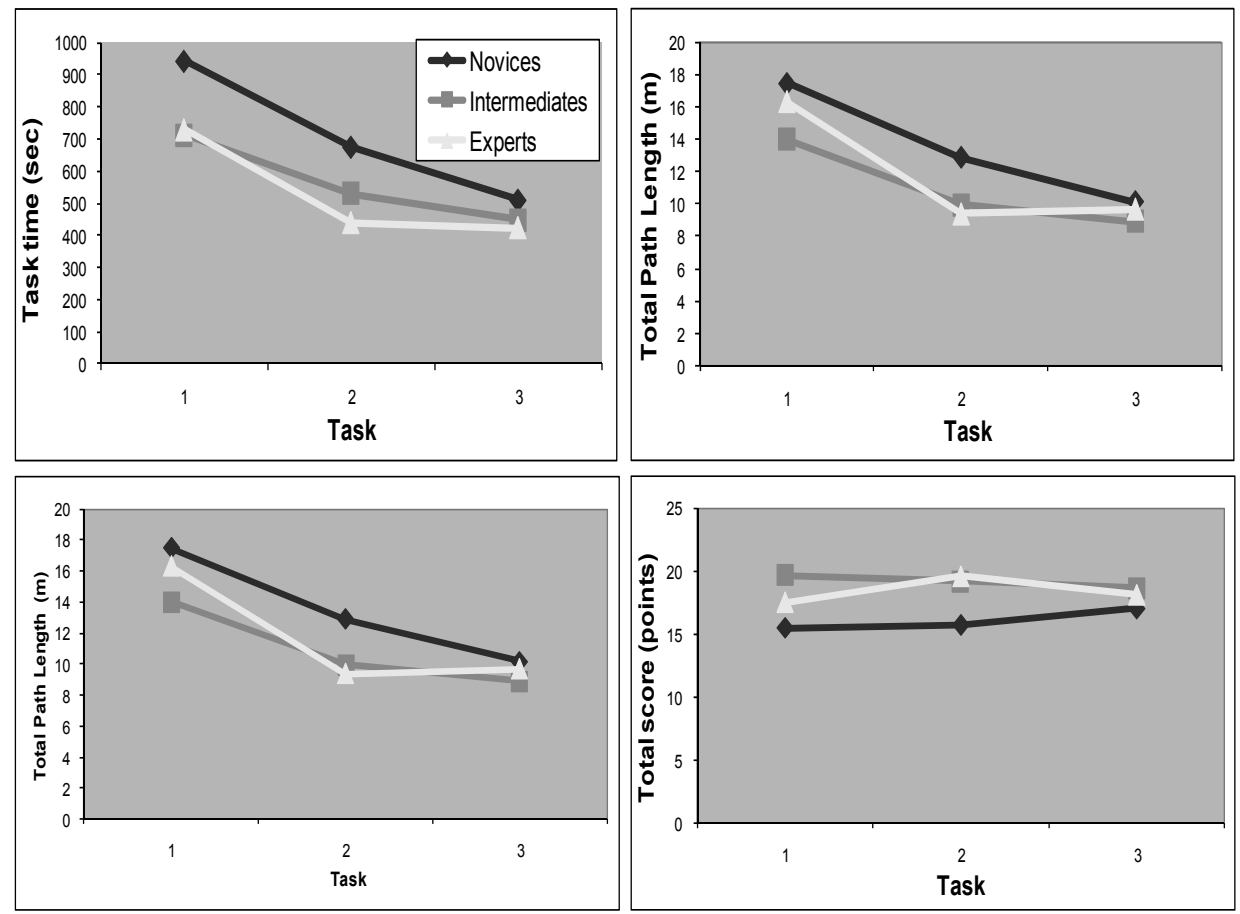

\section{Realism and usefulness}

The questionnaire showed that the experienced group rated the simulator negatively with respect to realism of anatomy and realism of tissue resistance $(<2.5)$. The participants' assessment of the usefulness of task of dissecting the renal hilum was negative as well $(<3.0)$. 
Table 3. Improvement of the four outcome parameters between task one and task two in novices, intermediates and experienced.

\begin{tabular}{|l|c|c|c|c|c|c|}
\hline $\begin{array}{l}\text { Outcome parameters } \\
\text { task 2 - task 1 }\end{array}$ & \multicolumn{3}{|c|}{ Novices } & \multicolumn{2}{c|}{ Intermediates } & Experienced \\
\hline & mean \pm sd & p-value & mean \pm sd & p-value & mean \pm sd & p-value \\
\hline Time $(\mathrm{sec})$ & $-267.2 \pm 255.2$ & 0.000 & $-183.0 \pm 209.3$ & 0.000 & $-219.4 \pm 153.4$ & 0.001 \\
\hline Hemorrhage $(\mathrm{ml})$ & $-519.3 \pm 732.0$ & 0.003 & $-235.9 \pm 680.2$ & N.S. & $-860.6 \pm 1044.9$ & 0.029 \\
\hline Path length $(\mathrm{m})$ & $-4.6 \pm 5.8$ & 0.001 & $-4.1 \pm 5.4$ & 0.000 & $-6.9 \pm 6.8$ & 0.010 \\
\hline Total score $($ points) & $0.0 \pm 5.2$ & N.S. & $-0.2 \pm 5.7$ & N.S. & $2.1 \pm 5.2$ & N.S. \\
\hline
\end{tabular}

N.S. = not significant.

Table 4. Improvement of the four outcome parameters between task two and task three in novices, intermediates and experienced.

\begin{tabular}{|l|c|c|c|c|c|c|}
\hline $\begin{array}{l}\text { Outcome parameters } \\
\text { task 3 - task 2 }\end{array}$ & \multicolumn{3}{|c|}{ Novices } & \multicolumn{2}{c|}{ Intermediates } & \multicolumn{2}{c|}{ Experienced } \\
\hline & mean $\pm \mathrm{sd}$ & p-value & mean $\pm \mathrm{sd}$ & p-value & mean $\pm \mathrm{sd}$ & p-value \\
\hline Time $(\mathrm{sec})$ & $-165.3 \pm 216.4$ & 0.002 & $-82.8 \pm 158.6$ & 0.006 & $-15.7 \pm 162.8$ & N.S. \\
\hline Hemorrhage $(\mathrm{ml})$ & $-238.0 \pm 573.6$ & N.S. & $-55.5 \pm 574.2$ & N.S. & $-66.6 \pm 742.4$ & N.S. \\
\hline Path length $(\mathrm{m})$ & $-2.8 \pm 5.1$ & 0.018 & $-1.1 \pm 3.8$ & N.S. & $0.3 \pm 4.8$ & N.S. \\
\hline Total score $($ points) & $1.3 \pm 5.2$ & N.S. & $-0.7 \pm 5.8$ & N.S. & $-1.5 \pm 5.6$ & N.S. \\
\hline
\end{tabular}

N.S. = not significant.

\section{DISCUSSION}

Considering that the LN-VR simulator should be able to judge participants' individual competence levels, it should at the very least be able to discriminate between novice and experienced level. For a simulator to be useful for urology specialist training, however, it should also be able to discriminate between intermediate and experienced levels. Unfortunately, the simulator proved to be unable to make this kind of distinction. An explanation for this absence of discriminatory power may be looked for in three directions. The simulator records 62 parameters, of which we selected four as outcome parameters for the analysis. The literature offers no suggestions as to which parameters are representative of performance in real-time surgery. Satava and coworkers stressed that critical outcomes must be measured; such as measures related to patient safety. ${ }^{24}$ It is not sufficient to measure objective parameters only. Martin and associates developed Objective Structured Analysis of Technical Skills to assess students' performance of operative skills. ${ }^{25}$ Combining these metrics in a validation study might provide better evidence for simulator validity.

Experiences with learning curves in LN show that the results after performance of 10 to 50 procedures reach a level that is similar to that of open surgery. ${ }^{6-8}$ That is the reason 
we defined the intermediate group as having performed fewer than 10 LNs and the experienced group as having performed $10 \mathrm{LNs}$ or more. Still, this cut-off point is arbitrary. When we compared in our dataset the results of a highly experienced subgroup ( $\geq 50$ $L N$ ) with those of a group of highly inexperienced intermediates $(<1 \mathrm{LN})$, however, we still observed no differences on any of the outcome parameters.

The reason for the lack of construct validity of this simulator has to be found in an inappropriate setup, a low complexity, a minimal realism, no task variance, and a scoring mechanism not able to delineate errors. Despite 62 parameters, there appeared to be no parameters that were sufficiently specific to discriminate between our groups in the third task.

The lack of significant intergroup differences and especially the absence of differences between the intermediate and experienced groups left us no choice but to conclude that the LN-VR simulator has inadequate construct validity. In combination with the negative comments on realism and usefulness made by the experienced group in the evaluation questionnaire, we conclude that the LN-VR-simulator in its current form is not a suitable simulator for urologic training programs.

Novices are expected to show steep learning curves, intermediates are expected to have less steep learning curves, and experienced professionals should show hardly any improvement on simulators. ${ }^{16}$ In contrast to these expectations, the learning curves of all groups in this study showed significant improvement between task 1 and 2 on a number of outcome parameters and hardly any improvement at all between task 2 and 3. Moreover, the three groups demonstrated the same performance level for task 3 , suggesting that the novice, intermediate and experienced groups had reached the same outcome level, despite our setup with alternating tasks to avoid unconscious handling, as in video games. This unexpected development of the learning curves may be attributable to the fact that the learning curve is more a reflection of participants' increasing dexterity in manipulating the simulator than a sign of real improvement in the necessary practical skills.

Suggestions to improve the simulator are: More realistic anatomy, including complications, use of different instruments, more realistic tissue resistance that gives the user more accurate haptic feedback, more variation in realistic procedures, and the ability to practice the entire procedure.

\section{CONCLUSION}

The results demonstrate that the LN-VR simulator does not discriminate between intermediate and experienced urologists. The learning curves suggest that the simulator evaluates dexterity in using the simulator rather than any real improvement in practical 
skills. This prompts the conclusion that the LN-VR simulator has insufficient construct validity and, in its present form, is not suitable for implementation in a urological training program for learning LN. Further development of the LN-VR simulator is needed. On the other hand, this study underlines that if the construct validity of a simulator has not been properly assessed, outcome results should be interpreted with caution.

\section{Acknowledgement}

The authors would like to thank Mereke Gorsira for her editorial assistance.

\section{Abbreviations used}

$\mathrm{LN}=$ laparoscopic nephrectomy

$\mathrm{VR}=$ virtual reality

Nov $=$ novices

Int $=$ intermediates

Exp $=$ experienced

N.S. = not significant

s.d. = standard deviation 


\section{REFERENCES}

1. Darzi A, Mackay S. Recent advances in minimal access surgery. BMJ 2002;324:31-4.

2. Figert PL, Park AE, Witzke DB, Schwartz RW. Transfer of training in acquiring laparoscopic skills. J Am Coll Surg 2001;193:533-7.

3. Clayman RV, Kavoussi LR, Soper NJ, Dierks SM, Meretyk S, Darcy MD, et al. Laparoscopic nephrectomy 1991. J Urol 2002;167:862.

4. Dunn MD, Portis AJ, Shalhav AL, Elbahnasy AM, Heidorn C, McDougall EM, et al. Laparoscopic versus open radical nephrectomy: a 9-year experience. J Urol 2000;164:1153-9.

5. Kercher KW, Heniford BT, Matthews BD, Smith TI, Lincourt AE, Hayes DH, et al. Laparoscopic versus open nephrectomy in 210 consecutive patients: outcomes, cost, and changes in practice patterns. Surg Endosc 2003;17:1889-95.

6. Kanno T, Shichiri Y, Oida T, Kanamaru H, Takao N, Shimizu Y. Complications and the learning curve for a laparoscopic nephrectomy at a single institution. Int J Urol 2006;13:101-4.

7. Higashihara E. Baba S, Nakagawa K, Murai M et al. Learning curve and conversion to open surgery in cases of laparoscopic adrenalectomy and nephrectomy. J of Urol 1998;159:650-653.

8. Phillips J, Catto JW, Lavin V, Doyle D, Smith DJ, Hastie KJ, et al. The laparoscopic nephrectomy learning curve: a single centre's development of a de novo practice. Postgrad Med J 2005;81: 599-603.

9. Satava RM. Virtual reality surgical simulator. The first steps. Surg Endosc 1993;7:203-5.

10. van Dongen KW, Tournoij E, van dZ, Schijven MP, Broeders IA. Construct validity of the LapSim: can the LapSim virtual reality simulator distinguish between novices and experts? Surg Endosc 2007;21:1413-7.

11. Verdaasdonk EG, Stassen LP, Monteny LJ, Dankelman J. Validation of a new basic virtual reality simulator for training of basic endoscopic skills: the SIMENDO. Surg Endosc 2006;20:511-8.

12. Brunner WC, Korndorffer JR, Jr., Sierra R, Massarweh NN, Dunne JB, Yau CL, et al. Laparoscopic virtual reality training: are 30 repetitions enough? J Surg Res 2004;122:150-6.

13. Maithel S, Sierra R, Korndorffer J, Neumann P, Dawson S, Callery M, et al. Construct and face validity of MIST-VR, Endotower, and CELTS: are we ready for skills assessment using simulators? Surg Endosc 2006;20:104-12.

14. Ritter EM, Kindelan TW, Michael C, Pimentel EA, Bowyer MW. Concurrent validity of augmented reality metrics applied to the fundamentals of laparoscopic surgery (FLS). Surg Endosc 2007;21: 1441-5.

15. Rosenthal R, Gantert WA, Hamel C, Hahnloser D, Metzger J, Kocher T, et al. Assessment of construct validity of a virtual reality laparoscopy simulator. J Laparoendosc Adv Surg Tech A 2007;17: 407-13.

16. Schijven M, Jakimowicz J. Construct validity: experts and novices performing on the Xitact LS500 laparoscopy simulator. Surg Endosc 2003;17:803-10.

17. Verdaasdonk EG, Stassen LP, Schijven MP, Dankelman J. Construct validity and assessment of the learning curve for the SIMENDO endoscopic simulator. Surg Endosc 2007;21:1406-12.

18. Yamaguchi S, Konishi K, Yasunaga T, Yoshida D, Kinjo N, Kobayashi K, et al. Construct validity for eye-hand coordination skill on a virtual reality laparoscopic surgical simulator. Surg Endosc 2007; 21:2253-7.

19. McDougall EM. Validation of surgical simulators. J Endourol 2007;21:244-7.

20. Bridgen D, Dangerfield P. The role of simulation in medical education. The Clinical Teacher. 2008; 5:167-170. 
21. Laguna MP, Reijke de TM, Wijkstra H, Rosette de la J. Training in laparoscopic urology. Curr Opin Urol 2006;16:65-70.

22. www.mentice.com Mentice AB, Gothenburg, Sweden on 01/11/2008.

23. Kommu SS, Dickinson AJ, Rane A. Optimizing outcomes in laparoscopic urologic training: toward a standardized global consensus. J Endourol 2007;21:378-85.

24. Satava RM. Historical review of surgical simulation--a personal perspective. World J Surg 2008;32: 141-8.

25. Martin JA, Regehr G, Reznick R, MacRae H, Murnaghan J, Hutchison C, et al. Objective structured assessment of technical skill (OSATS) for surgical residents. Br J Surg 1997;84:273-8. 



\title{
C H A P T E R 4
}

\section{The effect of a low fidelity model on cystoscopic skill training: a single blinded randomized controlled trial}

\author{
Marjolein C. Persoon \\ Barbara M.A. Schout \\ Arno M.M. Muijtjens \\ Ad J.M. Hendrikx \\ J. Alfred Witjes \\ Albert J.J.A. Scherpbier
}




\section{ABSTRACT}

\section{Introduction}

Models for training urological procedures without burdening patients are available at varying costs. We examined the value of training on a low fidelity model in addition to training on a high fidelity simulator in a cystoscopy training program.

\section{Methods}

Thirty-two medical students were randomized to an intervention and a control group. The former started by performing cystoscopy on a low cost, low fidelity, glass globe model before moving on to training on the URO Mentor (UM), a computerized simulator. The control group took part in the same UM training program but not in the low fidelity training. Performance on UM was assessed by a global rating score (GRS), \% of correctly inspected areas of the bladder (\% inspected areas), time, and number of traumas caused.

\section{Results}

The intervention group had generally higher scores. Its GRS on task 1 was significantly higher than that of the control group (Mann Whitney $U$ test, $p=0.046$, effect size (ES) 0.6) and the group also scored higher, albeit not significantly, on time and \% inspected areas. All students said they valued training with UM, but the appreciation of the intervention group was stronger (mean 8.9 vs. 8.1 on a scale from 1 to $10, p=0.017$, ES 1.8).

\section{Conclusion}

A low fidelity glass globe model appeared to be an inexpensive educational tool to practice the first steps of cystoscopy. It may reduce training time on the UM simulator. The combined use of a low and high fidelity training model may provide an optimal learning effect. 


\section{INTRODUCTION}

Practical, legal, and ethical considerations have created an increasing need for training opportunities outside the clinical setting. ${ }^{1,2}$ Additionally, educators are continuously looking for ways to optimize surgical training while minimizing the related costs. With the introduction of new technologies in health care, a variety of training models have evolved. Based on the materials used, a distinction can be made between inanimate, animate, and computerized simulators and there is evidence that all types can enhance trainees' performance. As a result simulators are swiftly becoming an integral part of medical education. ${ }^{3-7}$

Simulators can be graded on a scale from low to high fidelity models according to their resemblance to real life. It is not always clear whether expensive high fidelity models offer better value than low fidelity models. Several studies have demonstrated the effectiveness of bench-based training models in the acquisition of technical skills, with a learning effect of practicing on low fidelity bench models in novices implying that a model does not have to look realistic as long as the steps of the procedure can be practiced adequately. ${ }^{8-11}$ However, another study reported better results of training with a high-fidelity model among both junior and senior residents.?

Adequate performance of basic endourological skills is of crucial importance in urological clinical practice. The URO mentor (UM, Simbionix) is a computerized simulator with proven effectiveness as a tool for learning endoscopic skills. The animation of the inner bladder, ureter, and kidney in this high fidelity model is a close approximation of reality. Parameters of performance on UM can distinguish inexperienced urologists from experienced ones and training on UM has shown to improve performance of ureterorenoscopy and urethrocystoscopy (UCS). ${ }^{12-15}$ Unfortunately, the high cost of UM ( $85000 \$$ ) limits its availability to trainees so it should be used with the utmost efficiency. A cystoscopy training program using UM after initial training on a glass globe model was described in a previous paper by some of the authors. ${ }^{16}$ In this study we aimed to assess the value of initial training on a low fidelity glass globe model as part of a cystoscopic skill training program which also includes the use of the high fidelity UM simulator. To put it briefly, can a UM based cystoscopic skill training program be optimized by additional training on a simple glass globe model?

\section{MATERIALS AND METHODS}

Medical students in years four through six of a six-year undergraduate curriculum were recruited on clinical rotations in internal medicine, surgery and gynecology at the Catharina Hospital Eindhoven, the Netherlands. They were contacted through brochures and 
during plenary meetings. Written informed consent and approval of our institution was obtained. Students who had had previous experience with the UM or had performed cystoscopy previously were excluded. Participants were randomly assigned to the intervention or the control group using www.Randomization.com. A pilot with eight students was conducted to optimize and standardize the study protocol. The data from the pilot are not included in the present study.

First, all participants watched a fifteen-minute video explaining the basics of cystoscopy. The intervention group then performed cystoscopy on the glass jar model before proceeding to practice on the UM, while the control group practiced on the UM only. After the instruction, the students in the intervention group underwent a fifteen-minute cystoscopy training session in which they used a real cystoscope, while a transparent glass jar represented the bladder (Figure 1).

This glass globe model is a simple, 10 dollar model. It was described previously in a study on the effect of the UM on performance of cystoscopy in patients. ${ }^{17}$ The glass globe model was part of the training program for all participants and was developed in collaboration with urologists and educationalists. As the model bears no resemblance whatsoever to real anatomical structures, we classified it as a low-fidelity model. ${ }^{16-18}$ The duration of the training session was 15 minutes of which 10 minutes consisted of

Figure 1. Glass globe model for cystoscopy training

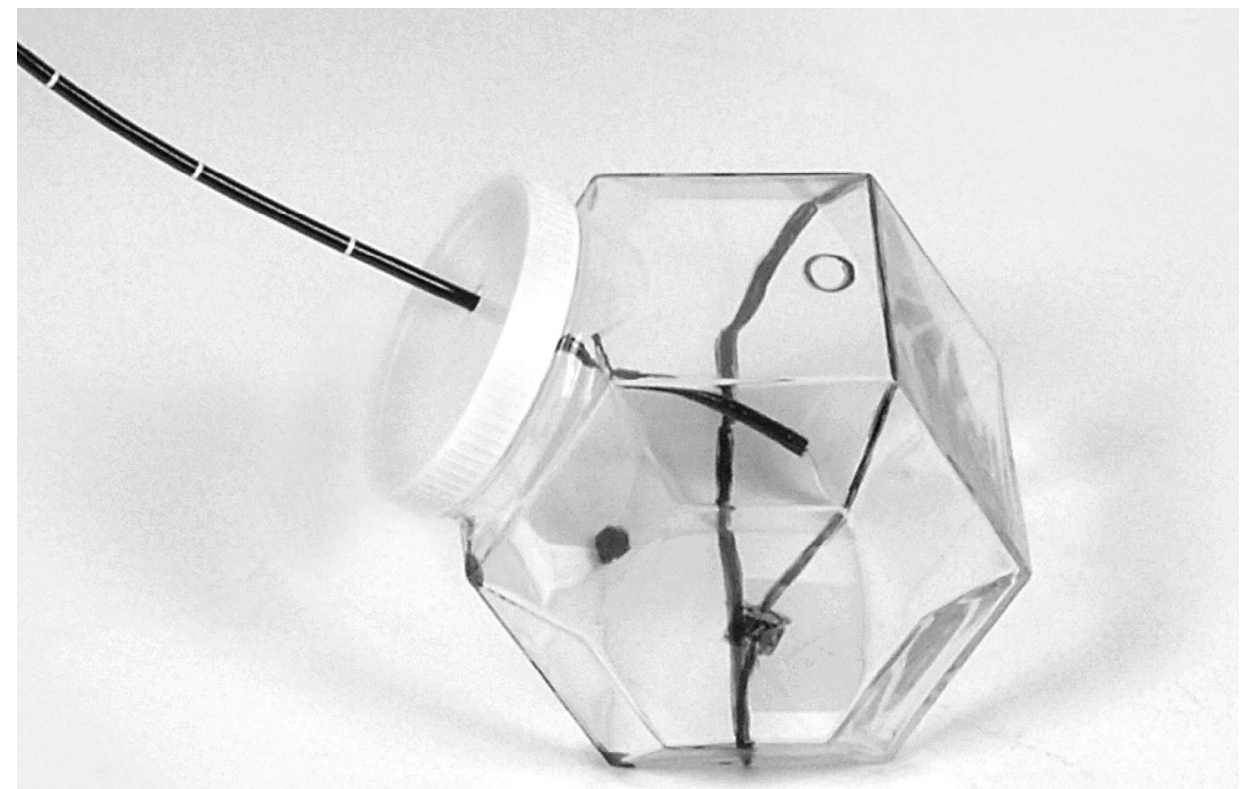


hands-on training. Movements of the real cystoscope were practiced in a glass globe, which represented the bladder. The glass globe was covered and the image was projected on a monitor. In addition, exercises were done in the transparent glass globe. Explanation on the different steps of the procedure and feedback was given to all participants. One urology resident with extensive experience in cystoscopy training on this model (>70 sessions) guided all the standardized individual sessions. The first assessment on performance was conducted in the first task on the UM. Before the actual study started, one training session on the glass globe was videotaped and evaluated by an educationalist and a urologist to ensure that the procedure was taught accurately. The participants were instructed how to handle the flexible scope and they practiced the procedure. The students in the control group spent fifteen minutes in a separate room engaged in non-cystoscopy related activities like using the computer or reading a book. All the participating students were instructed to make no mention of the glass globe training session during the next part of the study protocol to ensure that the UM supervisor was properly blinded.

After the glass globe training (intervention group) or the other activities (control group), each participant carried out an identical training protocol on UM, supervised by a second supervisor who was blinded to the participants previous cystoscopy training activities. The UM is a computerized simulator which simulates flexible and (semi) rigid ureterorenoscopy previously investigated and described in other studies. ${ }^{12-15}$ The protocol on the UM consisted of seven flexible UCS tasks: stone-manipulation(SM) tasks nrs 3 and 8, and basic tasks nrs 4, 5 and 9 of the UM. ${ }^{16,17}$ The first and seventh task were both SM task nr 3 on the UM in which a normal bladder without pathology was presented. The fourth task (SM task nr 8 on the UM) simulated a bladder with a stone in the left ureteral orifice. The first, fourth and seventh task of the protocol were used as test tasks, while tasks two, three, five and six were training tasks. In the training tasks two, three and five, bladders with animated flowers and numbers on the bladder mucosa were used. In task 6 , which is the last training task, a bladder with bladder stones was used. Handling of the cystoscope, anatomical knowledge, development of a systematic approach to cystoscopy and speed of the procedure were the topics of the training tasks. The students had ten minutes to complete each training task and received feedback on their performance afterwards. During the test tasks the trainees completed the procedure autonomously and verbal guidance was only given if they were unable to proceed. All the tasks consisted of inspection of the bladder and they were of comparable difficulty. The participants were asked to perform cystoscopy in a structured manner while inspecting and naming the relevant anatomical structures and landmarks (urethra, external sphincter, prostate, colliculus, bladder neck, trigone, trigonal ridge, ureteral orifice left and right, bladder base, lateral wall left and right, anterior dome, posterior dome, air bubble). The insertion of the cystoscope was explained in the video and during the introduction on the UM, 
but was performed by the supervisor since this part of the procedure is not close to reality on the simulator. A checklist was used to determine how many areas out of a predefined list were inspected and the score was the percentage of the total number of predefined areas inspected accurately (\% inspected areas). UM measured the time needed to perform the task as well as the traumas caused to the bladder wall. Overall performance was rated on a five-point global rating score (GRS), a modification of a method to assess technical skills, which was used in an earlier study to evaluate endourological skills (Figure 2). ${ }^{16,17,19}$ This score was used to measure the level of surgical skills and proved to be a good test of performance differences between novices and experts. ${ }^{19}$ In this study, five items were evaluated: respect for tissue, time and motion, handling of the scope, flow of procedure and forward planning, and knowledge of the procedure. ${ }^{11,20}$ All the students were evaluated by the same instructor, who had received cystoscopy training from experts and additional training in GRS scoring prior to the study.

To gain more insight into what the participating students thought of the training program, we asked them after the training was finished to indicate, on an anonymous

Figure 2. Global Rating Score to evaluate cystoscopy performance

\begin{tabular}{|c|c|c|c|}
\hline GRS 1 & & & \\
\hline \multirow[t]{2}{*}{$\begin{array}{l}\text { Respect for } \\
\text { tissue }\end{array}$} & $\begin{array}{l}\text { Scope frequently pushed } \\
\text { into urothelial wall. }\end{array}$ & $\begin{array}{l}\text { Scope occasionally pushed } \\
\text { into urothelial wall. }\end{array}$ & $\begin{array}{l}\text { No trauma to urothelial } \\
\text { wall with scope. }\end{array}$ \\
\hline & 2 & 3 & 5 \\
\hline \multicolumn{4}{|l|}{ GRS 2} \\
\hline \multirow[t]{2}{*}{$\begin{array}{l}\text { Time and } \\
\text { motion }\end{array}$} & Many unnecessary moves. & $\begin{array}{l}\text { Made some unnecessary } \\
\text { moves, but time more } \\
\text { efficient. }\end{array}$ & $\begin{array}{l}\text { No unnecessary moves and } \\
\text { time is maximized }\end{array}$ \\
\hline & 2 & 3 & 4 \\
\hline \multicolumn{4}{|l|}{ GRS 3} \\
\hline \multirow[t]{2}{*}{$\begin{array}{l}\text { Handling of } \\
\text { endoscope }\end{array}$} & $\begin{array}{l}\text { Frequently had scope } \\
\text { pointing away from centre } \\
\text { of urethra. Scope poorly } \\
\text { aligned during procedure. }\end{array}$ & $\begin{array}{l}\text { Had scope centred for } \\
\text { the most part. Better use } \\
\text { of scope angle during } \\
\text { procedure. }\end{array}$ & $\begin{array}{l}\text { Scope always centred. } \\
\text { Scope always set in good } \\
\text { angle throughout the } \\
\text { procedure. }\end{array}$ \\
\hline & 2 & 3 & 4 \\
\hline \multicolumn{4}{|l|}{ GRS 4} \\
\hline \multirow[t]{2}{*}{$\begin{array}{l}\text { Flow of } \\
\text { procedure } \\
\text { and forward } \\
\text { planning }\end{array}$} & $\begin{array}{l}\text { Frequently stopped } \\
\text { or needed advice or } \\
\text { assistance from examiner. }\end{array}$ & $\begin{array}{l}\text { Demonstrated the } \\
\text { ability to think forward } \\
\text { with relatively steady } \\
\text { progression of procedure. }\end{array}$ & $\begin{array}{l}\text { Obviously planned } \\
\text { procedure from beginning } \\
\text { to end with fluid motion. }\end{array}$ \\
\hline & 1 & 3 & 4 \\
\hline \multicolumn{4}{|l|}{ GRS 5} \\
\hline \multirow[t]{2}{*}{$\begin{array}{l}\text { Knowledge of } \\
\text { procedure }\end{array}$} & $\begin{array}{l}\text { Deficient knowledge. } \\
\text { Needed specific instruction } \\
\text { at most procedural steps. }\end{array}$ & $\begin{array}{l}\text { Knew all important aspects } \\
\text { of procedure. }\end{array}$ & $\begin{array}{l}\text { Demonstrated familiarity } \\
\text { with all aspects of } \\
\text { procedure. }\end{array}$ \\
\hline & 1 & 3 & 5 \\
\hline
\end{tabular}


evaluation form, the level of difficulty of each task on a scale from 1 (not difficult at all) to 10 (very difficult) and an overall judgment on a ten-point scale ( $1=$ not appreciated to $10=$ highly appreciated). The students in the intervention group were additionally asked to give their opinion on the relevance of the glass globe to the cystoscopic training program (yes/no categorical scale).

\section{Statistical analysis}

Mann-Whitney $U$ test was used to analyze between-group differences in mean GRS, \% inspected areas, time of procedure, and number of traumas. A p-value $<0.05$ was taken to indicate statistical significance. The practical significance of the results was expressed by effect size (ES), which is independent of sample size and a scale-free index. For the analysis, ES was defined as the absolute difference between the mean scores of the intervention $\left(\mathrm{M}_{\mathrm{i}}\right)$ and the control group $\left(\mathrm{M}_{\mathrm{c}}\right)$ divided by the standard deviation of the control group $\left(\sigma_{c}\right): E S=\left|M_{i}-M_{c}\right| / \sigma_{c}$. Effect sizes of $0.20,0.50$, and 0.80 were considered to indicate small (negligible), medium (moderate) and large (crucial) effects, respectively. ${ }^{21} \mathrm{ES}$ is only relevant for a variable with a statistically significant between-group difference. The Statistical Package for the Social Sciences (SPSS) version 16.0 was used for the data analysis.

\section{RESULTS}

Of the 32 students included in the study, sixteen were randomized to the intervention and sixteen to the control group. All participants completed the full study protocol. Demographics are shown in table 1.

The intervention group had significantly higher global rating scores $(p=0.046$, ES 0.6) than the control group for task 1. Figure 3 shows the mean values of GRS, \% of inspected

Table 1: demographics

\begin{tabular}{|c|c|c|c|c|c|c|}
\hline & & & \multicolumn{2}{|c|}{ Intervention ( $n=16)$} & \multicolumn{2}{|c|}{ Control $(n=16)$} \\
\hline & & & & $\%$ & & $\%$ \\
\hline \multicolumn{3}{|c|}{ Age(mean in years(SD)) } & $22(1.4)$ & & $22(1.0)$ & \\
\hline \multirow[t]{2}{*}{ Gender } & Fem & & 11 & 69 & 8 & 50 \\
\hline & Male & & 5 & 31 & 8 & 50 \\
\hline \multirow[t]{3}{*}{ Dominar } & land & Right & 14 & 88 & 13 & 82 \\
\hline & & Left & 1 & 6 & 2 & 12 \\
\hline & & Ambidexter & 1 & 6 & 1 & 6 \\
\hline \multicolumn{3}{|c|}{ Year of study (mean(SD)) } & $4.4(0.72)$ & & $4.3(0.7)$ & \\
\hline \multicolumn{3}{|c|}{ Observed UCS previously: yes } & 5 & 31 & 8 & 50 \\
\hline
\end{tabular}


areas, time, and number of traumas for the test tasks. All participants showed improvement in skills during the training program and after performing six tasks, the two groups showed comparable performance on the last task. The groups did not differ significantly in time needed and \% of inspected areas. Nevertheless, Figure 3 shows that the general pattern is in favor of the intervention group, except for the significantly higher number of traumas ( $p=0.001, E S 1.8$ ) caused by this group on task 1 . The differences between the groups on all the parameters decreased over the course of the training program.

Figure 3. Mean values for time, traumas, $\%$ of inspected areas and global rating score (GRS)
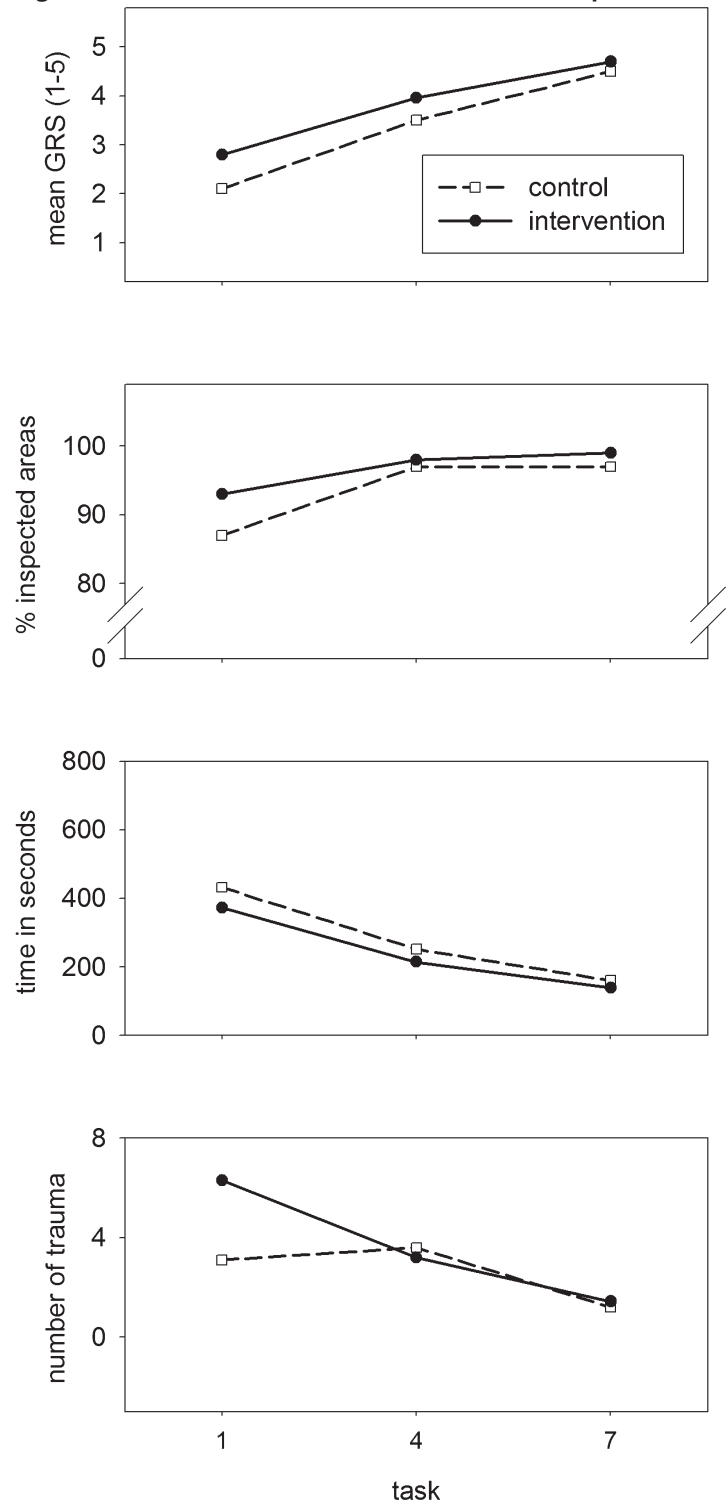
Figure 4. Percepted task difficulty for the control and intervention group. Shown are mean (square, dot) and the $95 \%$ confidence interval (error bars) for the 7 tasks (left panel), and the mean difficulty over all tasks (right panel). An asterix indicates a statistically significant between-group difference.

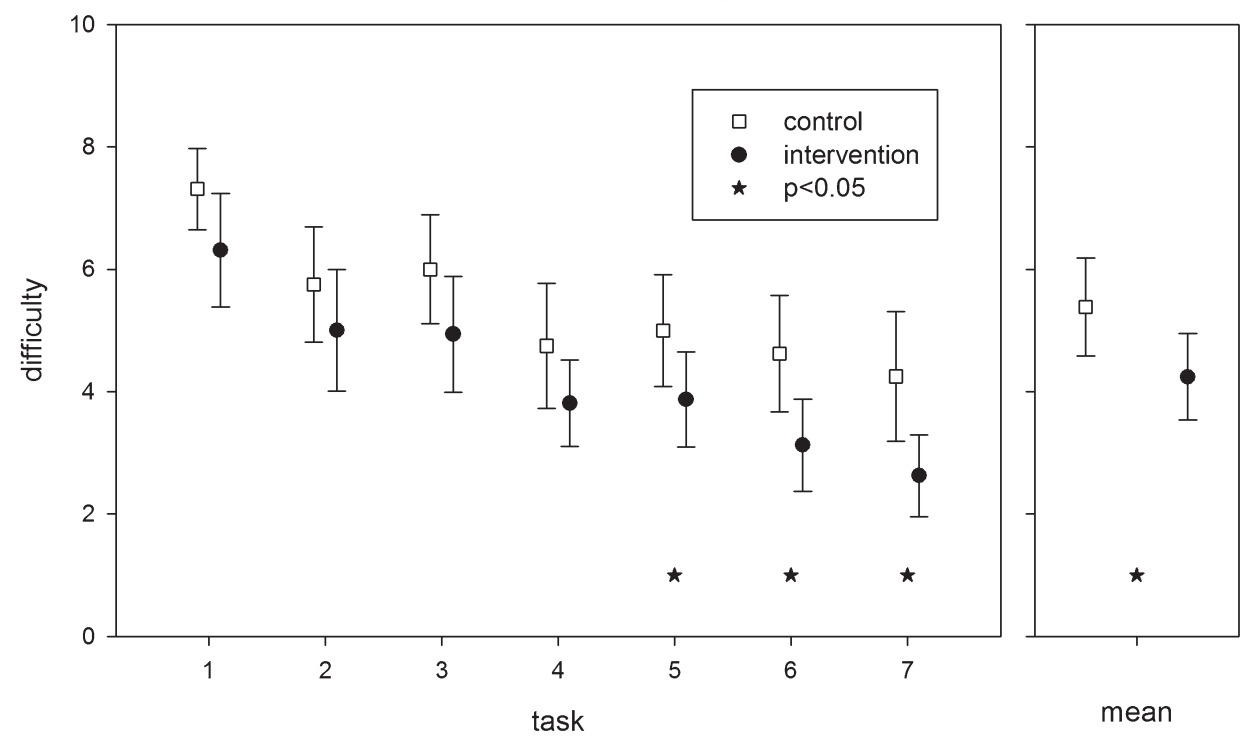

The students of the control group gave higher scores for task difficulty than the intervention group. This difference was significant for the last three tasks. In contrast to the decrease in between-group difference for GRS, \% inspected areas, time, and number of traumas, the between-group difference for the perceived difficulty of tasks persisted throughout the training protocol (Figure 4).

All participants valued training on UM highly, but the intervention group gave significantly higher ratings than the control group (8.9 vs 8.1 on a scale from 1 to 10 , $\mathrm{p}=0.017$, ES 1.8). At the same time, the vast majority of the students in the intervention group (87.5\%) indicated that training with the glass globe was important for learning cystoscopic skills.

\section{DISCUSSION}

The aim of this study is to provide more insight into the contribution of two different types of simulator to a cystoscopy training program. We compared UM, a high fidelity computerized simulator, and a low fidelity glass globe model by examining whether training on the low fidelity simulator in addition to training on the high fidelity one enhances cystoscopy learning.

The mean global rating scores for the first task show that the intervention group, having used the low fidelity simulator in addition to UM, outperform the control group, 
which only engaged in UM training. However, this difference gradually diminishes as the training program proceeds. For the \% of correctly inspected areas and for time, a trend in favor of the intervention group is seen, but the number of traumas is higher in this group than in the control group. On the item "respect for tissue" in the global rating score, this large difference was not seen. The intervention group scored slightly worse compared to the control group, however this was not significant. Training on the glass globe may have made students overconfident and less cautious, a notion that seems also supported by the lower ratings of task difficulty by the intervention group. Unlike the positive effect of glass globe training on the first task, which disappeared as the program progressed, the confidence reflected by the lower difficulty scores of the intervention group did not decrease in the following tasks and remained significant for the last three tasks. This indicates that the effect of glass globe training on confidence was stable, although both groups improved their performance and their performance scores moved closer together during the program.

Another interesting finding is that the students in the intervention group show greater appreciation of UM compared to the control group, probably due to the stark contrast between UM's lifelike animation and the artificiality of the glass globe model. When the intervention group participants were asked if they considered glass globe training an important component of the training program, $87.5 \%$ of the intervention group agreed. Two participants did not answer this question but anonymity prevented us from finding out why. The results of this study indicate that cystoscopy training on a low-fidelity model can contribute positively in a training program on the UM simulator.

This study is limited to the assessment of performance on the UM instead of on patients due to practical and ethical reasons. The intervention group made more traumas in the first test task, but it is unclear what the clinical relevance of this finding is. This has not been studied yet. In our opinion GRS is more important since it includes assessment of multiple aspects of the procedure. After the first test task the participants performed two training tasks of 10 minutes. During these tasks feedback was given on their performance and questions were answered. This might explain why no significant difference was found in the second test task which is the fourth task in the training protocol. It would be interesting to have evaluated the second and third task as well. However, for an optimal training effect we chose to give each participant individual feedback and we limited time to 10 minutes.

Advantages of training in a skills lab, irrespective of the use of high or low fidelity simulators, are that training opportunities are not dependent on the presence of a patient, that time savings can be made as well as gains in the quality of care during trainees' first procedures on real patients. Supervision and adequate feedback are of crucial importance for high as well as low fidelity simulators. ${ }^{22}$ Supervision is also required with training on the UM, because the simulator does not explain to students how to handle 
the cystoscope nor how to perform the different steps in the procedure systematically. There is no conclusive evidence in the literature with regard to the preferability of low or high fidelity simulators, but the choice seems to depend on which procedure is to be performed. 1,3,7,9,10,12 It should also be noted that performing a procedure requires more than psychomotor skills only. Didactic teaching of knowledge, instructions for the steps of the procedure, identification of and feedback on common errors are all examples of important aspects that have to be considered when a training program is being developed. ${ }^{23,24}$ Due to the variety of steps to be taken during the process of becoming skilled in performing a procedure, the effect a simulator is likely to have depends on the way it is embedded in the curriculum. Therefore, it seems advisable to evaluate not only the characteristics of simulators but also the training program as a whole. ${ }^{24}$ The way a simulator is incorporated in a training program together with the availability, or not, of financial resources may well be decisive aspects in decisions regarding the use of simulators. ${ }^{24,25}$

In conclusion, for cystoscopy training, a low-fidelity glass globe model appears to be a useful and inexpensive tool that can help students to take their first steps towards mastering cystoscopy and enhances the value of a training program with the high fidelity UM. An optimal effect will probably be achieved by a program that combines the use of low and high fidelity simulators. 


\section{REFERENCES}

1. Bridges $M$, Diamond DL: The financial impact of teaching surgical residents in the operating room. Am J Surg 1999;177:28-32.

2. Brigden D, Dangerfield P: The role of simulation in medical education. Clinical teacher 2008;5: 167-70.

3. Grober ED, Hamstra SJ, Wanzel KR, Reznick RK, Matsumoto ED, Sidhu RS, et al.: The educational impact of bench model fidelity on the acquisition of technical skill: the use of clinically relevant outcome measures. Ann Surg 2004;240:374-81.

4. Eversbusch A, Grantcharov TP: Learning curves and impact of psychomotor training on performance in simulated colonoscopy: a randomized trial using a virtual reality endoscopy trainer. Surg Endosc 2004;18:1514-8.

5. Ogan K, Jacomides L, Shulman MJ, Roehrborn CG, Cadeddu JA, Pearle MS: Virtual ureteroscopy predicts ureteroscopic proficiency of medical students on a cadaver. J Urol 2004; 172: 667-71.

6. Seymour NE: VR to OR: a review of the evidence that virtual reality simulation improves operating room performance. World J Surg 2008;32:182-8.

7. Sidhu RS, Park J, Brydges R, MacRae HM, Dubrowski A: Laboratory-based vascular anastomosis training: a randomized controlled trial evaluating the effects of bench model fidelity and level of training on skill acquisition. J Vasc Surg 2007;45:343-9.

8. Anastakis DJ, Regehr G, Reznick RK, Cusimano M, Murnaghan J, Brown M, et al.: Assessment of technical skills transfer from the bench training model to the human model. Am J Surg 1999;177: 167-70.

9. Fried GM, Feldman LS, Vassiliou MC, Fraser SA, Stanbridge D, Ghitulescu G, et al.: Proving the value of simulation in laparoscopic surgery. Ann Surg 2004;240:518-25.

10. Matsumoto ED, Hamstra SJ, Radomski SB, Cusimano MD: The effect of bench model fidelity on endourological skills: a randomized controlled study. J Urol 2002;167:1243-7.

11. Reznick R, Regehr G, MacRae H, Martin J, McCulloch W: Testing technical skill via an innovative "bench station" examination. Am J Surg 1997;173:226-30.

12. Gettman MT, Le CQ, Rangel LJ, Slezak JM, Bergstralh EJ, Krambeck AE: Analysis of a computer based simulator as an educational tool for cystoscopy: subjective and objective results. J Urol 2008;179:267-71.

13. Knoll T, Trojan L, Haecker A, Alken P, Michel MS: Validation of computer-based training in ureterorenoscopy. BJU Int 2005;95:1276-9.

14. Matsumoto ED, Pace KT, D’A Honey RJ: Virtual reality ureteroscopy simulator as a valid tool for assessing endourological skills. Int J Urol 2006;13:896-901.

15. Gettman MT, Le CQ, Rangel LJ, Slezak JM, Bergstralh EJ, Krambeck AE: Development of a standardized curriculum for teaching cystoscopic skills using a computer-based endourologic simulator. Simul Healthc 2009;4:92-7.

16. Schout BM, Muijtjens AM, Hendrikx AJ, Ananias HJ, Dolmans VE, Scherpbier AJ, et al.: Acquiring flexible cystoscopy skills on a virtual reality simulator by experts and novices. BJU Int 2009, In press.

17. Schout BM, Ananias HJ, Bemelmans BL, d'Ancona FC, Muijtjens AM, Dolmans VE, et al.: Transfer of cysto-urethroscopy skills from a virtual-reality simulator to the operating room: a randomized controlled trial. BJU Int 2009, [Epub ahead of print].

18. Maran NJ, Glavin RJ: Low- to high-fidelity simulation - a continuum of medical education? Med Educ 2003;37:22-8. 
19. Matsumoto ED, Hamstra SJ, Radomski SB, Cusimano MD: A novel approach to endourological training: training at the Surgical Skills Center. J Urol 2001;166:1261-6.

20. Martin JA, Regehr G, Reznick R, MacRae H, Murnaghan J, Hutchison C, et al.: Objective structured assessment of technical skill (OSATS) for surgical residents. Br J Surg 1997;84:273-8.

21. Hojat M, Xu G: A visitor's guide to effect sizes: statistical significance versus practical (clinical) importance of research findings. Adv Health Sci Educ Theory Pract 2004;9:241-9.

22. Mahmood T, Darzi A: The learning curve for a colonoscopy simulator in the absence of any feedback: no feedback, no learning. Surg Endosc 2004;18:1224-30.

23. Grantcharov TP, Reznick RK: Training tomorrow's surgeons: what are we looking for and how can we achieve it? ANZ J Surg 2009;79:104-7.

24. McDougall EM, Clayman RV: Rapid communication: minimally invasive urologic surgery curricula. J Endourol 2007;21:197-217.

25. Gallagher AG, Ritter EM, Champion H, Higgins G, Fried MP, Moses G, et al.: Virtual reality simulation for the operating room: proficiency-based training as a paradigm shift in surgical skills training. Ann Surg 2005;41:364-72. 



\section{CHAPTER 5}

\section{The effect of distractions in the operating room during endourological procedures}

Marjolein C. Persoon Hans J.H.P. Broos J. Alfred Witjes Ad J.M. Hendrikx Albert J.J.A. Scherpbier 


\section{ABSTRACT}

\section{Background}

Professionals working in the operating room (OR) are subject to various distractions which can be detrimental to their task performance and the quality of their work. This study aimed to quantify the frequency, nature and effect on performance of (potentially) distracting events occurring during endourological procedures and additionally explored urologists' and residents' perspectives on experienced ill effects due to distracting factors.

\section{Methods}

First, observational data were collected prospectively during endourological procedures in one OR of a teaching hospital. A seven-point ordinal scale was used to measure the level of observed interference with the main task of the surgical team. Second, semistructured interviews were conducted with eight urologists and seven urology residents in two hospitals to obtain their perspectives on the impact of distracting factors.

\section{Results}

A total of 78 procedures was observed. A median of 20 distracting events occurred per procedure which corresponds to an overall rate of one distracting event every 1.8 minutes. Equipment problems and procedure-related and medically irrelevant communication were the most frequently observed causes of interruptions and identified as the most distracting factors in the interviews. Occurrence of distracting factors in difficult situations requiring high levels of concentration was perceived by all interviewees as disturbing and negatively impacting performance. The majority of interviewees (13/15) thought distracting factors impacted more strongly on residents' compared to urologists' performance due to their different levels of experience.

\section{Conclusion}

Distracting events occur frequently in the OR. Equipment problems and communication, the latter both procedure-related and medically irrelevant have the largest impact on the sterile team and regularly interrupt procedures. Distracting stimuli can influence performance negatively and should therefore be minimized. Further research is required to determine the direct effect of distraction on patient safety. 


\section{INTRODUCTION}

Multiple other problems, besides procedural knowledge and psychomotor abilities, influence the performance of urological surgeons and residents in the operating room (OR). ${ }^{1,2}$ These factors include degree of motivation, lack of sleep, variability in patient pathology and distractions in the work environment. Research has revealed negative effects of distractions on performance outcomes in other disciplines. ${ }^{3-5}$

Several studies have shown that distractions and interruptions are common in the OR. Most distractions are case-irrelevant conversations, telephone calls, pagers, music and people entering the OR. ${ }^{6-8}$ Effects of distracting stimuli on patient outcome variables are difficult to measure since complications occur infrequently and randomized studies in patients are unethical. However, distracting events have been shown to impact technical skills performance in experimental settings. Hsu et al. showed that distraction had a negative effect on performance of a peg transfer task on a box trainer in basic laparoscopic skills training and that this effect was stronger for novices compared to experts. ${ }^{9}$ In addition, Pluyter et al. demonstrated a decline in task score and an increase in task errors and operating time when a laparoscopic task was performed under distracting conditions. ${ }^{10}$

Real-time studies of the impact of distractions in surgery are scarce. Previous studies only described small numbers within a large variety of procedures. ${ }^{6,7}$ Because of the proven negative effect of distracting events in other disciplines and in experimental settings, it is of paramount importance to explore the occurrence and impact of distraction in real-time surgical procedures. Given the limitations of quantitative methods for this type of study, we conducted a qualitative study using observations and interviews. ${ }^{11}$

The aim of this study was to quantify the frequency, nature and effects of distractions on interruptions of endourological procedures: How often does distraction occur in the OR? What is the nature of the distractions and how do they affect the task performance of the sterile team? Furthermore, urologists' and residents' perspectives on the experienced hindrance, possible effects of distracting factors, the need for restrictions and their opinion on preparation in a skills lab were explored with semi-structured interviews.

\section{MATERIALS AND METHODS}

We observed urology specialists and residents during performance of common endourological procedures (transurethral resection of the prostate (TURP), transurethral resection of a bladder tumour (TURBT) and ureteroscopic stone treatments (URS)) in a teaching hospital in the Netherlands. Conventional and laparoscopic procedures were excluded because they are different kinds of procedures requiring different instruments 
and techniques. Permission for the study was obtained from the institution's ethics committee. A distracting stimulus was defined as any event that can cause diversion from the task at hand and distraction as any observed behaviour indicating orienting away from the main task. When a distraction leads to a break in main task activity this was defined as an interruption. ${ }^{6}$

\section{Observations}

Data were collected between January and July 2009. During the first part of the study four urologists and three residents were observed during endourological procedures in the same OR. Positioning of equipment and location of the sterile field were comparable in all cases. Data collection started when the urologist or resident put on their sterile gloves and ended when the gloves were removed. Table 1 shows the different types of distracting stimuli. A seven point ordinal scoring list previously described by Healey et al. was used to categorize distracting stimuli and interruptions affecting sterile team members (table 2). ${ }^{6}$ Higher scores indicate a stronger impact on the flow of the procedure. A score of 1 represents a potentially distracting stimulus not followed by a response. The highest score, 7 , represents a stimulus that causes complete interruption of the primary task of the sterile team and disruption of the flow of the procedure. For each potentially distracting stimulus, frequency and severity of effect were measured. Additionally, it was recorded which member of the surgical team caused the distracting event, a distinction being made between non-sterile team members and sterile team members, i.e. urologists, residents and sterile nurses.

Prior to the actual study, we conducted a pilot study in which six endourological procedures (not included in the final study) were observed and rated in order to familiarize the researchers with the scoring list and to standardize practical issues such as the positioning of the observer in the OR for optimal registration of potentially distracting

Table 1: observed distracting stimuli

\begin{tabular}{|l|l|}
\hline Source & Definitions \\
\hline Pager & Any pager activated in the operating room \\
\hline Telephone & Any phone call made or received in the operating room \\
\hline Radio & Action or response related to the radio \\
\hline Door movement & One door movement: opening and closure of a door in the operating room \\
\hline Equipment & Any item of equipment not at hand or falling \\
\hline Procedure & Any conversation between team members relevant to the procedure \\
\hline $\begin{array}{l}\text { Patient-irrelevant } \\
\text { communication }\end{array}$ & $\begin{array}{l}\text { Any conversation irrelevant to the case, but relevant to other medical tasks in } \\
\text { the hospital }\end{array}$ \\
\hline $\begin{array}{l}\text { Medically-irrelevant } \\
\text { communication }\end{array}$ & Any conversation with no medical relevance \\
\hline
\end{tabular}


Table 2: seven-point ordinal scale and the related effect of the distracting stimulus

\begin{tabular}{|c|l|l|}
\hline Rating & Observed effects \\
\hline 1 & Potentially distracting stimuli: events with the potential to distract the sterile team \\
\hline 2 & $\begin{array}{l}\text { Sterile team member momentarily distracted: possible involvement of a single sterile member } \\
\text { in an event not related to the primary task. For example a short head turn in response to a visual } \\
\text { or auditory stimulus. }\end{array}$ \\
\hline 3 & $\begin{array}{l}\text { Sterile team member engages in distraction: similar distraction as in } 2 \text {, but the sterile member } \\
\text { engages with the source of distraction by verbally responding while maintaining primary task } \\
\text { activity (multitasking) }\end{array}$ \\
\hline 4 & $\begin{array}{l}\text { Sterile team member's primary task interrupted: a single team member ceases their current } \\
\text { tasks to engage entirely in the distracting stimulus }\end{array}$ \\
\hline 5 & $\begin{array}{l}\text { Sterile team momentarily distracted: } 2 \text { or more sterile team members respond to a stimulus } \\
\text { with a short head turn, no verbal response }\end{array}$ \\
\hline 6 & $\begin{array}{l}\text { Sterile team engage in secondary tasks: } 2 \text { or more team members engage with the source of } \\
\text { distraction by verbally responding while maintaining primary task activity }\end{array}$ \\
\hline 7 & $\begin{array}{l}\text { Sterile team's work interrupted - operation flow disrupted: interruption of the current primary } \\
\text { task of the sterile team, the operation flow is disrupted. }\end{array}$ \\
\hline
\end{tabular}

stimuli. The first 17 procedures of the actual study were observed by two independent observers: a researcher and an intern. Interobserver agreement, calculated as the number of agreements divided by the sum of agreements and disagreements multiplied by $100 \%$, was $80 \%$ during the first 17 procedures. ${ }^{12}$ Thereafter, the procedures were observed by the intern who was in his surgical rotation in the last year of the six-year curriculum. Staff members were used to seeing the intern in the OR as an observer. The observer did not participate in the procedure to minimize the impact on the environment under study. ${ }^{11}$ The OR team was informed that the intern was doing a research project investigating the logistics and the division of tasks during surgical procedures.

\section{Semi-structured Interviews}

After completing all the observations, the researcher and the intern conducted semistructured interviews with urology specialists and residents in two teaching hospitals exploring their thoughts on how distracting factors affect task performance of the surgical team. They were asked about personal experiences with different kinds of distraction and the usefulness of preparation in a skills lab. The interview was guided by thirteen questions and by any new questions prompted by issues brought up during interviews. After explaining the aim of the study, informed consent was obtained. Semi-structured interviews were used because they enable interviewees to talk about the effects of distraction in detail and depth and at the same time ensure that a predefined list of topics is addressed during each interview. ${ }^{13}$ All conversations were recorded on tape. The two interviewers analyzed the interviews independently and discussed their analysis to ensure similarity of interpretation. The responses were categorized by five themes: sources 
Table 3: Frequency of each source of distraction induced by each team member separately.

\begin{tabular}{|c|c|c|c|c|c|}
\hline & \multirow{2}{*}{$\begin{array}{c}\text { Number of } \\
\text { occurrences } \\
\text { per } \\
\text { procedure }\end{array}$} & \multicolumn{4}{|c|}{ Mean $\%$ of occurrences induced by } \\
\hline & & SU & SR & SN & NST \\
\hline Pager & 0.41 & 44 & 25 & 0 & 31 \\
\hline Telephone & 1.50 & 8 & 0 & 1 & 91 \\
\hline Radio & 2.62 & 31 & 22 & 24 & 23 \\
\hline Door movement & 8.85 & 0 & 1 & 0 & 99 \\
\hline $\begin{array}{l}\text { Procedure- } \\
\text { related } \\
\text { communication }\end{array}$ & 1.65 & 19 & 19 & 19 & 43 \\
\hline $\begin{array}{l}\text { Patient- } \\
\text { irrelevant } \\
\text { communication }\end{array}$ & 1.26 & 16 & 4 & 28 & 52 \\
\hline $\begin{array}{l}\text { Medically } \\
\text { irrelevant } \\
\text { communication }\end{array}$ & 2.13 & 16 & 1 & 30 & 53 \\
\hline Equipment & 1.72 & 0 & 0 & 0 & 0 \\
\hline
\end{tabular}

SU: sterile urologist, SR: sterile resident, SN: sterile nurse, NST: non sterile team member

of distraction, situations in which distraction is the most annoying, impact of distraction on level of performance, the need for restrictions and the usefulness of preparation in a skills lab.

\section{RESULTS}

A total of 78 endourological procedures were observed: 27 TURBTs, 26 TURPs and 25 URSs. Time to completion ranged from 8 to 107 minutes with a median of 35 minutes. No serious intra-operative complications occurred.

\section{Frequencies}

The total of distracting events observed per procedure ranged from 2 to 53 with a median of 20. Completion time of the procedures varied and the overall mean rate of occurrence of distracting stimuli was 1 every 1.8 minutes. Table 3 shows the mean frequencies and the team member involved for each source of distraction per procedure. Of all observed sources of distraction, an activated pager had the lowest (0.41) and door openings had the highest frequency per procedure (8.85). Non-sterile team members were the most frequent sources of medically irrelevant and patient-irrelevant communication. Compared to residents, urologists were more likely sources of patient-irrelevant and medically irrelevant communication (4 versus 16 and 2 versus 27 times, respectively; table 3 ). 


\section{Ratings}

Table 4 shows the mean ratings of all distracting stimuli indicating their impact on the flow of the procedure as defined in table 2. Equipment problems (e.g. stagnation of solution supply, equipment not at hand, suboptimal positioning of equipment) and procedure-related, patient-irrelevant and medically irrelevant communication were the sources of distraction with the highest ratings, i.e. most frequently interrupted a procedure. Pagers, telephone conversations, radio and door movements occurred frequently but had the lowest ratings, in other words did not appreciably impact the flow of the procedure.

Table 4: Mean Rating of each source of distraction induced by each team member, calculated from all 78 procedures

\begin{tabular}{|l|c|c|c|c|c|}
\hline & SU & SR & SN & NST & $\begin{array}{c}\text { Rating per } \\
\text { event }\end{array}$ \\
\hline Pager & 3.67 & 4.1 & 0 & 1.50 & 2.31 \\
\hline Telephone & 2.50 & 0 & 1.00 & 2.07 & 1.39 \\
\hline Radio & 1.38 & 1.06 & 1.11 & 1.02 & 1.14 \\
\hline Door movement & 0 & 1.00 & 0 & 1.56 & 1.28 \\
\hline $\begin{array}{l}\text { Procedure-related } \\
\text { communication }\end{array}$ & 5.68 & 5.54 & 4.69 & 3.27 & 4.80 \\
\hline $\begin{array}{l}\text { Patient-irrelevant } \\
\text { communication }\end{array}$ & 4.95 & 4.17 & 4.02 & 3.67 & 4.20 \\
\hline $\begin{array}{l}\text { Medically irrelevant } \\
\text { communication }\end{array}$ & 5.55 & 6.00 & 4.34 & 3.28 & 4.79 \\
\hline Equipment & - & - & - & - & 4.97 \\
\hline
\end{tabular}

SU: sterile urologist, SR: sterile resident, SN: sterile nurse, NST: non sterile team member

\section{Interviews}

Eight urologists with at least five years of experience in unsupervised performance of endourological interventions and seven residents in two teaching hospitals were interviewed. The residents were in their third to sixth year of the six-year urology program.

\section{Sources of distraction}

Both urologists and residents said that distractions mostly involved equipment not being at hand or failing, case-irrelevant communication surrounding the sterile field and having to respond to questions about another case. Music was considered to be distracting by only two interviewees and some found it helpful in relieving stress. One urologist said: 
"Emptiness of water supply and malfunctioning of the resectoscope often results in disruption of the surgical process. On the other hand, distractions like good music can contribute to a good work environment, which has a positive impact on performance."

Situations in which distraction is the most annoying

All interviewees reported being the most annoyed when they were distracted during difficult and stressful situations requiring high levels of concentration. Urologists and residents believed they were better able to deal with distractions during routine procedures without problems. Consequently, $87 \%$ of the interviewees thought distraction impacted residents more strongly than experienced urologists, as one interviewee said:

"Experienced urologists compared to residents are more in control when unexpected difficulties occur. They are better able to influence the environment to optimize the working climate."

Four urologists and one resident said that individual characteristics of residents and urologists had an important effect on the degree to which distractions affected performance.

Impact of distraction on level of performance

All interviewees stated that distraction could have a negative effect on the quality of surgical performance. However, none of them thought interruptions during a procedure compromised patient outcomes although they could slow performance and result in secondary tasks. As one of the residents put it:

"Distracting events that irritate me can affect my level of performance negatively. On the other hand, when I am aware of being distracted, I ask for silence in the OR. I don't think there is a negative effect for the patient".

\section{Need for restrictions}

The vast majority of the participants stated that distracting stimuli should be minimized in the OR. According to $87 \%$ of the participants it is mainly the responsibility of the urologist or resident performing the procedure to create an optimal environment by asking for silence when they are being distracted. However, as one resident stated:

"It depends on the relationship between resident and supervisor how free you feel to make comments on things like distraction during a procedure". 
A protocol with measures to reduce disturbance, such as reducing door movements, removing pagers from the $\mathrm{OR}$ and implementing a code of conduct were mentioned as measures to create an optimal work environment.

Usefulness of preparation in a skills lab

On this point there was no consensus. None of the residents and only two of the urologists saw a benefit of training in distracting circumstances outside the OR to prepare for real performance in the OR. However, the majority of participants (73\%) thought training in technical skills in a skills lab was good preparation for real-time surgery. In this way, routine performance is attained faster, which results in diminished susceptibility to distracting events in the OR. Others were sceptical about skills lab training since not all circumstances can be simulated. One urologist said:

"Specific training of skills could be indirectly useful as a preparation to perform in a distracting environment but it is not possible to prevent all distracting events."

\section{DISCUSSION}

Distraction has a proven negative impact on performance and human safety outside medicine and also on surgical tasks in experimental settings. ${ }^{3-5,9,10,12}$ In this study the impact of distraction and interruption on endourological procedures was investigated by measuring the frequency and impact of distraction and interruptions in one OR and by exploring the perceptions of urologists and residents. Distraction occurred at a mean frequency of once every 1.8 minutes. Equipment problems, procedure-related communication, patient-irrelevant communication and medically irrelevant communication have the strongest impact on the flow of the operation. Door openings and pagers occurred very frequently but did not in the least distract the sterile team. This is consistent with the results of the interviews. Both urologists and residents believe that distractions are less disturbing if the difficulty of the endourological task lies within their range of technical skills as compared to more challenging procedures. They also unanimously conclude from this that the effect of distracting stimuli is stronger in residents who are in their learning curve. This is supported by an in vitro study by Hsu et al., in which performance of experienced surgeons, in contrast to novices' performance, was not affected by cognitive distraction. This may be due to the fact that experienced surgeons have attained a level of automatic task performance that is impervious to distractions. ${ }^{9}$ This suggests that training technical skills to a high level of performance outside the OR could minimize the effect of distraction on performance during real-time surgery. However, in the interviews only two urologists thought 
preparation in a skills lab could be useful for diminishing susceptibility to distracting events in the OR.

OR personnel outside the sterile team are the most frequent sources of distraction due to communication, whether it is procedure-related, patient-irrelevant or medically irrelevant. All but two of the interviewees said it was the responsibility of the urologist to deal with distracting events. This means that the main surgeon should ask for silence when this is appropriate. For residents this can be more difficult than for urologists since interpersonal relationships and hierarchical structure determine to what degree they can influence the environment. Awareness of the presence of distracting stimuli and their potentially negative effect on the flow of procedures is therefore an important factor in dealing with distraction. As a first step, a protocol of restrictive measures to prevent distractions seems inevitable.

Pluyter et al. refer to the more complex environment in the OR during procedures involving multidimensional information technologies (IT), such as minimally invasive surgery. This may put extra physical and cognitive demands on the medical staff and cause errors. ${ }^{10}$ The hypothesis that dense IT usage is a source of distraction is supported by our study because we found that equipment problems were one of the main sources of distraction that could interrupt endourological procedures, in which more equipment and technology is used compared to open surgery.

Not all potentially distracting stimuli seem to have a negative effect on surgical procedures. ${ }^{14,15}$ Ullmann et al. evaluated the perceptions of physicians and nurses working in the OR with respect to the influence of music. Sixty-three percent of the responders believed that music had a positive effect on communications among staff, and $77 \%$ reported that music had a calming effect and made them more efficient. ${ }^{8}$ Moorthy et al. concluded that surgeons can "block out" noise and music due to the high levels of concentration required for complex surgical tasks. ${ }^{16}$ Our results support this notion since only 2 of 15 participants thought music was distracting in certain situations. However, there is an important difference between a potentially distracting factor like background music and cognitive distraction caused by conversations. Findings in the field of cognitive psychology have shown that simultaneous performance of two or more tasks can slow execution times and increase errors compared to single task performance. This notion is referred to as multi task interference and should be minimized. ${ }^{17,18}$

\section{Limitations of the study}

A limitation of the qualitative observation method used in this study is dependence on observers' ability to interpret events accurately and the possibility of variation between 
observers. Observers may identify and interpret events differently and may be biased. We therefore used two observers and made sure that acceptable inter observer agreement had been reached (80\%) before we allowed one observer to conduct observations on his own. Limitations of semi-structured interviews should also be considered. Although we processed the data anonymously, it cannot be ruled out that interviewees were biased and gave socially desirable answers, especially when they had been observed and had been involved in distractions during observation. In order to counter this effect we also interviewed surgeons in another teaching hospital who had not participated in the observational part of the study. The absence of meaningful differences between the two groups of interviewees suggests that there was little or no bias due to observation or to differences in organizational structure between the two hospitals.

\section{Recommendations for further research}

Horberry et al. determined that in-vehicle tasks impaired several aspects of driving performance and safety. ${ }^{19}$ In our study we observed no serious intraoperative complications that could be attributed to interruptions. However, our main focus was on distracting stimuli. Patient outcome is determined by complex interactions of many factors. It would therefore require larger numbers of procedures with standardized observation methods, for example video recordings, to further study the direct effects of distraction on patient safety.

We observed only endourological procedures in order to standardize the protocol. Further research should investigate distracting stimuli in laparoscopic and open surgery. More importantly, a protocol of measures in and outside the OR should be implemented and examined to minimize the effect of distraction on the performance of surgeons.

\section{CONCLUSION}

Distracting events are a frequent occurrence in the endourological OR. Equipment problems, procedure-related and medically irrelevant communication have the strongest impact on the sterile team and regularly interrupt procedures. Distracting stimuli are conceived as influencing performance negatively and should be minimized in the OR. Further research is required to determine any direct effect of distraction on patient safety.

\section{Acknowledgments}

The authors would like to thank Mereke Gorsira for her editorial assistance. 


\section{REFERENCES}

1. Hall JC, Ellis C, Hamdorf J. Surgeons and cognitive processes. Br J Surg 2003:90:10-6.

2. Kohls-Gatzoulis JA, Regehr $\mathrm{G}$, Hutchison $\mathrm{C}$. Teaching cognitive skills improves learning in surgical skills courses: a blinded, prospective, randomized study. Can J Surg 2004:47:277-83.

3. Forster S, Lavie N. Failures to ignore entirely irrelevant distractors: the role of load. J Exp Psychol Appl 2008:14:73-83.

4. McEvoy SP, Stevenson MR, McCartt AT, Woodward M, Haworth C, Palamara P. Role of mobile phones in motor vehicle crashes resulting in hospital attendance: a case-crossover study. BMJ 2005:331:428.

5. McEvoy SP, Stevenson MR, Woodward M. The contribution of passengers versus mobile phone use to motor vehicle crashes resulting in hospital attendance by the driver. Accid Anal Prev 2007: 39:1170-6.

6. Healey AN, Primus CP, Koutantji M. Quantifying distraction and interruption in urological surgery. Qual Saf Health Care 2007:16:135-9.

7. Primus CP, Healey AN, Undre S. Distraction in the urology operating theatre. BJU Int 2007:99: 493-4.

8. Ullmann Y, Fodor L, Schwarzberg I, Carmi N, Ullmann A, Ramon Y. The sounds of music in the operating room. Injury 2008:39:592-7.

9. Hsu KE, Man FY, Gizicki RA, Feldman LS, Fried GM. Experienced surgeons can do more than one thing at a time: effect of distraction on performance of a simple laparoscopic and cognitive task by experienced and novice surgeons. Surg Endosc 2008:22:196-201.

10. Pluyter JR, Buzink SN, Rutkowski AF, Jakimowicz JJ (2009) Do absorption and realistic distraction influence performance of component task surgical procedure? Surg Endosc [Epub ahead of print]

11. Mays N, Pope C. Qualitative research: Observational methods in health care settings. BMJ 1995; 15:182-4.

12. Mudford OC, Taylor SA, Martin NT. Continuous recording and interobserver agreement algorithms reported in the Journal of Applied Behavior Analysis (1995-2005). J Appl Behav Anal 2009: 42:165-9.

13. Britten N. Qualitative interviews in medical research. BMJ 1995:22:251-3.

14. Liu EH, Tan S. Patients' perception of sound levels in the surgical suite. J Clin Anesth 2000:12: 298-302.

15. Schneider AJ, Biebuyck JF. Music in the operating-room. Lancet 1990:9:1407.

16. Moorthy K, Munz Y, Undre S, Darzi A. Objective evaluation of the effect of noise on the performance of a complex laparoscopic task. Surgery 2009136:25-30.

17. Levy J, Pashler H. Is dual-task slowing instruction dependent? J Exp Psychol Hum Percept Perform 2001:27:862-9.

18. Meyer DE, Kieras DE. A computational theory of executive cognitive processes and multiple-task performance: Part 1. Basic mechanisms. Psychol Rev 1997:104:3-65.

19. Horberry T, Anderson J, Regan MA, Triggs TJ, Brown J. Driver distraction: the effects of concurrent in-vehicle tasks, road environment complexity and age on driving performance. Accid Anal Prev 2006:38:185-91. 



\title{
CHAPTER 6
}

\section{The influence of distraction on the performance of endourological tasks: a randomised controlled trial}

\author{
Marjolein C. Persoon \\ Kim van Putten \\ Arno M.M. Muijtjens \\ J. Alfred Witjes \\ Ad J.M. Hendrikx \\ Albert J.J.A. Scherpbier
}




\section{SUMMARY}

\section{Objective}

- To establish the effect of distraction on the performance of cystoscopy and basic endourological tasks on a virtual reality simulator.

\section{Subjects and Methods}

- A total of 86 third-year medical students from Maastricht University who had had no previous experience in performing the tasks on the virtual reality (VR) simulator, were randomly assigned to the intervention or control group.

- All participants performed three endourological tasks on the VR simulator. Participants in the intervention group were distracted 1 minute into the third task. The distraction consisted of being asked to answer questions about a medical case that had been presented to all the participants before the hands-on session. After two adequate verbal responses the conversation was terminated.

- Number of traumata, number of missed lesions in the bladder and time to completion were measured by the VR simulator.

\section{Results}

- Number of traumata and missed lesions as well as time to completion were significantly higher in the intervention than in the control group with effect sizes (using Cohen's categorization) of $0.48,0.41$ and 0.50 respectively.

- Nevertheless, only $9.5 \%$ of the participants in the intervention group reported feeling burdened by the distraction.

\section{Conclusions}

- Distraction during the performance of endourological skills resulted in significantly poorer performance by medical students on all the variables measured in a controlled learning environment.

- Most students did not realize they are affected by distraction.

- Further research is needed to determine the impact of distraction on more experienced participants and on patient safety. 


\section{INTRODUCTION}

Besides knowledge of procedures and psychomotor skills, multiple factors and skills influence the performance of surgeons and junior doctors in the operating theatre. ${ }^{1,2}$ These factors include the degree of motivation, lack of sleep, variability of patient pathology and the learning environment. The prevailing training method follows the traditional apprenticeship model of "see one, do one, teach one." However, ethical, practical and legal objections have been raised to this approach. Educators are therefore exploring other training formats, such as simulators made from different types of material on which trainees can practise skills without putting patients at risk. ${ }^{3,4}$ Virtual reality (VR) simulators have been and are being developed and evaluated for their usefulness and realism. Prior studies have shown a positive relationship between training on virtual reality models and enhanced performance of procedures..$^{5-9}$ Furthermore, appropriately validated VR simulators can facilitate objective assessment of performance and exploration of factors that influence performance.

Distraction is one of the factors that can potentially influence doctors' performance in the operating theatre. It can be defined as any event that diverts attention away from the task in hand. Studies have shown that distractions and interruptions are not unusual in theatre. The most common distractions are non-patient related conversations, telephone calls, beepers going off, music, and persons entering the operating theatre..$^{10-12}$ In daily life, distractions have been proven to have a negative effect on the concentration and safety of pedestrians and drivers. ${ }^{13-15}$ Because of the complexity of urological procedures, we hypothesise that distractions have a negative effect on the performance of procedures by urologists and junior doctors. In comparison with other professional fields, like aviation and traffic, urology and surgery have seen few studies of the impact of distractions on performance. Hsu et al. reported a negative effect of distraction on the performance of a peg transfer task on a box trainer in basic laparoscopic skills training. This effect was larger in the novice group than in the expert group. ${ }^{16}$ Ethical dilemmas, however, are a barrier to performing studies of the real-time effects of distractions during procedures in patients. Where other studies have focused on the occurrence of distractions and interruptions, we sought to gain more insight into the effects of distraction on performance of basic urological tasks in a controlled condition that closely resembled real-time procedures. In a prospective, intervention blinded, randomised study we aimed to answer the following research question: what is the effect of distraction on the performance by novices of cystoscopy and basic endourological tasks on a VR simulator? 


\section{SUBJECTS AND METHODS}

Third-year medical students from the Faculty of Health, Medicine and Life Sciences of Maastricht University, who had recently started initial clinical training at the Maastricht University Medical Centre (MUMC), were invited to participate in the study on a voluntary basis. Participants who had used the Uromentor VR simulator before the study were excluded. None of the participants had ever performed a cystoscopy. Written informed consent was obtained from all the participants and permission for the study was obtained from the institutional ethics committee. Participants were informed that the objective of the study was to gain more insight into learning processes during training with the Uromentor. This was done to ensure that the participants were blinded to the actual intervention.

We randomised a total of 86 participants to the intervention or control group using www. randomization.com. We used the original randomisation generator which randomises each subject to a single treatment. Permuted block randomisation was applied using three blocks amounting to 30,30 , and 26 subjects, respectively. The participants watched a 20-minute introductory video showing a urologist performing a cystoscopy in a real patient. Subsequently, all participants performed three basic tasks on the Uromentor: a structured cystoscopy (task 1), extracting a bladder stone (task 2) and a combination of extracting three bladder stones and a structured cystoscopy (task 3). The students were instructed to take snapshots of seven animated flowers in the bladder, indicating lesions that had to be inspected (task 3). Contrary to the control group, the students in the intervention group were distracted one minute after commencing the third task. The distraction consisted of a person asking questions about a patient case that had been presented in written form to all the participants prior to the hands-on training session, and which the participants had studied for three minutes. The conversation continued until two adequate responses had been obtained. We created the distraction for this study and aimed to simulate a real-life situation in which dual-tasking is expected. Five different versions of a basic urological patient case were used to prevent participants from learning about the case from previous participants. The questions were also presented to the participants in the control group after the training session in order to prevent disclosure of the objective of the study, which would reduce the reliability of the study. The study protocol is summarised in figure 1. To standardise the protocol, the same person assisted (flushing and handling the grasping instrument on demand) and distracted the participants. The protocol had been optimised during a pilot study with 12 participants, who were not included in the study. 
Figure 1. Summarized study protocol

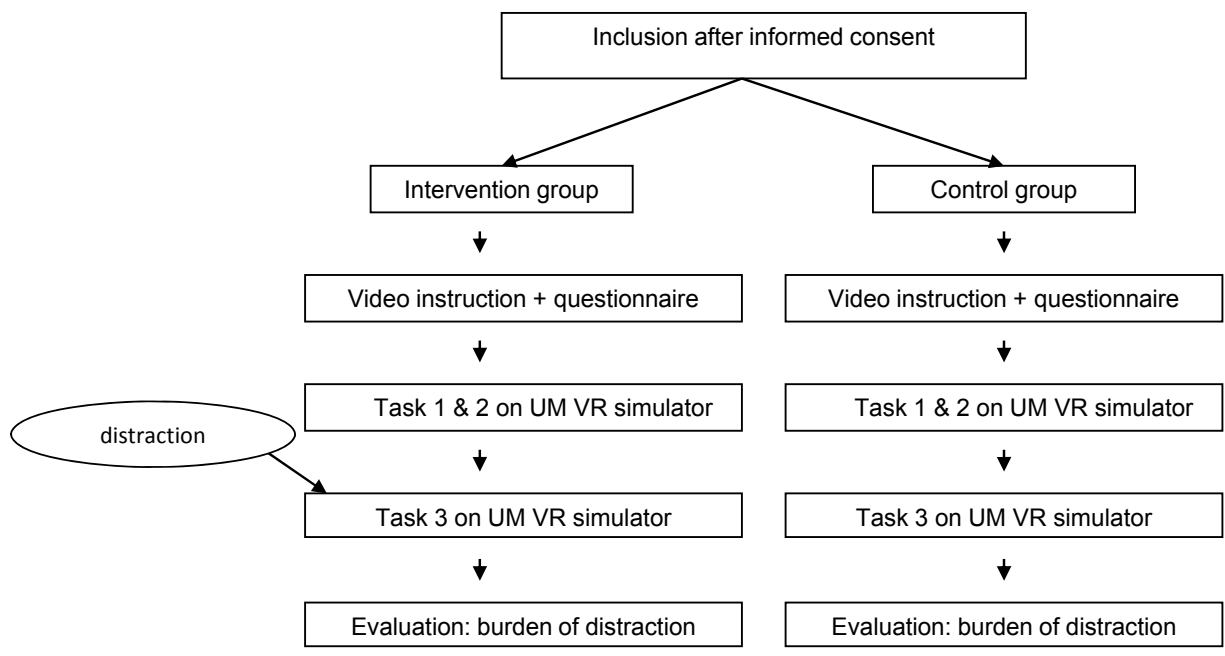

\section{Performance variables}

The three tasks were performed on the Uromentor (Simbionix ${ }^{\circledR}$, Israel), which is a computerized VR simulator which simulates flexible and (semi) rigid ureterorenoscopy. It was previously investigated in other studies and has shown to effectively discriminate

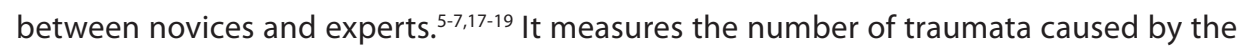
cystoscope or additional tools as well as completion time. In addition, it records snapshots of the animated flowers in the bladder. A missed snapshot was scored as a missed lesion. The measurements of these variables during task 3 were used as performance indicators.

A questionnaire was administered before the training session to collect demographic data. After the training session, all participants answered a yes-no question, inquiring if they had felt burdened by any distraction.

\section{Sample size calculation}

We conducted a priori power analysis using G*Power version 3.0.3 with 80\% power and a selected value of a (the probability level of a Type I error) of 0.05 . We estimated that 75 participants were needed to detect medium to large effects on different outcome variables. 


\section{Data analysis}

Our main aim was to investigate whether the performance variables were affected by the intervention. As gender had been identified as a possible confounder and/or moderator variable, we analysed the effect of the intervention using Intervention, Gender and Gender*Intervention (interaction term) as independent variables in a stepwise regression procedure. For ease of interpretation, Intervention and Gender were defined as 0-1 variables. Intervention: control group 0, intervention group 1; Gender: male 0, female 1. Three performance variables were used as dependent variables: Completion time, Number of traumata and Number of lesions missed. Because we expected Number of traumata to have a skewed distribution, we used a logarithmic transformation of this variable in the analysis: Log(Number of traumata). Because of the limited outcome values $(<8)$ of Number of lesions we transformed this discrete variable into the $0-1$ variable Lesion missed, with 0 indicating no lesion missed and 1 indicating at least one lesion missed. A stepwise logistic regression procedure was applied to investigate the effect of the distraction on Lesion missed. The log-odds of having missed one or more lesions, log(Prob(lesion missed)/Prob(no lesion missed), was expressed as a linear model of the independent variables. For such a model the effect of an independent variable represents the change in odds due to a change of one in the independent variable. As all the independent variables in the current study are $0-1$ variables, this effect amounts to the change in odds between groups ' 1 ' and ' 0 '.

For the linear regression the significance of an effect was obtained by applying a ttest, where for logistic regression a Wald test was applied. For the linear regression the standard regression coefficient is presented as an indicator of the effect size, and for the logistic regression, Nagelkerke's R was used to indicate effect size. For both indicators Cohen's categorisation of correlation-like effect sizes was used, i.e. effect sizes of 0.10 , 0.30 , and 0.50 indicate small, moderate, and large effects, respectively. ${ }^{20}$

Because the logistic procedure did not converge due to the rare occurrence of experienced burden due to a disruption, we investigated the effect of the intervention on this variable by applying a Fisher exact test to the $2 \times 2$ frequency table of Experienced burden of disruption (0.1) versus Intervention (1.0). A significant result indicates that the probability of Experienced burden of disruption is different in the Intervention group compared to the control group. Statistical analyses were performed using the Statistical Package for the Social Sciences (SPSS) version 15.0. 


\section{RESULTS}

For the analysis of the pilot study we used data of ten participants. Two participants did not finish the protocol due to clinical obligations. During the pilot study we changed the 'basket' in the 'alligator grasper' as the tool of choice in the UM to remove the bladder stones in task three. The reason for this was a flickering image of the basket when it opened to grasp a stone. This effect was not present in all cases and we were unable to determine the cause, even after contacting the simulator's developer. The alligator grasper was consistent in use and therefore chosen for the actual study. Mean time to completion was 25 minutes for the intervention group and 18 minutes for the control group. Also the mean number of traumata and missed lesions were higher in the intervention group ( 26 vs 14 and 0.2 vs 0 ). Two participants in the intervention group reported experiencing burden due to distraction compared to no participants in the control group.

For the final analysis we used data of 82 participants. Four participants, two in each group, were unable to complete the protocol because they almost fainted. Demographics are shown in table 1 . Since none of the (logistic) regression analyses showed confounding or moderating effects of gender, the presentation of the results is restricted to the overall effect of the distraction. Table 2 shows the effects of distraction on the performance variables of the Uromentor and the experienced burden due to disruption. Time to completion, number of traumata, and the odds of missing a lesion were all significantly higher in the intervention group than in the control group. The corresponding effect sizes were moderate to large: 0.50 for time to completion, 0.48 for number of traumata and 0.41 for missed lesions. These results indicate that the performance of the participants who had been distracted was significantly lower than that of the non-

Table 1: Demographics of participants

\begin{tabular}{|c|c|c|}
\hline Demographics & $\begin{array}{l}\text { Intervention group } \\
\qquad(n=42)\end{array}$ & $\begin{array}{l}\text { Control group } \\
(n=40)\end{array}$ \\
\hline \multicolumn{3}{|l|}{ Gender, n (\%) } \\
\hline Male & $11(26 \%)$ & $16(40 \%)$ \\
\hline Female & $31(74 \%)$ & $24(60 \%)$ \\
\hline Age in years, mean (SD) & $21.0(1.0)$ & $21.9(4.0)$ \\
\hline \multicolumn{3}{|l|}{ Hand dominance, n (\%) } \\
\hline Left & $8(19 \%)$ & $2(5 \%)$ \\
\hline Right & $32(76 \%)$ & $36(90 \%)$ \\
\hline Two-handed & $2(5 \%)$ & $2(5 \%)$ \\
\hline Surgical field of interest, n (\%) & $19(45 \%)$ & $24(60 \%)$ \\
\hline Previous experience on VR-simulators, n (\%) & $1(2 \%)$ & $2(5 \%)$ \\
\hline Sum of physical and mental state scores (SD) & $8.0(2.7)$ & $8.5(2.7)$ \\
\hline
\end{tabular}


Table 2. Effect of distraction on the performance variables of the Uromentor and on the experienced burden of disruption.

\begin{tabular}{|c|c|c|c|c|c|c|}
\hline \multirow{2}{*}{$\begin{array}{l}\text { Variable } \\
\text { Time to completion (in } 10^{3} \text { seconds) } \\
\text { mean (SD) }\end{array}$} & \multirow{2}{*}{$\begin{array}{c}\text { Control } \\
\text { group }\end{array}$} & \multirow{2}{*}{$\begin{array}{c}\text { Intervention } \\
\text { group } \\
1.42(0.3)\end{array}$} & \multicolumn{2}{|c|}{$\begin{array}{l}\text { Difference } \\
\text { Intervention } \\
\text { vs. Control }\end{array}$} & \multicolumn{2}{|c|}{ Effect size } \\
\hline & & & 0.32 & **1) & Beta & 0.50 \\
\hline $\begin{array}{l}\text { Log (number of trauma) mean (SD) } \\
\text { Corresponding number of trauma }\end{array}$ & $\begin{array}{c}1.13(0.17) \\
13.5\end{array}$ & $\begin{array}{c}1.33(0.20) \\
21.4\end{array}$ & $\begin{array}{c}0.20 \\
7.9\end{array}$ & ** & Beta & 0.48 \\
\hline Log-odds at least one lesion missed & 0.5 & 2.2 & $\begin{array}{c}4.6 \\
\text { (ratio) }\end{array}$ & * & Nagelkerke $\mathrm{R}$ & 0.41 \\
\hline Experienced burden of disruption & $0 \%$ & $9.5 \%$ & $9.5 \%$ & ns & & \\
\hline
\end{tabular}

1) indication statistical significance $p<0.001\left({ }^{* *}\right), p<0.05(*), p>0.05$ (ns)

distracted participants. Burden of disruption was not experienced by any participant in the control group and by only $9.5 \%$ of the participants in the intervention group.

\section{DISCUSSION}

We evaluated the effects of cognitive distraction during the performance of endoscopic urological tasks in a controlled situation. Distraction had a significant negative effect on all variables of the performance of novices as assessed by the VR simulator. Although their performance was clearly negatively affected, over $90 \%$ of the participants in the intervention group did not report experiencing any burden of disruption during the session.

We conducted an adequately powered randomised controlled trial. Third-year medical students, training in a university hospital, were included because they were a homogeneous group with respect to previous experience in performing urological skills and had had more extensive clinical experience compared to first- and second-year students. We chose questions requiring verbal responses as the distraction because of the similarity to daily practice and we used an extensively validated virtual reality simulator, which quite realistically simulates the anatomy of the bladder and endourological skills performance. The participants were novices in performing endourological procedures. As a consequence, the negative effects of distraction that we measured apply to individuals who are in their learning curve. However, the tasks required basic endourological skills and the level of difficulty was adjusted to the participants' level of experience.

One of the researchers guided the participants during the protocol. This researcher was not blinded to the intervention and could therefore potentially cause bias. However, we 
used only data that had been measured objectively by the software of the Uromentor. Furthermore, prior to the study, we had standardised the protocol and the guidance by the researcher in a pilot study among ten participants who did not participate in this study. In this way, it was ensured that conditions were identical for all participants. In the pilot study as well, the participants who were distracted performed less well than the control group. Data of four participants were excluded from the analysis because of missing data due to fainting. This could be interpreted as a sign of excessive stress, but this hypothesis did not correspond with the explanations of their fainting given by these participants. It seems unlikely that these events affected the results because they occurred in the same number of participants in both groups.

Healey et al. reported significant amounts of distraction and interrupting events in the operating theatre but not all were interpreted negatively. ${ }^{10}$ Similarly, Moorthy et al. concluded that surgeons are able to "block out" noise and music, because of the high level of concentration required for complex surgical tasks ${ }^{21}$ In fact, music was experienced as a calming factor by $63 \%$ of the team in the operating theatre, while only $20 \%$ saw it as a distracting factor. ${ }^{11}$ However, a critical difference between a potentially distracting factor, like background music, and the cognitive distraction in this study is that the study participants were required to give a response. Results in studies in the domain of cognitive psychology have shown that simultaneous performance of two or more tasks can slow execution times and result in more errors than when tasks are performed separately. This is referred to as multi-task interference. ${ }^{22,23}$ In daily life also, distraction has been proven to lead to more accidents and errors. ${ }^{24,25}$ The results in our study appear to be consistent with these findings. Endoscopic procedures require performance of complex manual tasks in combination with decision making, interpretation of findings and sustained high levels of concentration. This can be interpreted as a dual task interference scenario in which a surgeon has to carry out both psychomotor and cognitive tasks. ${ }^{26} \mathrm{Few}$ studies have examined the effects of distracting factors on the performance of surgical procedures. Hsu et al. reported a negative effect of distraction on performance of a peg transfer task on a box trainer for basic laparoscopic skills. This effect was larger in the novice group than in the expert group. This is in line with results from earlier studies, which generally found that effects of task interference on performance were severe during learning periods but could be reduced by practice. Nevertheless, such effects cannot be completely eliminated. ${ }^{22,27}$ To our knowledge no adequately powered study has been performed to assess the effect of cognitive distractions on the performance of endourological procedures.

It is of concern that only $9.5 \%$ of the participants in the intervention group felt burdened by the distraction, while objective measurements clearly showed that their performance 
was significantly worse compared to that of the control group. Apparently, without objective measurements, self-assessment of performance is unreliable. It is important for clinicians to be aware that distractions can affect their own performance as well as that of their trainees. Especially in situations demanding high levels of concentration, such as surgical procedures, sources of distraction should be minimised to optimise patient outcomes. Our finding that the participants in the intervention group were not aware of any distraction complicates matters still further and demands further study. We arranged a cognitive distraction for the participants in the intervention group by asking them to answer questions during the hands-on training session. However, it is unclear how other types of distraction impact on surgical performance. Furthermore, the effects of potentially distracting events on the performance of more experienced professionals should be studied as well, in order to assure patient safety in the clinical setting. In the aviation industry, training environments with simulators that require handling more than one task at a time, have proven to be successful in improving performance outcomes. ${ }^{28}$ In view of the potentially severe negative impact of distraction during surgical procedures it is of critical importance to determine how medical professionals can be prepared to safely perform complex procedures on real patients in situations where they are exposed to various sources of distraction.

In conclusion, distraction during the performance of endourological skills led to significantly diminished performance on all measured variables in medical students in a controlled learning environment. Perhaps an even more critical finding of the study is that most of the students did not even notice the distraction. Further research should determine the effects of distractions in more experienced participants and on patient safety.

\section{Acknowledgements}

The authors would like to thank Mereke Gorsira for her editorial assistance. 


\section{REFERENCES}

1. Hall JC, Ellis C, Hamdorf J. Surgeons and cognitive processes. Br J Surg 2003; 90: 10-6.

2. Kohls-Gatzoulis JA, Regehr G, Hutchison C. Teaching cognitive skills improves learning in surgical skills courses: a blinded, prospective, randomized study. Can J Surg 2004; 47:277-83.

3. Sachdeva AK, Bell RH, Jr., Britt LD, Tarpley JL, Blair PG, Tarpley MJ. National efforts to reform residency education in surgery. Acad Med 2007; 82: 1200-10.

4. Smith AJ, Aggarwal R, Warren OJ, Paraskeva P. Surgical training and certification in the United kingdom. World J Surg 2009; 33: 174-9.

5. Matsumoto ED, Pace KT, D'A Honey RJ. Virtual reality ureteroscopy simulator as a valid tool for assessing endourological skills. Int J Urol 2006; 13: 896-901.

6. Michel MS, Knoll T, Kohrmann KU, Alken P. The URO Mentor: development and evaluation of a new computer-based interactive training system for virtual life-like simulation of diagnostic and therapeutic endourological procedures. BJU Int 2002; 89: 174-7.

7. Schout BM, Muijtjens AM, Hendrikx AJ, Ananias HJ, Dolmans VE, Scherpbier AJ, et al. Acquiring flexible cystoscopy skills on a virtual reality simulator by experts and novices. BJU Int 2009; [Epub ahead of print].

8. Seymour NE. VR to OR: a review of the evidence that virtual reality simulation improves operating room performance. World J Surg 2008; 32: 182-8.

9. Shah J, Darzi A. Virtual reality flexible cystoscopy: a validation study. BJU Int 2002; 90: 828-32.

10. Healey AN, Primus $C P$, Koutantji M. Quantifying distraction and interruption in urological surgery. Qual Saf Health Care 2007; 16: 135-9.

11. Ullmann Y, Fodor L, Schwarzberg I, Carmi N, Ullmann A, Ramon Y. The sounds of music in the operating room. Injury 2008; 39: 592-7.

12. Primus CP, Healey AN, Undre S. Distraction in the urology operating theatre. BJU Int 2007; 99: 493-4.

13. McCartt AT, Hellinga LA, Bratiman KA. Cell phones and driving: review of research. Traffic Inj Prev 2006; 7: 89-106.

14. Nasar J, Hecht P, Wener R. Mobile telephones, distracted attention, and pedestrian safety. Accid Anal Prev 2008; 40: 69-75.

15. Strayer DL, Drews FA, Crouch DJ. A comparison of the cell phone driver and the drunk driver. Hum Factors 2006; 48: 381-91.

16. Hsu KE, Man FY, Gizicki RA, Feldman LS, Fried GM. Experienced surgeons can do more than one thing at a time: effect of distraction on performance of a simple laparoscopic and cognitive task by experienced and novice surgeons. Surg Endosc 2008; 22: 196-201.

17. Gettman MT, Le CQ, Rangel LJ, Slezak JM, Bergstralh EJ, Krambeck AE. Analysis of a computer based simulator as an educational tool for cystoscopy: subjective and objective results. J Urol 2008; 179: 267-71.

18. Gettman MT, Le CQ, Rangel LJ, Slezak JM, Bergstralh EJ, Krambeck AE. Development of a standardized curriculum for teaching cystoscopic skills using a computer-based endourologic simulator. Simul Healthc 2009; 4: 92-7.

19. Shah J, Montgomery B, Langley S, Darzi A. Validation of a flexible cystoscopy course. BJU Int 2002; 90: 833-5.

20. Hojat $M, X u$ G. A visitor's guide to effect sizes: statistical significance versus practical (clinical) importance of research findings. Adv Health Sci Educ Theory Pract 2004; 9: 241-9. 
21. Moorthy K, Munz Y, Undre S, Darzi A. Objective evaluation of the effect of noise on the performance of a complex laparoscopic task. Surgery 2004; 136: 25-30.

22. Levy J, Pashler H. Is dual-task slowing instruction dependent? J Exp Psychol Hum Percept Perform 2001; 27: 862-9.

23. Meyer DE, Kieras DE. A computational theory of executive cognitive processes and multiple-task performance: Part 1. Basic mechanisms. Psychol Rev 1997; 104: 3-65.

24. Forster S, Lavie N. Failures to ignore entirely irrelevant distractors: the role of load. J Exp Psychol Appl 2008; 14: 73-83.

25. McEvoy SP, Stevenson MR, McCartt AT, Woodward M, Haworth C, Palamara P, et al. Role of mobile phones in motor vehicle crashes resulting in hospital attendance: a case-crossover study. BMJ 2005; 331: 428.

26. Kahol K, Vankipuram M, Smith ML. Cognitive simulators for medical education and training. J Biomed Inform 2009; 42: 593-604.

27. Ruthruff E, Hazeltine $\mathrm{E}$, Remington RW. What causes residual dual-task interference after practice? Psychol Res 2006; 70: 494-503.

28. Lee A. Flight simulation: virtual environments in aviation. Hampshire, England: Ashgate Publishing; 2005. 



\title{
CHAPTER 7
}

\section{Learning curves in laparoscopic radical prostatectomy: When is proficiency reached?}

\author{
Marjolein C. Persoon \\ Ad J.M. Hendrikx \\ Evert L. Koldewijn \\ Irene M. Tjiam \\ Eric J.E.J. Vrijhof \\ J.Alfred Witjes \\ Albert J.J.A. Scherpbier
}




\section{ABSTRACT}

\section{Objective}

The first step in defining procedural proficiency is to analyze learning curves and define the number of procedures required to arrive at a certain level of proficiency. We aimed to determine criteria to define when a laparoscopic radical prostatectomy (LRP) procedure can be considered technically successful or unsuccessful. We explored urologists' opinions and studied the literature to identify LRP learning curves and definitions of proficiency.

\section{Methods}

Based on an analysis of articles retrieved by a Medline search and the opinions of four urologists experienced in performing open (1) and laparoscopic (3) LRP, we constructed a list of potential adverse events during LRP or within one year postoperatively. Twenty urologists who routinely performed LRP were asked to rate the severity of the events. The results were the basis for a discussion among eight urologists aimed at establishing criteria for LRP proficiency.

\section{Results}

Of 248 articles retrieved, twenty met the inclusion criteria. The results of LRP procedures were most commonly described in terms of operating time, positive surgical margins (PSM), conversions, complications, and estimated blood loss (EBL). No study provided a clear definition of LRP proficiency. After two rounds of questionnaires, consensus was reached on the severity of 24 adverse events. A meeting of eight urologists led to consensus on a combination of events that could be used to define LRP as unsuccessful, but strong disagreement precluded the inclusion of five important events.

\section{Conclusions}

Neither the literature nor a survey and a meeting of urologists resulted in a clear definition of LRP proficiency. Continuation of the debate with participation of a large number of international urologists is of paramount importance for the further development of training programs and the setting of standards of care. 


\section{INTRODUCTION}

From the late nineties, the use of urological minimally invasive techniques has seen a rapid increase. ${ }^{1}$ Radical prostatectomy (RP) is the standard for the surgical treatment of localized prostate cancer, and it is increasingly performed laparoscopically. ${ }^{2-4}$ However, laparoscopic surgery requires other skills than open surgery, which necessitates the development of special training programs. ${ }^{5}$ There is also a growing need for training programs outside the operating theatre due to practical, ethical and legal objections to training in the operating room. ${ }^{6,7}$ In order to ensure patient safety and to develop and evaluate training programs, we need to know more about the learning curves of surgeons in performing laparoscopy. Multiple shapes of learning curves are possible for different procedures and individuals. ${ }^{8}$ The learning curve generally starts with a steep rise reflecting a rapid increase in skill and the curve mostly ends in a plateau phase. ${ }^{9}$ Subramonian proposed a reproducible, simple definition to quantify the surgical learning curve: 'The time taken and/or the number of procedures an average surgeon needs to be able to perform a procedure independently with a reasonable outcome. $^{10}$

Several institutions have described initial results for laparoscopic radical prostatectomy (LRP) and estimations of the learning curve vary between 50 and 300 procedures. ${ }^{11-15}$ Since multiple factors influence outcome measures and learning curves, analyzing learning curves and defining criteria for proficiency is a tough task. Defining criteria is both crucial and complicated. It requires answers to the questions: when are the results of a surgical procedure good enough? Which criteria and outcome measures should be used? We conducted a study to establish criteria for defining when a LRP procedure is considered to be technically successful or unsuccessful. We did so by exploring the opinions of urologists with laparoscopic and open RP experience and by examining the literature on LRP learning curves and definitions of proficiency.

\section{SUBJECTS AND METHODS}

\section{Literature search}

We searched the Medline database for studies describing the rising and plateau phases of LRP learning curves, and we examined how proficiency was defined in these studies. We used the search terms: proficiency OR learning OR learning curve AND prostatectomy and limited the search to human and adult studies. Other inclusion criteria were Englishlanguage articles published between January 1990 and July 2010 which described at least two measurements on the learning curve of individual surgeons and original 
articles on LRP without a robotic interface. The latter criterion was used to minimize the influence of different techniques on outcome results, as we feared that this would complicate the comparison between learning curves and outcome results of different studies. As our aim was to analyze learning curves and definitions of proficiency for LRP, studies comparing different techniques or reporting initial results without a description of learning curves were excluded.

\section{Expert opinion}

Four urologists from two teaching hospitals constructed a list of adverse events that can occur during LRP or within one year postoperatively. All urologists were familiar with the procedure. One of the urologists only used the laparoscopic approach (> 70 procedures) while the others mainly used open radical prostatectomy ( $>70$ procedures). The list was included in an electronic questionnaire, which we sent to twenty urologists who frequently performed laparoscopy. They were considered to be experts in laparoscopy in the Netherlands and frequently acted as faculty of laparoscopy courses for urologists in the Netherlands. After three weeks we emailed a reminder to the non-respondents. The questionnaire asked the participants to rate the severity of each event on an ordinal scale from 0 (trivial) to 3 (severe) (Figure 1). Additionally, the questionnaire collected data on the participants' experience in performing urological laparoscopic procedures, the number of LRP procedures performed annually, and their experience in performing LRP. We sent a similar questionnaire to thirty urologists who only performed open radical prostatectomy (open RP group) to identify any discrepancy between the opinions of urologists using different techniques.

Based on the answers, we categorized the events in three categories of increasing severity: Grade 1, Grade 2 and Grade 3. Grade 1 applied to events that were considered to be trivial or mild by at least $75 \%$ of the participants. Grade 2 included events that were rated as mild or moderate by at least $75 \%$, and an event was categorized as Grade 3 when at least $75 \%$ qualified it as moderate or severe.

A second questionnaire was sent to the urologists performing LRP (LRP group) asking them whether they agreed that the occurrence of two Grade 2 events or one Grade 3 event could be used to define an LRP procedure as unsuccessful. The definition was finalized in a group session with eight experts. 
Figure 1: Summary of the first questionnaire: For each item A-T participants indicated the severity of the event.

\section{In general, the severity of the event mentioned is:}

0: trivial 1: mild

2: moderate

3: severe

A A blood transfusion is needed.

B Injury of a major vessel requiring an extra intervention.

C During positioning of the trocars, the epigastric vessels are injured.

D 1. Operation time, including lymph node dissection is $>300$ minutes (measured from skin incision to skin closure).

2. Operation time, without lymph node dissection is $>240$ minutes.

E Conversion to an open procedure.

F Rectal injury which is sutured.

G Rectal injury resulting in a colostomy.

H Injury to the obturatory nerve.

I 1. Wound infection requiring placement of a drain.

2. Wound infection for which conservative methods are sufficient.

J 1. Urine leakage from the wound requiring an intervention (drain placement or reoperation).

2. Urine leakage from the wound which is handled conservatively.

K 1. An ileus or peritonitis occurs postoperatively necessitating reoperation.

2. An ileus which is handled conservatively.

L 1. A urethrovesical stricture requiring an operation.

2. A urethrovesical stricture not requiring an operation.

M 1. A lymphocele requiring an operation.

2. A lymphocele not requiring an operation.

N 1. Herniation on the trocar placement site requiring an operation.

2. Herniation on the trocar placement site not requiring an operation.

- Resection margins in T1-T2 operated tumors are positive.

P Resection margins are positive, prostate capsule is incomplete.

Q Resection margins are positive: the intention was nerve sparing surgery; the patient has maintenance of erectile function.

$\mathbf{R}$ Resection margins are positive: the intention was nerve sparing surgery; the patient has lost erectile function.

S After 12 months the patient has urine incontinence requiring daily use of pads

T A hydronephrosis due to a suture (partly) in the ostium.

\section{RESULTS}

\section{Literature}

We retrieved a total of 248 articles. After reading the titles and abstracts we selected 32, of which we read the full text. This resulted in inclusion of twenty articles. ${ }^{11,16-34}$ 


\section{Outcome measures}

The most common outcome measures that were used to describe the results of LRP procedures were operating time, positive surgical margins (PSM), conversions, complications, and estimated blood loss (EBL). ${ }^{11,17-20,23-31,34}$ One article used biochemical cancer recurrence as the main outcome measure. ${ }^{33}$ Baumert et al. used PSM as the main outcome measure and described the learning curve for PSM. ${ }^{16}$ Ferguson et al. described a learning curve using time as the main outcome measure. ${ }^{21}$ One study also included patients' postoperative quality of life. ${ }^{27}$

\section{Time}

Poulakis et al. reported that an operating time of 3-4 hours was reached after 15 cases, while Tse et al. reported a decrease in mean operating time from 4.4 hours in the first 100 procedures to 3.3. hours in the second 100 procedures. ${ }^{32,35} \mathrm{~A}$ significant decrease in time after 20 procedures (from 9.9 to 5.1 hours) was described by Reham et al. ${ }^{27}$ In an analysis of fifty procedures, Ferguson et al. found a significant decrease in time between the first 10 and the fourth 10 procedures (4.5 vs. 4.0 hours). ${ }^{21}$ Ghavamian described a significant decrease after 10 procedures (from 6.9 to $4.7 \mathrm{~h}$ in the second 10 procedures) and reported that a plateau was reached after 35 procedures with a mean operating time of 4 hours or less. ${ }^{22}$ Brown et al. found no decrease in time over 32 procedures, and Hellawell et al. also reported no significant decrease in the mean operating time of 3.8 hours during the first 50 procedures. ${ }^{18,23}$

\section{Positive surgical margins}

In an analysis of 100 cases, Baumert et al. found a significant decrease in procedure time and the rate of multiple PSMs in the second 50 procedures. ${ }^{16}$ El Feel et al. reported an occurrence rate of PSM of $19 \%$ for surgeons who had performed over 100 LRPs, while for junior surgeons ( $<30$ cases performed) the rate was $34 \%$ in 38 cases. ${ }^{20}$ Rehman et al. reported a PSM rate of 20 to $22 \%$ after the first 10 cases. ${ }^{27}$ In another series, the PSM rate decreased from 19 to $15 \%$ over 350 cases. ${ }^{34}$ Rodriquez described a decrease in PSM to $11.5 \%$ after 200 cases in pT2a-c tumors. ${ }^{28}$

\section{Conversions}

In an analysis of 114 cases, Martina et al. found only two conversions in the first ten procedures. $^{24}$ In 350 procedures, described by Guillonneau, no conversion occurred after seventy cases. ${ }^{34}$

\section{Proficiency}

The studies used very diverse outcome measures and gave no clear definition of proficiency. They all referred to other series published in literature, and some compared data 
of trainees with those of mentors or surgeons, who were considered proficient. ${ }^{11,17,29-31}$ Several studies stated the number of procedures required to reach certain outcome measures. According to Blana et al. 25 procedures were required to achieve comfort and to rotate operation teams. ${ }^{17}$ Stolzenburg et al. set up a modular training scheme and found that 32-43 procedures sufficed for participating trainees to achieve competent performance..$^{30,31}$ Skrekas et al. described 44 cases, performed by a mentor and a trainee. The trainee performed the last 28 procedures with no decrease in time. The mentor's mean operative time was significantly shorter than that of the trainee. Two learning curves were identified for operating time: one to reach safety and one for efficiency of performance..$^{29}$ Eden et al. demonstrated that time, EBL, number of complications, and incontinence rates stabilized at 150-200 procedures, but estimated that 700 procedures were needed for potency. ${ }^{19}$ Vickers et al. retrospectively analyzed biochemical recurrence and concluded that little learning took place before 250 procedures. ${ }^{33}$

\section{Expert opinion}

Twelve urologists of the LRP group (60\%) responded to the initial questionnaire (Figure 1). Their mean number of years of experience in laparoscopic urological surgery was 8.8 years and the mean number of LRPs performed during their career as a urologist was 329. Of the group who performed only open RPs, thirteen urologists (43\%) responded.

Table 1 shows the results of the categorization of the responses of both groups of urologists. Neither group showed consensus of opinion on all items. There were no clear biases or differences in judgment between the groups with regard to what was considered a successful procedure. Since LRP was the focus of our study we continued the study with only the LRP group.

On items $\mathrm{E}$ (conversion to an open procedure) and $\mathrm{Q}$ (positive resection margins: intention was nerve sparing and maintenance of erectile function, Figure 1), the opinions differed too much to enable categorization based on $\geq 75 \%$ consensus. These items were therefore excluded from the analysis, but ways will have to be found to achieve consensus in the future. The results and the categories were sent to the participants with a second questionnaire, in which they were asked whether they agreed with the definition of an unsuccessful LRP as a procedure in which at least two events from the moderate category or one event from the severe category occurred. The opinions of the eight urologists who responded varied: three experts agreed, four disagreed and one did not answer the question. We discussed the results of the second questionnaire in a face-to-face group session with eight LRP experts. No consensus was reached on the items relating to PSM, but consensus on the categorization was reached for the remaining items, and the participants agreed on a definition of an unsuccessful LRP as one in which two Grade 2 or one Grade 3 event occurred. The final categorization is summarized in Table 2. 
Table 1: Responses of all participants who routinely perform LRP or open RP. Items are categorized as Grade 1, 2 or 3 according to level of severity. Only items on which $>75 \%$ consensus was reached by the participants were categorized.

\section{Event}

\section{A lymphocele not requiring an operation.}

A blood transfusion is needed.

Wound infection requiring placement of a drain (or opening of the wound for an open RP).

During positioning of the trocars, the epigastric vessels are injured.

Operation time, including lymph node dissection, is > 300 minutes.

Operation time, without lymph node dissection, is $>240$ minutes.

Herniation on the trocar placement site not requiring an operation.

Urine leakage from the wound which is handled conservatively.

An ileus which is handled conservatively.

A urethrovesical stricture not requiring an operation.

A lymphocele requiring an operation.

Resection margins in pT2 operated tumors are positive.

Resection margins are positive, prostate capsule is incomplete.

Rectal injury has occurred which is sutured.

A urethrovesical stricture requiring an operation.

Urine leakage from the wound requiring an intervention.

Resection margins are positive: the intention was nerve sparing surgery; the patient has lost erectile function.

Herniation on the trocar placement site requiring an operation.

Injury to the obturatory nerve.

After 12 months the patient has urine incontinence requiring daily use of pads.

Rectal injury resulting in a colostomy.

An ileus or peritonitis occurs postoperatively necessitating reoperation.

Injury of a major vessel.

A hydronephrosis due to a suture (partly) in the ostium. Resection margins are positive: the intention was nerve sparing surgery; the patient has maintenance of erectile function.

Conversion to an open procedure.

\begin{tabular}{|c|c|}
\hline \multicolumn{2}{|c|}{ Grade of severity } \\
\hline LRP Group & Open RP Group \\
\hline 1 & 1 \\
\hline 1 & 1 \\
\hline 1 & 2 \\
\hline 1 & Not applicable \\
\hline 1 & 2 \\
\hline 1 & 2 \\
\hline 1 & Not applicable \\
\hline 1 & 1 \\
\hline 1 & 2 \\
\hline 1 & 1 \\
\hline 2 & 2 \\
\hline 2 & No consensus \\
\hline 2 & 2 \\
\hline 2 & 2 \\
\hline 2 & 2 \\
\hline 2 & 2 \\
\hline 2 & No consensus \\
\hline 2 & Not applicable \\
\hline 2 & 3 \\
\hline 2 & 1 \\
\hline 3 & 3 \\
\hline 3 & 3 \\
\hline 3 & 3 \\
\hline 3 & 2 \\
\hline No consensus & No consensus \\
\hline No consensus & Not applicable \\
\hline
\end{tabular}


Table 2: Events on which consensus was reached for inclusion in the following definition of successful performance of a LPR procedure: Occurrence of two Grade 2 events or one Grade 3 event.

\begin{tabular}{|l|c|}
\hline Event & Grade of severity \\
\hline A lymphocele requiring an operation. & 2 \\
\hline Rectal injury which is sutured. & 2 \\
\hline A urethrovesical stricture requiring an operation. & 2 \\
\hline Urine leakage from the wound requiring an intervention. & 2 \\
\hline Herniation on the trocar placement site requiring an operation. & 2 \\
\hline The obturatory nerve is injured. & 2 \\
\hline After 12 months the patient has urine incontinence requiring daily use \\
\hline of pads. & 2 \\
\hline Rectal injury resulting in a colostomy. & \\
\hline An ileus or peritonitis occurs postoperatively necessitating reoperation. & 3 \\
\hline Injury of a major vessel. & 3 \\
\hline A hydronephrosis due to a suture (partly) in the ostium. & 3 \\
\hline
\end{tabular}

\section{DISCUSSION}

We conducted a literature study on learning curves and definitions of proficiency with regard to LRP and explored experts' opinions in order to arrive at criteria to define when a LRP procedure can be considered to be technically successful or unsuccessful. The literature study revealed considerable variety in outcome measures that were used to describe the results of LRP procedures, with operating time, positive margins, conversions, complications, and blood loss being used most frequently. Operating time was commonly used to determine the learning curve of surgeons. This parameter is quite easy to measure, and it generally decreases with experience. However, time alone is not sufficient to determine proficiency, for other factors, like complications and PSM, must be taken into account as well.

We found no clear definition of proficiency in LRP in the literature. The numbers of procedures that were reported as indicators of proficiency in relation to various outcome measures varied from 15 procedures for time to 700 procedures for potency rates. ${ }^{19,26}$ Generally, the results of the studies were compared to other studies or the results of mentors and trainees were compared. However, in complicated cases, the varying necessity of lymphadenectomy, different definitions of complications, and variations in measuring methods are likely to lead to variations in results among urologists and hospitals.

When we asked urologists who were experienced in LRP to come up with a definition of an unsuccessful LRP procedure, it turned out that consensus on all parameters was unattainable. Although time is frequently mentioned as an outcome measure in the 
literature, an operating time without lymph node dissection of $>240$ minutes was rated as trivial by the majority of the urologists.

It seems reasonable to define procedural proficiency as the value of a certain outcome measure at which a certain plateau in the learning curve is reached. For operating time this seems quite feasible. For parameters as EBL, incontinence, and complications, however, the numbers of procedures needed to reach a plateau are estimated to be substantially higher (150-200). ${ }^{19}$ For biochemical recurrence and potency, the plateau is reached after 250 and 700 procedures, respectively. ${ }^{19,33}$ Although it is clear that skills improve with the number of procedures performed, it is impossible to establish a number at which proficiency is reached, because of the large variation between parameters and individuals in the number at which a plateau in the learning curve is reached. Consensus on a definition of successful or unsuccessful LRP was further complicated by lack of agreement about the parameters or combination of parameters to be considered. Moreover, complexity of patients and techniques also influence learning curves. It appears that a definition of proficiency requires a compromise between what is feasible in clinical practice and the best possible results. Although this it will be hard to achieve, it is of paramount importance to arrive at a workable definition of proficiency not only for training purposes, but also for gaining insight into feasible standards of care. We believe that the criteria in Table 2 can be used as a first step in this process.

\section{Limitations and future research}

In order to determine the participants' experience in LRP, we asked them how many LRP procedures they performed annually and how many years of experience they had in performing LRP. This retrospective estimation by the participants, however, is likely to differ from the actual numbers. Another limitation of the study which may have influenced the results is the limited number of urologists in the Netherlands who perform LRP and their limited experience with LRP compared to international experts. Despite the small numbers of participants, this study clearly illustrates the difficulty of reaching consensus with regard to proficiency in LRP. We therefore recommend further research with larger numbers of urologists and international experts.

We explored the opinions of urologists and analyzed data from the literature to learn more about the learning curve for LRP. It should be noted, however, that it is the patient who has to live with the consequences of disease and treatment. Hence, it seems worthwhile to explore patients' opinions as to when a LRP can be considered a success, and to combine these insights with the criteria discussed by the urologists. 


\section{CONCLUSION}

Neither the literature nor a survey and a meeting of urologists resulted in a clear definition of LRP proficiency. A compromise between what is feasible in clinical practice and the best possible results will be inevitable in defining workable criteria for proficiency. Continuation of the debate with participation of a large number of international urologists is of paramount importance for the further development of training programs and the setting of standards of care.

\section{Acknowledgements}

The authors would like to thank Mereke Gorsira for her editorial assistance. 


\section{REFERENCES}

1. Rodriguez A, Pow-Sang JM: Laparoscopic surgery in urologic oncology. Cancer Control 2006;13: 169-78.

2. Guillonneau B, Vallancien G: Laparoscopic radical prostatectomy: the Montsouris technique. J Urol 2000;163:1643.

3. Schuessler WW, Schulam PG, Clayman RV et al: Laparoscopic radical prostatectomy: initial shortterm experience. Urology 1997;50:854.

4. Cathelineau X, Sanchez-Salas R, Barret E et al: Radical prostatectomy: evolution of surgical technique from the laparoscopic point of view. Int Braz J Urol 2010;36:129.

5. Figert PL, Park AE, Witzke DB et al: Transfer of training in acquiring laparoscopic skills. J Am Coll Surg 2001;193:533.

6. Chikwe J, de Souza AC, Pepper JR. No time to train the surgeons. BMJ 2004;328:418.

7. Smith AJ, Aggarwal R, Warren OJ et al: Surgical training and certification in the United kingdom. World J Surg 2009;33:174.

8. Ramsay CR, Grant AM, Wallace SA et al: Assessment of the learning curve in health technologies. A systematic review. Int J Technol Assess Health Care 2000;16:1095.

9. Dagash $\mathrm{H}, \mathrm{Chowdhury} \mathrm{M,} \mathrm{Pierro} \mathrm{A.} \mathrm{When} \mathrm{can} \mathrm{I} \mathrm{be} \mathrm{proficient} \mathrm{in} \mathrm{laparoscopic} \mathrm{surgery?} \mathrm{A} \mathrm{systematic}$ review of the evidence. J Pediatr Surg 2003;38:720.

10. Subramonian K, Muir G. The 'learning curve' in surgery: what is it, how do we measure it and can we influence it? BJU Int 2004;93:1173.

11. Fabrizio MD, Tuerk I, Schellhammer PF. Laparoscopic radical prostatectomy: decreasing the learning curve using a mentor initiated approach. J Urol 2003;169:2063.

12. Abbou CC, Salomon L, Hoznek A et al: Laparoscopic radical prostatectomy: preliminary results. Urology 2000;55:630.

13. Guillonneau B, Rozet F, Cathelineau X et al: Perioperative complications of laparoscopic radical prostatectomy: the Montsouris 3-year experience. J Urol 2002;167:51.

14. Rassweiler J, Sentker L, Seemann $O$ et al: Laparoscopic radical prostatectomy with the Heilbronn technique: an analysis of the first 180 cases. J Urol 2001;166:2101.

15. Turk I, Deger S, Winkelmann B et al: Laparoscopic radical prostatectomy. Technical aspects and experience with 125 cases. Eur Urol 2001;40:46.

16. Baumert $\mathrm{H}$, Fromont $\mathrm{G}$, Adorno RJ et al: Impact of learning curve in laparoscopic radical prostatectomy on margin status: prospective study of first 100 procedures performed by one surgeon. J Endourol 2004;18:173.

17. Blana A, Straub M, Wild PJ et al: Approach to endoscopic extraperitoneal radical prostatectomy (EERPE): the impact of previous laparoscopic experience on the learning curve. BMC Urol 2007;7: 11.

18. Brown JA, Sajadi KP. Laparoscopic radical prostatectomy: six months of fellowship training doesn't prevent the learning curve when incorporating into a lower volume practice. Urol Oncol 2009;27:144.

19. Eden CG, Neill MG, Louie-Johnsun MW. The first 1000 cases of laparoscopic radical prostatectomy in the UK: evidence of multiple 'learning curves'. BJU Int 2009;103:1224.

20. El-Feel A, Davis JW, Deger $\mathrm{S}$ et al: Positive margins after laparoscopic radical prostatectomy: a prospective study of 100 cases performed by 4 different surgeons. Eur Urol 2003;43:622-6. 
21. Ferguson $\mathrm{GG}$, Ames $\mathrm{CD}$, Weld $\mathrm{KJ}$ et al: Prospective evaluation of learning curve for laparoscopic radical prostatectomy: identification of factors improving operative times. Urology 2005;66: 840-4.

22. Ghavamian R, Schenk G, Hoenig DM et al: Overcoming the steep learning curve of laparoscopic radical prostatectomy: single-surgeon experience. J Endourol 2004;18:567.

23. Hellawell GO, Moon DA. Laparoscopic radical prostatectomy: reducing the learning curve. Urology 2008;72:1347.

24. Martina GR, Giumelli P, Scuzzarella S et al: Laparoscopic extraperitoneal radical prostatectomy-learning curve of a laparoscopy-naive urologist in a community hospital. Urology 2005;65:959.

25. McNeill AS, Nabi G, McLornan L et al: Endoscopic extraperitoneal radical prostatectomy: critical analysis of outcomes and learning curve. BJU Int 2010;106:537.

26. Poulakis V, Dillenburg W, Moeckel $M$ et al: Laparoscopic radical prostatectomy: prospective evaluation of the learning curve. Eur Urol 2005;47:167.

27. Rehman J, Ragab MM, Venkatesh $R$ et al: Laparoscopic radical prostatectomy: Washington University initial experience and prospective evaluation of quality of life. J Endourol 2004;18:277.

28. Rodriguez AR, Rachna K, Pow-Sang JM. Laparoscopic extraperitoneal radical prostatectomy: impact of the learning curve on perioperative outcomes and margin status. JSLS 2010;14:6.

29. Skrekas T, Mochtar CA, Lagerveld BW et al: Mentor-initiated approach in laparoscopic radical prostatectomy. J Endourol 2006;20:831.

30. Stolzenburg JU, Schwaibold H, Bhanot SM et al: Modular surgical training for endoscopic extraperitoneal radical prostatectomy. BJU Int 2005;96:1022.

31. Stolzenburg JU, Rabenalt R, Do M et al: Modular training for residents with no prior experience with open pelvic surgery in endoscopic extraperitoneal radical prostatectomy. Eur Urol 2006;49: 491.

32. Tse E, Knaus R. Laparoscopic radical prostatectomy - results of 200 consecutive cases in a Canadian medical institution. Can J Urol 2004;11:2172.

33. Vickers AJ, Savage $C J$, Hruza M et al: The surgical learning curve for laparoscopic radical prostatectomy: a retrospective cohort study. Lancet Oncol 2009;10:475.

34. Guillonneau B, Cathelineau X, Doublet JD et al: Laparoscopic radical prostatectomy: the lessons learned. J Endourol 2001;15:441.

35. Poulakis V, Witzsch $U$, De VR et al. Intensive laparoscopic training: the impact of a simplified pelvic-trainer model for the urethrovesical anastomosis on the learning curve. World J Urol 2006; 24:331. 

CHAPTER 8

\section{Conclusions and general discussion}




\section{CONCLUSIONS}

In this thesis we investigated several aspects of endo-urological and laparoscopic skills training in urology. Since in today's educational and health care climate the traditional Halstedian training approach has several drawbacks, educators all over the world are searching for new methods for the training of surgical skills. In order to ensure that educational research, aimed at the development of endoscopic and laparoscopic skills training for urology residents, actually succeeds in creating methods for the training of appropriate skills under optimal conditions, different types of simulators have to be explored and validated and human factors in relation to simulation have to be addressed.

In chapters 2 and 3 we described and assessed two simulators in different phases of the validation process. The first simulator, of trans rectal ultrasound (TRUS), offers the advantage of training with different patient cases without burdening patients, but does not yet allow simulation of prostate biopsies, a feature that would greatly enhance the model's usefulness since taking prostate biopsies is an invasive and uncomfortable procedure for patients.

Evaluating the construct validity of the second simulator, a virtual reality simulator for laparoscopic nephrectomy (LN-VR simulator) with previously established face and content validity, we discovered various drawbacks. The simulator was not able to distinguish between intermediate and experienced participants, analysis of the learning curves suggested that the tasks measured dexterity in using the simulator rather than improvement of actual operative skills and, although the visual aspects of the images appealed to many users. We therefore concluded that the current LN-VR-simulator did not have sufficient construct validity and was not yet ready for implementation in an urological training programme.

The study described in chapter 4 investigated a cystoscopy training programme, in particular whether the programme gained value when initial training on a low fidelity model preceded training on the URO mentor (UM), a high fidelity simulator with proven validity. ${ }^{1-7}$ Compared to students who trained only on UM, the students who first practised on the low-fidelity glass globe model considered the UM tasks to be less difficult and the vast majority of this group considered the glass globe training to be an important component of the training programme. The glass globe model thus appeared to offer an inexpensive educational tool for training the first steps of cystoscopy thereby complementing training on the UM simulator. We concluded that the combined use of a low and a high fidelity training model could enhance trainees' motivation and stimulate learning in a cystoscopy training programme.

After the simulator studies we focused on the human factor of surgical skills training in urology. Performance in this area, as in other areas of human activity, can be impaired by distractions, and the observational study described in chapter 5 revealed the oc- 
currence of many different kinds of distraction during endo-urological procedures. Interruptions due to equipment problems and communication (procedure related and medically irrelevant) had the largest impact on the sterile team. According to many of the urology residents and urologists we interviewed about the impact of distractions it was the responsibility of the urologist or the resident performing the procedure to make it clear that they felt bothered by distractions and to put an end to them.

The randomised controlled trial described in chapter 6 demonstrated that performance of endo-urological procedures was significantly worse when participants were interrupted by a distraction (intervention group) than when there was no interruption (control group) during the procedure. The fact that only $10 \%$ of the participants in the intervention group thought they were influenced by the distraction suggests that people may often be unaware of distractions, despite their clear adverse impact on performance.

Since defining the outcomes of a training programme, in terms of procedural skills to be achieved, is a key aspect of the development of such a programme, we have to gain insight into the learning curves for different skills and define criteria of proficiency. The study described in chapter 7 illustrates the difficulty of reaching consensus on proficiency in laparoscopic radical prostatectomy(LRP). Neither a review of the literature nor a survey and a meeting of urologists resulted in a clear definition of LRP proficiency. Continuation of the debate among large numbers of international urologists may be helpful in moving forward the development of training programmes and the setting of standards of care.

\section{GENERAL DISCUSSION}

\section{Simulators and training programmes}

Several simulators and combinations of simulators were studied in this thesis, but simulation alone does not suffice to construct an effective training programme. ${ }^{8}$ All the simulators studied (TRUS simulator, LN-VR nephrectomy simulator, UM and the glass globe model) additionally require guidance on how to use the simulator or a supervisor to provide feedback. As Issenberg et al. pointed out, high fidelity models can enhance training provided several factors are taken into consideration. ${ }^{9}$ Apart from allowing training of the appropriate motor skills, a simulator should ideally also provide background information about the procedure, its indications and potential complications. Feedback is another essential element of the learning process that can be provided by a simulator measuring performance parameters like time to completion and number and type of errors, but also by Objective Structured Assessment of Technical Skills (OSATS) by 
a supervisor and by retrospective evaluation of videotaped performance. ${ }^{9,10}$ Clearly today's simulators, including the ones we studied in chapters 2 and 3, do not yet include all aspects a simulator should ideally have. Our research team has developed clinical cases for the TRUS simulator to promote integration of knowledge and skills, but the TRUS does not yet have a built in feedback system, and trainees have to rely on supervisors for feedback. The LN-VR nephrectomy simulator measures several parameters like time and errors but provides no background information and its construct validity remains unproven. Furthermore, while conducting the studies we have gained first-hand experience that the development and assessment of a simulator for urological surgical skills is a difficult and costly task. Nevertheless, despite imperfections and the shortcomings of many models with regard to certain aspects and proper validation, there is evidence that increased time of practice on a high-fidelity simulator does enhance learning outcomes. ${ }^{11}$ This raises the question: how can simulators be used for optimal learning effect? From an educational point of view, McGaghie has described twelve important features and practices to optimise educational benefit from simulation based medical education (Table 1), the most important ones being feedback, deliberate practice and integration in the curriculum. Deliberate practice, according to Ericsson, is prerequisite for attainment of expert performance and maintenance of professional performance. ${ }^{12}$ It involves repetitive performance of the cognitive or psychomotor skills to be achieved, accompanied by skills assessment to provide learners with specific, informative feedback, and supports increasing skills performance in a controlled setting. ${ }^{13}$ Furthermore, the effect of simulator-based training being less than optimal without planning and scheduling of simulator-based training as an integral part of the wider medical curriculum, it should be a primary concern of educators to ensure that simulation-based

Table 1: Medical simulation features for effective learning ${ }^{(12)}$

\begin{tabular}{|l|}
\hline Simulation features \\
\hline 1 Feedback \\
\hline 2 Deliberate practice \\
\hline 3 Curriculum integration \\
\hline 4 Outcome measurement \\
\hline 5 Simulation fidelity \\
\hline 6 Skill acquisition and maintenance \\
\hline 7 Mastery learning \\
\hline 8 Transfer to practice \\
\hline 9 Team training \\
\hline 10 High-stakes testing \\
\hline 11 Instructor training \\
\hline 12 Educational and professional context \\
\hline
\end{tabular}


medical education is integrated with other educational activities like clinical work and lectures. With residency training consisting largely of scheduled clinical work, substantial changes in programme organisation and clinicians' attitude towards training will probably be needed before simulator training on a regular basis can be successfully incorporated in residency training.

In addition to addressing the general educational aspects of optimal learning conditions for simulator based training, another way to optimise the use of simulators is to perform a needs analysis identifying the specific aspects of a complex surgical procedure prior to the development of simulator-based training of the required skills. A thorough analysis of the learning goals and potential technical difficulties of specific procedures can guide the development of simulators and aid in positioning their use in a training programme. ${ }^{8}$ With this purpose in mind, Schout et al. analysed and described the pitfalls urology residents face in performing endourological procedures in the traditional masterapprentice model of clinical training. ${ }^{14}$ The development of simulators requires engineers providing technical information and building the simulator with input from clinicians and the target group, but educational expertise is needed as well. Junior doctors are trained by clinicians who, despite gaining considerable practical educational experience over the years, nevertheless have not received any specific educational training. Developing effective training programmes, however, requires contributions from educators applying educational theories to determine the optimal number of steps in the performance of a complex task and designing programmes that allow random practice of different skills to optimise the effect of training on performance in clinical practice..$^{15,16}$

\section{Assessment}

The increasing emphasis on doctors' public accountability and the effectiveness of training programmes calls for evidence of both surgeons' skill levels and outcomes of training, implying a need for appropriate assessment. Although assessment is generally considered to be a key issue in clinical training, assessment of simulation-based training is complicated by the fact that it is not always clear which parameters measured on a training model correspond to performance in real life. As discussed in chapter 3 , the parameters measured by the laparoscopic nephrectomy simulator are not all transferable to real life performance. Moreover, not all interventions that enhance performance during training have a positive effect on performance in real life. For example, compared to repeated practice of the same tasks, random practice of different tasks usually leads to poorer performance during training but ultimately results in better performance in the real world. ${ }^{17,18}$

A parameter frequently mentioned in the literature and generally easy to measure in simulated as well as real-time procedures is time. However, while time generally 
decreases during the learning curve, there are many other factors determining the ultimate success of a procedure. So while outcome indicators of simulated performance include number of errors, inefficient use of instruments using motion tracking, missed lesions or fictitious blood loss, outcome indicators of real life procedures encompass complications of varying severity, blood loss, length of hospital stay and, in cases of malignancy, oncological results and mortality. Although the ultimate goal of training is to ensure patient safety and a positive impact on indicators of patient outcome, it is not easy to prove which variables measured on a simulator correspond with positive patient outcomes, a problem that is complicated by the lack of consensus on how a positive patient outcome is to be defined and how it should be measured. We made an attempt to reach consensus on when proficiency can be considered to have been achieved for a laparoscopic radical prostatectomy procedure and made a start defining criteria for proficiency in chapter 7. But when we reviewed the literature to investigate how the learning curve of individuals for LRP is described and how proficiency is defined, we discovered not only a wide variety of outcome measures but also differences between outcome measures in relation to the plateau phase of the learning curve. Operating time, for example, can be measured quite easily and has been shown to decrease significantly within forty procedures. ${ }^{19-21}$ For biochemical recurrence, however, Vickers et al. concluded that little learning took place before 250 procedures ${ }^{19}$ This variety confuses decision making with regard to the number of procedures needed to perform for a urologist to become proficient. Furthermore, patient outcome measures depend on many factors besides surgical skills, complicating the discussion on which measures are the most important ones and how they should be measured. The difficulty we experienced in reaching consensus within a small group of urologists on only one procedure illustrates the importance of further discussions on this matter in larger group of experts.

\section{Human factors}

Knowledge and psychomotor skills gained during a training programme are no guarantee for successful procedures in real life. Apart from training in a skills laboratory, another way to optimise performance in real life is to identify and anticipate human factors that potentially impact on performance. Although research in psychology and in various areas of human activity has demonstrated negative effects of distraction on performance, research in this area is scant in urology. ${ }^{23-26}$ The effect of distraction on operation flow and performance, studied in chapters 5 and 6, proved considerable. The importance of awareness of potential adverse effects emerged from the combined results of the observational study in chapter 5 and the randomised controlled trial in chapter 6 . The majority of trainees and urologists we interviewed considered distraction to be potentially disturbing but thought they were competent to minimise it by 
communicating with the operation team. In their view, it was they who were responsible for reducing disturbing distractions. Given the hierarchical relationship of senior urologists and trainees, however, it may be difficult for trainees to express their discomfort when distraction is an issue. More importantly, in the study described in chapter 6 , only $10 \%$ of the students in the intervention group, whose performance had been interrupted by a distraction during the study, actually felt distracted despite moderate and large effect sizes demonstrating that their performance was worse compared to that of the control group who were not distracted. Although these participants were younger than the residents we interviewed, it seems quite likely that, in real life too, residents may not be aware of the occurrence of distractions. Their assumption that they are able to control the situation in the operating theatre and eliminate negative effects of distractions should therefore give rise to serious doubt. The first step in minimising negative effects of distraction on performance and eventually on patient outcome may be to increase trainees' awareness of the potential negative impact of distractions and of the difficulties they may encounter in trying to prevent them.

\section{Limitations and future perspectives}

In this thesis we investigated only four simulators covering a limited number of procedures. Further studies are clearly needed, but the limited number of urologists in the Netherlands, which moreover are spread over different regions and whose clinical experience is heterogeneous, makes it difficult to perform studies of simulators and training programmes with large groups of participants. International collaboration and adequate pre-tests to assess performance prior to simulator use may help to overcome this problem.

The development and validation of simulators are ongoing processes. With new surgical techniques and changes in clinical practice, simulators and training programmes require continuous adaptation to the needs of the target group. This requires a method for systematic and effective needs analysis for different procedures to determine which information should be included in a training programme and which pitfalls should be anticipated for certain procedures. Collaboration of clinicians, educationalists and engineers in an early phase of the development of a simulator may be beneficial not only in evaluating a simulator but also for simultaneous evaluation of a simulator and an entire training programme.

In this thesis we did not investigate the actual implementation of skills laboratory training in a residency training programme. Although it is obvious that simulators and training programmes once developed have to be implemented in daily practice, there are barriers to incorporating simulation-based training in residency training, such as practical issues like limited time and resources and the novelty of this type of training to 
the clinical workplace and medical staff accustomed as they are to on-the-job training in the clinical workplace. A change in mentality and in the organisation of residency training as well as further research on the process and difficulties of the implementation of simulation-based training may aid in integrating simulation-based training in clinical education.

One of the advantages of training in a skills laboratory is that it provides a learning environment that is safe for patients and trainees alike. A further way to improve residency training may be to analyse the clinical learning environment in order to identify factors that negatively affect training and to find ways to address them. This thesis has focused on distraction as one factor that is likely to have a negative effect on surgical performance. It is important to continue research on this topic in order to find ways to eliminate the distractions most likely to impair surgical performance and to reduce their adverse effects by teaching residents how to deal with them.

Finally, a prerequisite for the development of effective training programmes is to determine which goals are to be achieved. The ultimate standard by which we can measure the effectiveness of training and evaluate the effects of other factors, such as like distraction, is the well-being of patients. Which variables are important in defining patient outcome and when is proficiency reached? These are questions that so far have remained unanswered for many procedures and require debate among experts in the field as well as public debate in order to arrive at a balance between the best possible results and their feasibility for society. 


\section{REFERENCES}

1. Gettman MT, Le CQ, Rangel LJ, Slezak JM, Bergstralh EJ, Krambeck AE. Analysis of a computer based simulator as an educational tool for cystoscopy: subjective and objective results. J Urol 2008;179:267-71.

2. Gettman MT, Le CQ, Rangel LJ, Slezak JM, Bergstralh EJ, Krambeck AE. Development of a standardized curriculum for teaching cystoscopic skills using a computer-based endourologic simulator. Simul Healthc 2009;4:92-7.

3. Michel MS, Knoll T, Kohrmann KU, Alken P. The URO Mentor: development and evaluation of a new computer-based interactive training system for virtual life-like simulation of diagnostic and therapeutic endourological procedures. BJU Int 2002;89:174-7.

4. Schout BM, Muijtjens AM, Hendrikx AJ, Ananias HJ, Dolmans VE, Scherpbier AJ, et al. Acquiring flexible cystoscopy skills on a virtual reality simulator by experts and novices. BJU Int 2010;105: 234-9.

5. Schout BM, Ananias HJ, Bemelmans BL, d'Ancona FC, Muijtjens AM, Dolmans VE, et al. Transfer of cysto-urethroscopy skills from a virtual-reality simulator to the operating room: a randomized controlled trial. BJU Int 2010;106:226-31.

6. Shah J, Montgomery B, Langley S, Darzi A. Validation of a flexible cystoscopy course. BJU Int 2002; 90:833-5.

7. Shah J, Darzi A. Virtual reality flexible cystoscopy: a validation study. BJU Int 2002;90:828-32.

8. Farmer. Handbook of simulator training. Ashgate Publishing Ltd, England; 1999.

9. Issenberg SB, McGaghie WC, Petrusa ER, Lee GD, Scalese RJ. Features and uses of high-fidelity medical simulations that lead to effective learning: a BEME systematic review. Med Teach 2005; 27:10-28.

10. Martin JA, Regehr G, Reznick R, MacRae H, Murnaghan J, Hutchison C, et al. Objective structured assessment of technical skill (OSATS) for surgical residents. Br J Surg 1997;84:273-8.

11. McGaghie WC, Issenberg SB, Petrusa ER, Scalese RJ. Effect of practice on standardised learning outcomes in simulation-based medical education. Med Educ 2006;40:792-7.

12. McGaghie WC, Issenberg SB, Petrusa ER, Scalese RJ. A critical review of simulation-based medical education research: 2003-2009. Med Educ 2010;44:50-63.

13. Ericsson KA. Deliberate practice and the acquisition and maintenance of expert performance in medicine and related domains. Acad Med 2004;79:S70-S81.

14. Schout BM, Persoon MC, Martens EJ, Bemelmans BL, Scherpbier AJ, Hendrikx AJ. Analysis of pitfalls encountered by residents in transurethral procedures in master-apprentice type of training. J Endourol 2010;24:621-8.

15. Nadolski RJ, Kirschner PA, van Merrienboer JJ. Optimizing the number of steps in learning tasks for complex skills. Br J Educ Psychol 2005;75:223-37.

16. Pollock E, Chandler P, Sweller J. Assimilating complex information. Learning and Instruction 2002; 12:61-86.

17. Schmidt RA, Bjork RA. New conceptualizations of practice: common principles in three paradigms suggest new concepts for training. Psychological Science 1992;3:207-17.

18. Lee TD, Simon DA. Contextual interference. In: Williams AM, Hodges NJ, editors. Skill aquisition in sport: Research, theory and practice.London: Routlegde; 2004. p. 29-44.

19. Vickers AJ, Savage CJ, Hruza M et al: The surgical learning curve for laparoscopic radical prostatectomy: a retrospective cohort study. Lancet Oncol 2009;10:47. 
20. Ferguson GG, Ames CD, Weld KJ, Yan Y, Venkatesh R, Landman J. Prospective evaluation of learning curve for laparoscopic radical prostatectomy: identification of factors improving operative times. Urology 2005;66:840-4.

21. Ghavamian R, Schenk G, Hoenig DM, Williot P, Melman A. Overcoming the steep learning curve of laparoscopic radical prostatectomy: single-surgeon experience. J Endourol 2004;18:567-71.

22. Rehman J, Ragab MM, Venkatesh R, Landman J, Lee D, Chen C, et al. Laparoscopic radical prostatectomy: Washington University initial experience and prospective evaluation of quality of life. J Endourol 2004;18:277-87.

23. Forster S, Lavie N. Failures to ignore entirely irrelevant distractors: the role of load. J Exp Psychol Appl 2008;14:73-83.

24. Healey AN, Primus CP, Koutantji M. Quantifying distraction and interruption in urological surgery. Qual Saf Health Care 2007;16:135-9.

25. McEvoy SP, Stevenson MR, McCartt AT, Woodward M, Haworth C, Palamara P, et al. Role of mobile phones in motor vehicle crashes resulting in hospital attendance: a case-crossover study. BMJ 2005;331:428.

26. Primus CP, Healey AN, Undre S. Distraction in the urology operating theatre. BJU Int 2007;99: 493-4. 

S U M M A R Y 


\section{SUMMARY}

Nowadays, many procedures in urology can be performed with minimally invasive techniques like (percutaneous) endoscopy or laparoscopy. In endourological procedures the endoscope and operating instruments are introduced through the natural orifice of the urethra into the bladder and, when indicated, further into the ureters. In percutaneous endoscopy small incisions are made to introduce an endoscope into the renal collecting system. In laparoscopy, incisions of $+/-1 \mathrm{~cm}$ are used to introduce laparoscopic operating instruments in the abdomen or pelvis to reach the objected organ(s).

Most urological training programs are based on the traditional master-apprentice type of training in which skills are learned by performing on patients under supervision of a more experienced colleague in real-life clinical settings. ${ }^{1}$ Nowadays, attention for patient safety makes errors and serious complications due to inexperience ethically and legally unacceptable. Particularly for the technically challenging techniques like endoscopy and laparoscopy, ethical, practical and legal objections have been raised to the traditional approach. ${ }^{2,3}$ Educators are therefore exploring other training formats, such as simulators made from different types of material on which trainees can practise skills matching their level of education, without putting patients at risk. Simulation-based education can complement education in real clinical settings. ${ }^{4,8}$ Training of endourological and laparoscopic skills can be done on inanimate, animate or computerized simulators. ${ }^{9-11}$ Before a simulator is implemented in a training program for surgical skills, it 's value as an effective trainer and predictor of performance should be established by objective research. ${ }^{12}$ Accurate methods of assessment of the performances of trainees or surgeons, are of paramount importance to evaluate the effect of training programs. Also, due to the increased attention on patient safety in public debate, there is an increasing demand for measurements to prove the capability of the surgeon, urologist and doctors in general. ${ }^{2}$

Besides procedural knowledge and psychomotor abilities, multiple other factors can influence the performance of urological surgeons and residents in the operating room (OR). ${ }^{13,14}$ Distraction is one of the environmental factors that can potentially influence doctors' performance in the OR.

In this thesis we aimed to investigate several aspects of training endourological and laparoscopic skills in urology. Human factors, the exploration and validation of simulators are important aspects of research on training of endoscopic and laparoscopic urological skills in order to ensure that the right skills are trained under optimal circumstances (Chapter 1).

In Chapter 2, a new simulator for teaching transrectal ultrasound (TRUS) is described and the results of a preliminary evaluation of the simulator's realism and usefulness for training are presented. A simulator for abdominal ultrasound was adjusted by the devel- 
oper to enable simulation of TRUS by providing an opening for inserting a dummy rectal probe. Data from ultrasound prostate imaging of eight real patients were obtained with the regular ultrasound machine used in daily practice. These data was transferred to the simulator by connecting the computer of the simulator to the ultrasound machine and used to create images in the TRUS simulator. Residents and urologists used the simulator and judged it's realism and usefulness. Forty-seven participants rated the simulator's overall realism and usefulness for training purposes as 3.8 (SD 0.7) and 4.0 (SD 0.8) on a five-point Likert scale, respectively. The absence of an option for prostate biopsy and the lack of tissue resistance were mentioned as two important shortcomings. In conclusion, this simulator enables training with different patient cases and minimizes the burden to patients. However, simulation of prostate biopsies should be added to increase the model's usefulness since taking prostate biopsies is an invasive and uncomfortable procedure for the patient.

Another simulator, which was studied and described in Chapter 3, is the virtual reality simulator for laparoscopic nephrectomy. Sixty-four participants with different levels of experience performed three basic tasks on the simulator. Their performance was measured by the simulator and included time, blood loss, path length and a total score. The simulator was not able to distinguish between intermediate and experienced participants. The analysis of the learning curves suggests that the tasks measured dexterity in using the simulator rather than an actual improvement of operative skills. This laparoscopic nephrectomy simulator is therefore in its present form not suitable for implementation in a urological training program.

In Chapter 4, the value of training on a low fidelity model in addition to training on a high fidelity simulator in a cystoscopy training program was studied. Thirty-two medical students were randomized to an intervention or a control group. The intervention group started by performing cystoscopy on a low cost, low fidelity, glass globe model before moving on to training on the URO Mentor (UM), a virtual reality simulator. The control group took part in the same UM training program but not in the low fidelity training. Performance on the UM was assessed by a global rating score (GRS), \% of correctly inspected areas of the bladder, time, and number of traumas caused to the bladder wall. The intervention group had generally higher scores, although not significantly in all parameters. All students said they valued training with UM, but the appreciation of the intervention group was stronger. In conclusion, the glass globe model appeared to be an inexpensive educational tool to practice the first steps of cystoscopy. The combined use of a low and high fidelity training model may provide an optimal learning effect.

As in other fields of society, distraction can impair performance. In the observational study described in Chapter 5 we documented different kinds of distraction during endo-urological procedures in the operating theatres of two hospitals. A seven-point scale was used to measure the level of observed interference with the main task of the 
surgical team. The first level on the scale represented merely a potential distraction without reaction from any member of the operation team and a distraction scored "7" when the sterile team's work was interrupted and the operation flow was disrupted. Equipment problems and communication (procedure-related and medically irrelevant), have the largest impact on the sterile team and regularly interrupt procedures. During interviews with residents in urology and urologists many participants felt that it was the responsibility of the urologist or resident who is performing surgery to make clear to the surrounding staff to eliminate distractions when they feel bothered by it.

In the randomized controlled trial in Chapter 6, eighty-six third-year medical students without experience on the UM virtual reality simulator, were randomly assigned to the intervention or control group. They performed three endourological tasks on the UM. The students in the intervention group were distracted by being asked to answer questions about a medical case after one minute into the third task. After two adequate verbal responses the conversation was terminated. Performance was measured by the UM and included number of traumata, number of missed lesions in the bladder and time to completion. The distracted participants performed significantly worse compared to participants who were not distracted. However, only $10 \%$ of the participants in the intervention group felt distracted. This means that the vast majority of participants did not realize they were distracted although this had significant influence on their performance.

It is important for the development of training programs and for deciding when surgeons are good enough to perform a certain procedure, to define criteria of proficiency. In the study described in Chapter 7 we aimed to determine criteria to define when a laparoscopic radical prostatectomy(LRP) procedure can be considered technically successful or unsuccessful. The opinions of eight urologists who were experienced in laparoscopy were explored and literature was studied to identify LRP learning curves and definitions of proficiency. The results of LRP procedures were most commonly described in terms of operating time, positive surgical margins, conversions, complications, and estimated blood loss. No study provided a clear definition of proficiency. Among the urologists, consensus was reached on a combination of events that could be used to define LRP as unsuccessful, but disagreement precluded the inclusion of five important events. This study illustrates the difficulty on reaching consensus on when proficiency for LRP is reached. Continuation of the debate with participation of a large number of international urologists is important for the further development of training programs and the setting of standards of care.

In Chapter 8 the general conclusions of the studies are described, followed by a general discussion on the limitations and benefits of simulation. In addition, the effect of non-technical factors like distraction are discussed. Finally, future perspectives and suggestions for further research are presented. 


\section{REFERENCES}

1. Halsted W. The training of the surgeon. Bull Johns Hopkins Hosp 1904;15:267-76.

2. Inspectie voor de gezondheidszorg. Risico's minimaal invasieve chirurgie onderschat. 2007 Nov 1.

3. Hamdorf JM, Hall JC. Acquiring surgical skills. Br J Surg 2000;87:28-37.

4. Kneebone RL, Scott W, Darzi A, Horrocks M. Simulation and clinical practice: strengthening the relationship. Med Educ 2004;38:1095-102.

5. Sachdeva AK, Bell RH, Jr., Britt LD, Tarpley JL, Blair PG, Tarpley MJ. National efforts to reform residency education in surgery. Acad Med 2007;82:1200-10.

6. Smith AJ, Aggarwal R, Warren OJ, Paraskeva P. Surgical training and certification in the United kingdom. World J Surg 2009;33:174-9.

7. Ziv A, Wolpe PR, Small SD, Glick S. Simulation-based medical education: an ethical imperative. Simul Healthc 2006;1:252-6.

8. Issenberg SB, McGaghie WC, Petrusa ER, Lee GD, Scalese RJ. Features and uses of high-fidelity medical simulations that lead to effective learning: a BEME systematic review. Med Teach 2005; 27:10-28.

9. Schout BM, Hendrikx AJ, Scherpbier AJ, Bemelmans BL. Update on training models in endourology: a qualitative systematic review of the literature between January 1980 and April 2008. Eur Urol 2008;54:1247-61.

10. Schreuder HW, Oei G, Maas M, Borleffs JC, Schijven MP. Implementation of simulation in surgical practice: minimally invasive surgery has taken the lead: the Dutch experience. Med Teach 2011; 33:105-15

11. Torricelli FC, Guglielmetti G, Duarte RJ, Srougi M. Laparoscopic skill laboratory in urological surgery: tools and methods for resident training. Int Braz J Urol 2011;37:108-12.

12. McDougall EM. Validation of surgical simulators. J Endourol 2007;21:244-7.

13. Hall JC, Ellis C, Hamdorf J. Surgeons and cognitive processes. Br J Surg 2003;90:10-6.

14. Kohls-Gatzoulis JA, Regehr G, Hutchison C. Teaching cognitive skills improves learning in surgical skills courses: a blinded, prospective, randomized study. Can J Surg 2004;47:277-83. 

SA M E N VAT T ING 


\section{SAMENVATTING}

Tegenwoordig worden veel urologische operaties met minimaal invasieve technieken uitgevoerd, zoals (percutane) endoscopie en laparoscopie. Bij endo-urologische procedures worden de endoscoop en de andere instrumenten via de urethra in de blaas gebracht, en zo nodig in de ureteren. Bij percutane endoscopische ingrepen worden kleine incisies in de huid gemaakt om vervolgens de endoscoop in het pyelum te brengen om via deze weg de operatie uit te voeren. Bij laparoscopie worden kleine incisies van circa $1 \mathrm{~cm}$ gemaakt om de instrumenten door de buikwand, in de buik of het bekken te plaatsen zodat de beoogde organen worden bereikt.

Het aanleren van vaardigheden binnen de urologie is van oudsher gebaseerd op het meester-gezel principe waarbij de vaardigheden in de praktijk worden geleerd op patiënten. De ervaren arts begeleidt hierbij de arts in opleiding. ${ }^{1}$ Tegenwoordig is er meer aandacht voor patiëntveiligheid en zijn fouten of complicaties als gevolg van onervarenheid van de arts ethisch en juridisch niet meer te verantwoorden. Met name voor technisch ingewikkelde procedures zoals bij de endoscopie en laparoscopie is kritiek geuit op het meester-gezel model van onderwijzen. ${ }^{2,3}$ Opleiders en onderwijskundigen in de hele wereld zijn daarom op zoek naar alternatieve methoden van training. In dit kader worden simulatie modellen van verschillende materialen onderzocht, waarop artsen en medisch specialisten in opleiding hun vaardigheden kunnen oefenen zonder dat dit risico's voor de patiënt met zich meebrengt. Onderwijs op simulatie modellen kan daarom een goede aanvulling zijn op het leren in de praktijk. ${ }^{4-8}$ Het oefenen van endo-urologische en laparoscopische vaardigheden kan op modellen van dierlijk of niet-dierlijk materiaal, of op computer simulatie modellen. ${ }^{9-11}$ Voordat een simulatie model structureel gebruikt wordt in een trainingsprogramma voor het aanleren van operatieve vaardigheden is het belangrijk dat het de juiste vaardigheden aanleert en dat de vaardigheden van de leerling daadwerkelijk verbeteren in de praktijk. Om dit vast te stellen is onderzoek een vereiste. ${ }^{12}$

Om het effect van trainingsprogramma's te beoordelen is het belangrijk om methoden te vinden om de prestaties te beoordelen van operateurs zoals chirurgen, urologen en arts assistenten die in opleiding zijn. Ook vanwege de toenemende aandacht vanuit de maatschappij voor kwaliteit van zorg, is het belangrijk om methoden te vinden om de bekwaamheid van de operateurs aan te tonen. ${ }^{2}$

Naast kennis van de procedure en handvaardigheid zijn er meerdere factoren die prestaties van urologen en arts-assistenten in de operatiekamers kunnen beïnvloeden. ${ }^{13,14}$ Afleiding is een van deze omgevingsfactoren die van invloed kan zijn op de prestaties van artsen.

De studies in dit proefschrift hebben als doel om de verschillende aspecten die een rol spelen van het aanleren van endo-urologische en laparoscopische vaardigheden in 
de urologie te identificeren en te onderzoeken. Menselijke factoren en het onderzoeken van verschillende typen simulatoren zijn belangrijke onderdelen in wetenschappelijk onderzoek naar training van endo- en laparoscopische urologische vaardigheden, zodat de juiste vaardigheden kunnen worden aangeleerd in een optimale omgeving (hoofdstuk 1).

In hoofdstuk 2, wordt een nieuwe simulator voor het aanleren van echografie van de prostaat beschreven. Tevens is geëvalueerd wat urologen en arts-assistenten in opleiding tot uroloog (AIOS urologie) vinden van het nut en het realisme van de simulator. Een bestaande simulator voor echografie van het abdomen werd aangepast door de ingenieur die het apparaat ontwikkelde. Er werd onder andere een opening gecreëerd in het mannequin om het inbrengen van de imitatie echokop mogelijk te maken. Van acht patiënten werden de echografische beelden van de prostaat verzameld met het echografie apparaat wat gebruikt wordt in de dagelijkse praktijk. Door dit echografie apparaat te verbinden met de simulator werden de gemaakte beelden overgeplaatst naar de simulator om simulaties mogelijk te maken. Zeven- en veertig arts-assistenten in opleiding tot uroloog en urologen oefenden met de simulator en beoordeelden het nut en het realistische aspect van de simulator door een vragenlijst in te vullen. De gemiddelde beoordeling voor realisme en nut voor trainingsdoeleinden van de simulator werden beoordeeld met 3.8 (SD 0.7) en respectievelijk 4.0 (SD 0.8) op een vijf-punts Likert schaal. De afwezigheid van de mogelijkheid om prostaatbiopten te nemen en de afwezigheid van adequate weefselweerstand werden genoemd als twee belangrijke tekortkomingen van de simulator. Concluderend werd gesteld dat deze simulator het mogelijk maakt om echografie van de prostaat met verschillende patiënt casus te kunnen oefenen zonder nadeel voor de patiënt. Echter, de mogelijkheid om het nemen van prostaat biopten te oefenen is een belangrijke toevoeging om het nut van de simulator te vergroten aangezien dit een invasief en oncomfortabel onderzoek is voor de patiënt.

In hoofdstuk 3 werd een computer simulatie model, ook wel virtual reality simulator genoemd, voor de laparoscopische nefrectomie onderzocht. Vier- en-zestig deelnemers met drie verschillende niveaus van laparoscopische ervaring voerden drie taken uit op de simulator. De prestaties werden gemeten door de simulator en werden uitgedrukt in tijd, bloed verlies, bewegingen van de instrumenten en een totaal score. Er kon door de simulator geen onderscheid gemaakt worden tussen de middelste groep en de groep met de meeste ervaring. De analyse van de leercurves suggereert dat de deelnemers, in plaats van operatieve vaardigheden, met name handigheid ontwikkelen in het gebruik van de simulator. Deze simulator is daarom nog niet geschikt om geïmplementeerd te worden in een urologisch trainingsprogramma voor laparoscopie.

In hoofdstuk 4 werd de waarde onderzocht van het trainen op een simpele glazenbol als aanvulling op trainen op een virtual reality simulator bij het aanleren van de cystoscopie. Twee-en dertig medisch studenten werden gerandomiseerd in een interventie 
en een controle groep. De interventie groep begon met het oefenen van de cystoscopie op een goedkoop, niet realistisch uitziend, glazen bol model wat voorheen een oude snoeppot was. Hierna kregen ze een training op de URO mentor (UM), een gevalideerde virtual reality simulator voor endo-urologische procedures. De controle groep volgde dezelfde training op de UM, zonder training op het glazenbol model vooraf. De prestaties werden beoordeeld door het \% correct geïnspecteerde gebieden in de blaas, tijd, het aantal traumata aangebracht aan de blaaswand en een globale score van de procedure (global rating scale). Over het algemeen hadden de deelnemers uit de interventie groep betere prestaties dan de deelnemers uit de controle groep, hoewel niet significant op alle parameters. Alle studenten waardeerden de training op de UM maar de waardering was hoger in de interventie groep. Het glazenbol model blijkt een simulator waarmee de eerste stappen van de cystoscopie kunnen worden aangeleerd. Het is waarschijnlijk de combinatie van niet-realistisch uitziende modellen met computersimulatie modellen die zorgt voor een optimaal leereffect.

Net als in andere domeinen van de samenleving, kan afleiding een negatieve invloed hebben op prestaties in de operatiekamer. In hoofdstuk 5 wordt een observationeel onderzoek beschreven waarin werd onderzocht welke vormen van afleiding aanwezig waren op de operatiekamers tijdens endo-urologische operaties. In twee ziekenhuizen vonden observaties plaats volgens een vooraf vastgestelde methode. Er werd een zeven-punts schaal gebruikt om vast te stellen in welke mate een potentieel afleidende gebeurtenis invloed had op de voortgang van de operatie. Hierbij werd een gebeurtenis tijdens de operatie als "1" geclassificeerd als het ging om een potentiële afleiding, zonder dat een van de leden van het operatieteam een non-verbale of verbale reactie gaf. Bij een gebeurtenis met score "7" was er sprake van een afleidende factor die een onderbreking van de operatie tot gevolg had. De afleidingen die de grootste invloed hadden op de voortgang van de operatie en geregeld leidden tot onderbrekingen van de procedure waren apparatuur en communicatie gerelateerd. Hierbij ging het zowel om procedure gerelateerde als medisch irrelevante communicatie. Tijdens interviews met arts-assistenten in opleiding en urologen gaf een groot deel van de deelnemers aan dat zij vinden dat het de verantwoordelijkheid is van de opererende uroloog of arts assistent, om aan te geven wanneer hij of zij last heeft van afleidende factoren.

In de gerandomiseerde studie in hoofdstuk 6, werden zes-en-tachtig medisch studenten zonder ervaring op de UM virtual reality simulator gerandomiseerd in een interventie en een controle groep. Alle deelnemers voerden drie dezelfde endo-urologische taken uit op de UM. Aan de studenten in de interventie groep werden na de eerste minuut in de derde taak, vragen gesteld over een medische casus. Na twee adequate antwoorden werd het gesprek beëindigd. Tijd, gemiste laesies in de blaas en aantal traumata werden gemeten en geregistreerd door de UM. De deelnemers uit de interventie groep presteerden significant slechter op alle gemeten parameters, vergeleken met de 
deelnemers uit de controle groep. Opvallend was dat slechts $10 \%$ van de deelnemers uit de interventiegroep aangaf zich afgeleid te voelen.

Voor de ontwikkeling van trainingsprogramma's, en om te bepalen wanneer een operateur goed genoeg is om een bepaalde procedure uit te voeren, is het belangrijk om criteria te definiëren wanneer een adequaat niveau voor het uitvoeren van een bepaalde procedure is bereikt. De studie in hoofdstuk 7 had als doel om criteria te definiëren om te bepalen wanneer een laparoscopische radicale prostatectomie (LRP) technisch succesvol was uitgevoerd. De meningen van acht urologen met ervaring in de laparoscopie werden in kaart gebracht en de literatuur werd onderzocht om verschillende leercurves van LRP en definities van technische bekwaamheid vast te stellen. De resultaten van LRP procedures werden in de meeste studies weergegeven in operatie tijd, tumor positieve snijvlakken, aantal conversies, complicaties en geschat bloed verlies. In geen enkele studie werd een eenduidige definitie genoemd wanneer een niveau van technische bekwaamheid was bereikt. Onder de ondervraagde urologen was consensus bereikt over een aantal gebeurtenissen en complicaties waarmee men een uitgevoerde LRP operatie als niet-geslaagd kon beoordelen. Echter, op vijf belangrijke items kon geen consensus worden bereikt. Deze studie illustreert de moeilijkheid van het bereiken van consensus op het gebied van definiëren van technische bekwaamheid voor de LRP. Voortzetting van de discussie hierover met een groter aantal internationale urologen is belangrijk voor de verdere ontwikkeling van trainingsprogramma's en voor het vaststellen van kwaliteitseisen.

In hoofdstuk 8 worden de conclusies van de studies beschreven, gevolgd door een algemene discussie over de beperkingen en voordelen van simulatie modellen. Tevens wordt het effect van afleiding besproken. Tot slot komen enkele toekomstperspectieven en ideeën voor verder onderzoek aan bod. 


\section{REFERENTIES}

1. Halsted W. The training of the surgeon. Bull Johns Hopkins Hosp 1904;15:267-76.

2. Inspectie voor de gezondheidszorg. Risico's minimaal invasieve chirurgie onderschat. 2007 Nov 1.

3. Hamdorf JM, Hall JC. Acquiring surgical skills. Br J Surg 2000;87:28-37.

4. Kneebone RL, Scott W, Darzi A, Horrocks M. Simulation and clinical practice: strengthening the relationship. Med Educ 2004;38:1095-102.

5. Sachdeva AK, Bell RH, Jr., Britt LD, Tarpley JL, Blair PG, Tarpley MJ. National efforts to reform residency education in surgery. Acad Med 2007;82:1200-10.

6. Smith AJ, Aggarwal R, Warren OJ, Paraskeva P. Surgical training and certification in the United kingdom. World J Surg 2009;33:174-9.

7. Ziv A, Wolpe PR, Small SD, Glick S. Simulation-based medical education: an ethical imperative. Simul Healthc 2006;1:252-6.

8. Issenberg SB, McGaghie WC, Petrusa ER, Lee GD, Scalese RJ. Features and uses of high-fidelity medical simulations that lead to effective learning: a BEME systematic review. Med Teach 2005; 27:10-28.

9. Schout BM, Hendrikx AJ, Scherpbier AJ, Bemelmans BL. Update on training models in endourology: a qualitative systematic review of the literature between January 1980 and April 2008. Eur Urol 2008;54:1247-61.

10. Schreuder HW, Oei G, Maas M, Borleffs JC, Schijven MP. Implementation of simulation in surgical practice: minimally invasive surgery has taken the lead: the Dutch experience. Med Teach 2011; 33:105-15.

11. Torricelli FC, Guglielmetti G, Duarte RJ, Srougi M. Laparoscopic skill laboratory in urological surgery: tools and methods for resident training. Int Braz J Urol 2011;37:108-12.

12. McDougall EM. Validation of surgical simulators. J Endourol 2007;21:244-7.

13. Hall JC, Ellis C, Hamdorf J. Surgeons and cognitive processes. Br J Surg 2003;90:10-6.

14. Kohls-Gatzoulis JA, Regehr G, Hutchison C. Teaching cognitive skills improves learning in surgical skills courses: a blinded, prospective, randomized study. Can J Surg 2004;47:277-83. 

DA N K W O O R D 


\section{DANKWOORD}

Promoveren doe je niet alleen, en dat heb ik gelukkig gemerkt. Toen ik in 2008 begon in het Catharina Ziekenhuis in Eindhoven (CZE) aan een promotieonderzoek over training en simulatie modellen in de urologie wist ik nauwelijks wat het inhield om onderzoek te doen, laat staan een proefschrift schrijven. Dat dit boekje er ooit zou komen had ik toen niet gedacht! Ik heb een hoop leuke, slimme, gezellige mensen ontmoet, leuke reizen gemaakt en veel geleerd. Ik wil iedereen enorm bedanken die in wat voor mate dan ook betrokken is geweest bij het tot stand komen van dit boekje. Hierbij neem ik graag de kans om een aantal mensen in het bijzonder noemen.

Beste dr. Hendrikx, Ad, zonder jouw enthousiasme en inzet was het project "Training in Urology"(TIU) er niet geweest. Zelfs toen je met Loes aan het fietsen was naar Mallorca hebben we in Eindhoven nooit lang hoeven wachten op een antwoord op een mailtje. Ik bewonder je veelzijdigheid als dokter, regelaar, onderzoeker en ondernemer maar vooral ook je oprechte interesse en nieuwsgierigheid voor nieuwe dingen en andere mensen in alle uithoeken van de wereld. Ontzettend bedankt voor de begeleiding, ondersteuning en het mogelijk maken van dit proefschrift.

Beste prof. Scherpbier, Albert. Hoe druk je het ook hebt, of je nou op doorreis bent vanuit Amsterdam, of net van de andere kant van de wereld terug bent, je lijkt zelden haast te hebben. Jij staat altijd open voor nieuwe ideeën en dankzij jouw steun konden de onderzoeken worden uitgevoerd. Jouw expertise op het gebied van medisch onderwijs en onderzoek is van grote waarde geweest. Je stelde vol vertrouwen alle middelen beschikbaar, niet alleen voor de studies, maar ook voor de persoonlijke ontwikkeling van je promovendi. Bedankt!

Beste dr. Schout, Barbara, al in de eerste week in het CZE wist ik dat jij in dit dankwoord moest komen. Jij hebt mij op weg geholpen en laten zien hoe onderzoek doen in zijn werk gaat. Ik heb veel geleerd van jouw gedegen manier van werken en jouw capaciteit om altijd vooruit te denken. Daarnaast ben je een gezellig congres maatje en vriendin geworden. Ik heb er alle vertrouwen in dat er nog vele boekjes gaan volgen met jou als copromotor.

Beste prof. Witjes, Fred. Toen jij bij het project aansloot kwam ik er al snel achter dat er weinig mensen zijn die jou niet kennen binnen de urologie. Met jouw directe aanpak, nuchtere blik en kennis van zaken krijg je veel voor elkaar. Je zegt waar het op staat en weet vaak tijdens discussies precies duidelijk te krijgen waar het om gaat. Daarnaast is het altijd gezellig als jij weer met je motorhelm onder je arm de vergaderzaal binnen loopt. 
Beste Irene, onderzoeksmaatje, paranimf. Toen jij als $3^{e}$ promovenda in het CZE kwam, heb je je al snel onmisbaar gemaakt in het project TIU. Stilzitten is niet aan jou besteed. Je bleek altijd voor iedereen klaar te staan en er was altijd tijd voor een kopje thee. Ik hoop nog veel theetjes met je te drinken en kijk nu al uit naar jouw promotie feestje!

Hans en Kim, wat heb ik een geluk gehad met jullie beiden als semi-artsen. Jullie hebben bergen werk verzet en onmisbare informatie verzameld. Buiten onderzoek doen blijken jullie ook nog enorm sociaal te zijn, wat het ook nog eens leuk maakte met jullie te werken. Ik ben blij dat jullie een plekje hebben binnen de urologie.

Zonder deelnemers, geen onderzoek. Alle studenten, co-assistenten, arts-assistenten en urologen die hebben meegedaan aan de onderzoeken wil ik hartelijk bedanken voor hun tijd en moeite.

De arts-assistenten en de urologen in het CZE; Carsten, Geerte, Henri, Mike, Rik, Rob, Veronique, Evert Koldewijn, Wout Scheepens, Eric Vrijhof, Michel de Wildt, jullie waren dichtbij en werden daarom vaak gestrikt voor vragenlijsten of oefeningen. Bedankt voor jullie herhaaldelijke deelname, gezelligheid en begeleiding in de kliniek.

Rob, de lap nef studie was mijn introductie in het onderzoek en de eerste virtual reality simulator die ik leerde kennen. Dank zij jou is het artikel er gekomen. Ik heb bovendien niemand de linkshandige versie zo snel zien doen als jij;D. Maartje, toen ik in het CZE kwam was je net klaar met jouw wetenschappelijke stage en ik leerde je pas echt kennen in Den Bosch. Je bent een onwijs gezellige collega en ik ben blij dat we alle cursussen samen konden doen.

Evert, met jouw enthousiasme en kennis heeft het project TIU er een waardevolle copromotor bij!

Ook de urologen van de SWEN wil ik hartelijk bedanken voor het meedenken en meedoen aan de onderzoeken en het optreden als experts bij verschillende studies. De SWEN reis naar Californië en de etentjes met jullie waren behalve leerzaam ook erg gezellig.

Een groot aantal mensen uit het CZE wil ik bedanken voor hun hulp; alle secretaresses van de urologie, verpleegkundigen van het UBC en afdeling 8 Oost, Cees, Gert en Angelique, jullie inzet in het skillslab maakt het mogelijk daar onderzoek te doen. Guy, Mike en Willem van de audiovisuele dienst, zonder jullie hadden een aantal posters, figuren, plaatjes, filmpjes en foto's er niet zo goed uitgezien.

In Maastricht bij de Faculty of Health, Medicine and Life Sciences zijn er veel mensen geweest die achter de schermen de onderzoeken mogelijk maakten en allerlei praktische zaken regelden. 
Mereke Gorsira, je hebt het vermogen je inhoudelijk te verdiepen in elk onderwerp en daarmee het engels en het hele stuk te verbeteren. Arno Muijtjens, ingewikkelde statistiek maak jij begrijpbaar. Bedankt voor jullie hulp bij elk artikel!

Collega's en chirurgen in Den Bosch, bedankt voor de gezelligheid en alle leerzame momenten de afgelopen twee jaar.

Werken en promoveren is vooral leuk als je het niet 24 uur per dag doet....

Alle lieve vrienden en vriendinnetjes wil ik bedankten voor alle gezelligheid, interesse en wijze raad: Sanne, Robin, LB'tjes; Ellen, Iris, Niels, Anne S, Anne P, Sara, Esther, Pieternel en Kim. Antropologie meiden, Sylvia, Bregje, Lilian, Anne-Floor en Juletta, ondanks alle drukke agenda's wordt er bijna elke week samen gegeten. Ik hoop daar binnenkort weer wat vaker bij te zijn!

Najade, met door de jaren heen altijd gezellige activiteiten en steeds meer oud-leden, ik kijk nu al uit naar alle reünietjes.

Lieve Marian, Bart, Anne en Aileen, jullie ken ik al zo'n 20 jaar, ja, we worden oud...;) Bedankt dat jullie het nog steeds met me uithouden.

Lieve Jetske, jouw cocktails en de effecten ervan zal ik niet snel vergeten. Natuurlijk is dat niet het enige, ik ben heel blij dat je nu in Utrecht woont!

Lieve Anke, borrel-, hardloop-, stap-maatje en vriendin, ik ken weinig mensen die zo kordaat zijn als jij. Een echte multitasker ben je. Je huissleutel heb ik inmiddels weer teruggegeven maar gelukkig woon ik nu bijna om de hoek. Bedankt dat jij mijn paranimf wilt zijn.

Gelukkig is er in alle tijden mijn familie, van Personen en Vlotten kant.

Lieve Oma Vlot, van al je kleinkinderen hou je precies bij wat ze doen en je kan er ook nog over meepraten, ik hoop nog vele verhalen en wijsheden over vroeger te horen.

Geert-Jan, Afke en Joran, stabiele factoren door de jaren heen, jullie zijn er altijd op de belangrijke momenten. En Jildou, bedankt voor de kaft!

Lieve papa en mama, wat ben ik blij met ouders zoals jullie. Jullie zijn er onvoorwaardelijk en laten me vrij om mijn eigen weg te zoeken. Dit boekje is ook van jullie.

Als laatste mag natuurlijk niet ontbreken Michel, de stoerste en liefste jongen die ik ken. 

C URRICULUM VITAE 


\section{CURRICULUM VITAE}

Marjolein Persoon was born on April $13^{\text {th }} 1981$ in Rotterdam. She received her primary education in Monrovia, Liberia, and in Vlijmen, the Netherlands. After secondary school at the Frederik Hendrik College (Atheneum) in 's-Hertogenbosch, she studied Cultural Anthropology at Utrecht University for one year. In 2000 she started medical school at the University Medical Center Utrecht. During medical school she did several rotations abroad, in Blantyre, Malawi, and Stockholm, Sweden. After graduating in October 2006, she started working as a resident in surgery at the Twee Steden Hospital in Tilburg. In February 2008 she became resident in urology at the Catharina Hospital in Eindhoven (CZE) and PhD candidate on the project 'Training in Urology', which resulted in this thesis. During this period she attended several conferences and courses abroad and learnt about organizing training courses in the skills lab of the CZE. In 2010 she started her formal training in urology at the University Medical Center Utrecht (Prof. dr. J.H.L.R. Bosch) affiliated to the Jeroen Bosch Hospital in 's-Hertogenbosch and the Elisabeth Hospital in Tilburg. Currently, she works as a specialist trainee in urology at the department of surgery of the Jeroen Bosch Hospital for the two-year surgical part of the training in urology (Dr. K. Bosscha). 

LIST OF PUBLICATIONS 


\section{LIST OF PUBLICATIONS}

Persoon MC, Hendrikx AJM, Koldewijn EL, Tjiam IM, Vrijhof HJEJ, Witjes JA, Scherpbier AJJA. Learning curves in laparoscopic radical prostatectomy: When is proficiency reached? Submitted.

Tjiam IM, Persoon MC, Hendrikx AJM, Muijtjens AMM, Witjes JA, Scherpbier AJJA. Development and evaluation of a model for Basic Laparoscopic Urological Skills training. Submitted.

Persoon MC, van Putten K, Muijtjens AMM, Witjes JA, Hendrikx AJM, Scherpbier AJJA. The effect of distraction on the performance of endourological tasks: a randomized controlled trial. BJU Int. 2011 May;107(10):1653-7.

Persoon MC, Broos HJ, Witjes JA, Hendrikx AJM, Scherpbier AJJA. The effect of distractions in the operating room during endourological procedures. Surg Endosc. 2011 Feb;25(2):437-43.

Persoon MC, Schout BMA, Martens EJ, Tjiam IM, Tielbeek AV, Scherpbier AJJA, Witjes JA, Hendrikx AJM. A simulator for teaching transrectal ultrasound procedures: how useful and realistic is it? Simul Healthc. 2010 Oct;5(5):311-4.

Persoon MC, Schout BMA, Muijtjens AMM, Hendrikx AJM, Witjes JA, Scherpbier AJJA. The effect of a low-fidelity model on cystoscopic skill training: a single-blinded randomized controlled trial. Simul Healthc. 2010 Aug;5(4):213-8.

Persoon MC, Tjiam IM, Hendrikx AJM, Scherpbier AJJA. Opleiding en Training. In: Aanbevelingen laparoscopie in de urologie. Redactie van Basten JP, Beerlage $\mathrm{H}$, Tjiam IM. Verhagen Grafische Media Veldhoven 2010.

Schout BMA, Persoon MC, Martens EJ, Bemelmans BLH, Scherpbier AJJA, Hendrikx AJM. Analysis of pitfalls encountered by residents in transurethral procedures in masterapprentice type of training. J Endourol. 2010 Apr;24(4):621-8.

Wijn RP, Persoon MC, Schout BMA, Martens EJ, Scherpbier AJJA, Hendrikx AJM. Virtual reality laparoscopic nephrectomy simulator is lacking in construct validity. J Endourol. 2010 Jan;24(1):117-22. 
Persoon MC, Scherpbier AJJA, Oei SG, Meijerink WJHJ, Schijven MP, Schout BMA, Hendrikx AJM. Fundamentals of Laparoscopic Surgery: Leren opereren zonder patiënt. Ned Tijdschr Geneeskd. 2008;152:B22.

Persoon MC, Hennipman A, Stapper G, Lock MTWT. Urologische aspecten bij retroperitoneale sarcomen. Nederlands Tijdschrift voor Urologie 2007(4): 119-122. 

SHE DISSERTATION SERIES 


\section{SHE DISSERTATION SERIES}

In the SHE Dissertation Series dissertations are published of PhD candidates from the School of Health Professions Education (SHE) who defended their PhD thesis at Maastricht University. The most recent ones are listed below. For more information go to: www.maastrichtuniversity.nl/she.

Durning, S.J. (09-09-2011). Exploring the Influence of Contextual Factors of the Clinical Encounter on Clinical Reasoning Success (Unraveling context specificity).

Govaerts, M.J.B. (08-09-2011). Climbing the Pyramid;Towards Understanding Performance Assessment.

Stalmeijer, R. E. (07-07-2011). Evaluating Clinical Teaching through Cognitive Apprenticeship.

Malling, B.V.G. (01-07-2011). Managing word-based postgraduate medical education in clinical departments.

Veldhuijzen, J.W. (17-06-2011). Challenging the patient-centred paradigm: designing feasible guidelines for doctor patient communication.

Van Blankenstein, F. (18-05-2011). Elaboration during problem-based, small group discussion: A new approach to study collaborative learning.

Van Mook, W. (13-05-2011). Teaching and assessment of professional behavior: Rhetoric and reality.

De Leng, B. (8-12-2009). Wired for learning. How computers can support interaction in small group learning in higher education.

Maiorova, T. (29-05-2009). The role of gender in medical specialty choice and general practice preferences.

Bokken, L. (04-03-2009). Innovative use of simulated patients for educational purposes.

Wagenaar, A. (18-09-2008). Learning in internships. What and how students learn from experience. 
Driessen, E. (25-06-2008). Educating the self-critical doctor. Using portfolio to stimulate and assess medical students' reflection.

Derkx, H. (18-06-2008). For your ears only. Quality of telephone triage at out-of-hours centres in the Netherlands.

Niessen, Th. (30-11-2007). Emerging epistemologies: making sense of teaching practice.

Budé, L. (05-10-2007). On the improvement of students' conceptual understanding in statistics education.

Niemantsverdriet, S. (26-07-2007). Learning from international internships: A reconstruction in the medical domain.

Marambe, K. (20-06-2007). Patterns of student learning in medical education - A Sri Lankan study in traditional curriculum.

Pleijers, A. (19-01-2007). Tutorial group discussion in problem-based learning.

Sargeant, J. (21-09-2006). Multi-source feedback for physician learning and change.

Dornan, T. (12-06-2006). Experience-based learning.

Wass, V. (12-05-2006). The assessment of clinical competence in high stakes examinations.

Prince, K. (21-04-2006). Problem-based learning as a preparation for professional practice. 
